\title{
NEWS, RENEWED: \\ TOWARDS A SUSTAINABLE BUSINESS MODEL \\ FOR ONLINE JOURNALISM
}

BY

\section{ALEXANDER COLIN CLARK}

\author{
A thesis \\ Submitted to the Victoria University of Wellington \\ In partial fulfilment of the requirements for the degree of \\ Master of Advanced Technology Enterprise
}

Victoria University of Wellington

2015 


\begin{abstract}
The News, Renewed project was established to pursue the following core objectives:

1) To identify the most promising business model for funding online journalism, through academic research.

2) To enable implementation of the most promising monetisation strategy, through the development of a technology enterprise.
\end{abstract}

From March to April 2014, Alex Clark conducted an online survey completed by 416 consumers, assessing willingness to pay for ten online monetisation strategies. Strategies assessed include: payment-per-article, a payment-to-remove advertising, crowdfunding, donations, a mobile application, a 'freemium' model (charging only for premium content), a standalone subscription to a single news website, a national package of all news websites in New Zealand, a global package of all news websites in the world, as well as a multimedia package containing news, music, television and movies.

Survey data revealed that strategies embracing global bundling were most popular with respondents. While only one respondent $(0.24 \%)$ said they would 'definitely' pay for a standalone subscription at $\$ 10$ per month (NZD), 23 respondents (5.4\%) said they'd definitely pay for a global news package, and $46(10.8 \%)$ said they'd definitely pay for a news and multimedia package. Consumer preference for global bundling remained strong when viewing survey data through other analytical lenses, such as an aggregate of 'probably' and 'definitely' responses, as well as estimated conversion rates calculated using Predicted Purchase Intent values.

Upon completion of the survey, Alex worked with two developers to create PressPass, a platform focused on enabling the implementation of a bundling strategy by the journalism community. Once a prototype had been developed, Alex met with leading news organisations within New Zealand and the USA to share his findings and seek feedback about his proposed solution. In New Zealand, he met with NZME, TVNZ and 
MediaWorks. In the USA, he met with the New York Times, The Economist and National Geographic.

The News, Renewed thesis analyses the qualitative and quantitative findings from Alex's consumer survey, while also providing qualitative insights from his interviews with industry leaders. The thesis has been submitted in partial fulfilment of the requirements for the Master of Advanced Technology Enterprise at Victoria University of Wellington. 


\section{ACKNOWLEDGEMENTS}

The News, Renewed project has been a collective endeavour, made possible through the support of many individuals and organisations.

To Mum, Dad, and Zac. Thank you for memorable weekend breaks with the lamb, horse, cats, dogs, chickens, rabbits and birds. A weekend at home has always left me feeling refreshed and ready to tackle more research.

To my Grandparents: Alex Scott, Kathy Scott, and Marie Clark. I feel blessed to have so many homes away from home. I have enjoyed your company during my stays, and the tranquil environment for studying.

To my Aunt, Dr Adele J. Scott. Thank you for supporting me at a moment's notice, sharing your knowledge and experience, bringing me cheese toasties at $3 \mathrm{am}$, and for simply being an awesome Aunt.

To my supervisors, Dr Brenda Chawner and Dr Jean-Gregoire Bernard. Thank you for your support and guidance, from the earliest stages of ideation through to thesis submission.

To the founding developers of the PressPass platform, Puneeth Anandaraj and Paul Smith. Thank you for your countless hours of hard work and expertise, which are helping to transform the News, Renewed project from vision into reality.

To PressPass' team mentor, Michael Elwood-Smith. Our entrepreneurial journey has been fuelled by your perceptive insights and recommendations.

To my friends who hosted me throughout the USA: Morgan Alperin, David 'Taco' Bell, Lindsey Brodie, Ben Bruno, Danny Hertel, Stephanie Kurylo, Ebba Wiig and Zoë Wong-Weissman. Thank you for an enjoyable journey, and for sharing the luxury of your couches and spare rooms. My meetings in the USA would not have been possible without your support. 
To my friends within the Victoria University Tramping Club and across New Zealand. You've all kept me sane, and have helped me pull through the most gruelling periods of 18-hour days and 100-hour weeks. Special shout out to 'Johnboy' Copeland, for fuelling my final few hours with a pizza delivery.

To the Victoria University of Wellington, thank you for the privilege of receiving the Master's by Thesis Scholarship. Your generous support has made the News, Renewed project possible, allowing me to pursue PressPass with my full attention throughout the duration of the scholarship.

To Professor Kate McGrath, Vice-Provost of Research within the School of Chemical and Physical Sciences. Thank you for having the vision to establish the Master of Advanced Technology Enterprise programme.

To the Programme Directors who have managed the 2014 cohort of MATE students, Dr Paul Smith (Jan-July 2014), Professor David Bibby (July-Dec 2014), and Jenny Douché, M.B.A. (Dec 2014-present). Thank you for making MATE possible through your dedication and hard work.

To John Francis, Founder of Tearaway Magazine. Thank you for enriching my life with a passion for journalism. Trusting a scrawny 18-year-old with the role of editor took a leap of faith (and required considerable mentorship). I'm grateful for the knowledge and experience that you shared with me. News, Renewed would not exist without your pivotal influence on my life journey.

To the respondents who took my survey, thank you for providing the insights that have underpinned the News, Renewed project. The survey was long and arduous, and I am grateful for your perseverance and generous donation of your time.

To interviewees from within The Economist, MediaWorks, National Geographic, the New York Times, NZME, and TVNZ. Thank you for taking the time to share your industry insights, which continue to shape the development of PressPass. 
To the organisations that support New Zealand's innovation ecosystem: Kiwi Landing Pad (John Holt, Sian Simpson), Creative HQ (Nick Churchhouse, Laura Reitel, Alan Hucks), Grow Wellington (Adrian Gregory, Vanessa Young, Mathieu Carrere, Dorien Vermaas), Lightning Lab (Sam Bonney, Mark MacLeod-Smith, Connor Archbold), VicLink (Geoff Todd, Julie Chrisford), Angel HQ (Dave Allison), NZTE (John Bryan), Enspiral (Joshua Vial, Link Gasking). Thank you for taking the time to share your knowledge and for guiding my entrepreneurial journey.

To individuals within the journalism and business community: Peter Griffin (Science Media Centre), Stephen Olsen (Newsroom), Sean Wilson (Syl Semantics), John Rankin (Affinity IT), Colin Peacock \& Jeremy Rose (MediaWatch, Radio NZ), David Lane (President of the NZ Open Source Society), Bernard Hickey (Hive News), Russell Brown (Public Address), Richard MacManus (Founder of ReadWriteWeb), Felix Salmon (Fusion), Jordan Carter (Internet NZ), Geoff King (Committee to Protect Journalists), Mark Burdett \& Peter Eckersley (Electronic Frontier Foundation), Monica Chew (Mozilla), Matt Cameron (Scripted), Vicki \& Ryan Johnson (ProFellow);

And,

To individuals within the academic community: Justin Ellis, Joseph Lichterman \& John Breen (Harvard's Nieman Journalism Lab), Vicki Hammarstedt \& Dr Edward Wasserman (Berkeley School of Journalism), Dawn Garcia (Managing Director of the JSK Fellowship at Stanford University), Dr Jay Rosen (Director of Studio20 at New York University), Jeremy Caplan (Director of Education, Tow-Knight Centre for Entrepreneurial Journalism), Randy Picht, Roger Gafke, René Rau, Mike McKean, Dr Esther Thorson \& Brian Steffens (Reynolds Journalism Institute, Missouri School of Journalism), Rosental Alves (Knight Chair in International Journalism and Professor of Entrepreneurial Journalism at the University of Texas at Austin), Dr Kurt Beyer (Berkeley Haas School of Business), Merja Myllylahti (Auckland University of Technology), Dr David Pearce, Matt Plummer, Dr Peter Thompson \& Dr Ian Welch (Victoria University of Wellington), and Dr Gavin Ellis (University of Auckland);

Thank you for your constructive feedback and insights. 
Disclaimer: Acknowledgement of the individuals and organisations listed does not imply their endorsement of News, Renewed, PressPass, or the conclusions outlined within this thesis. 


\section{CONTENTS}

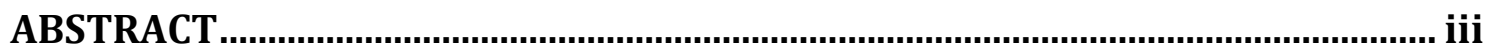

ACKNOWLEDGEMENTS

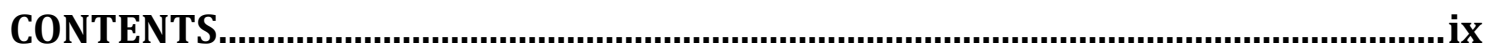

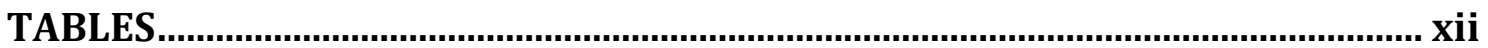

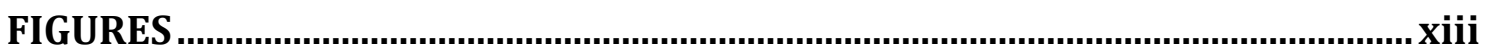

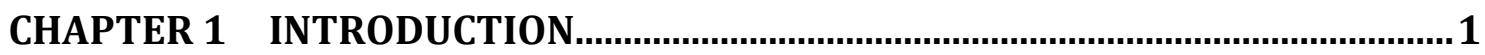

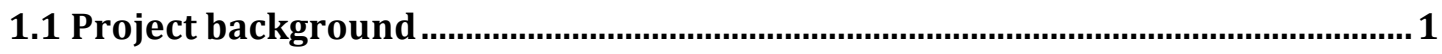

1.2 The Master of Advanced Technology Enterprise ...................................................... 2

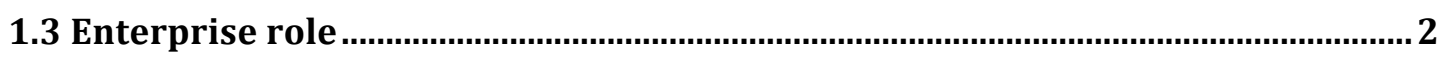

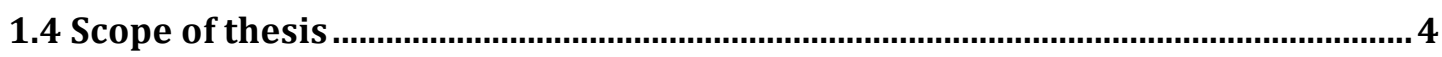

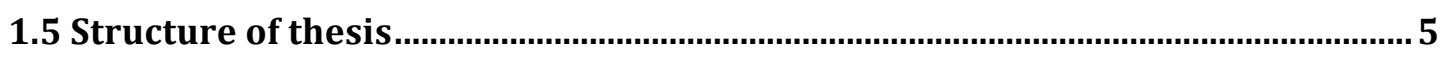

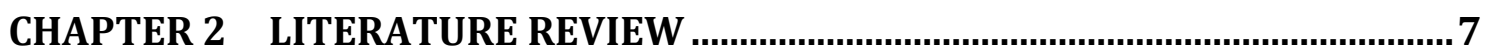

2.1 The economic landscape of online journalism ....................................................... 7

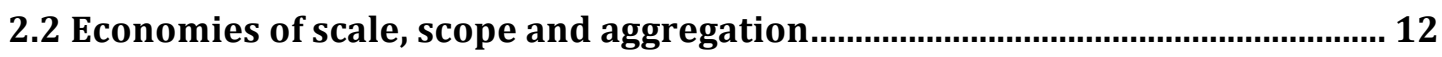

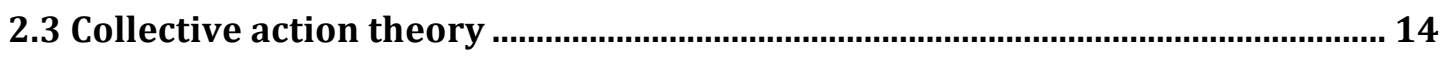

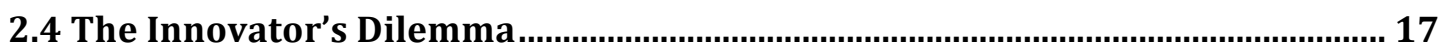

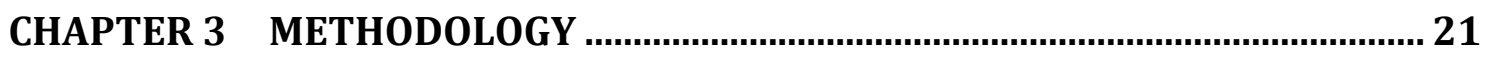

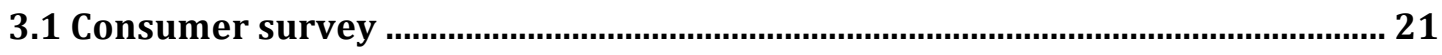

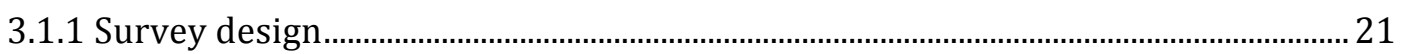

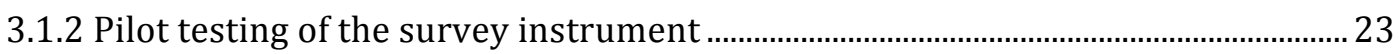

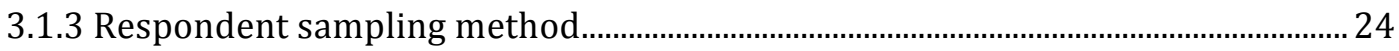

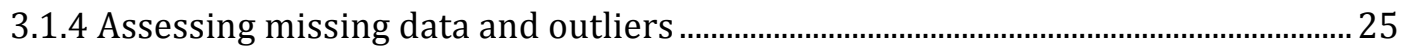

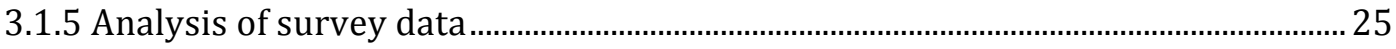

3.1.6 Limitations of survey data and methods of analysis .............................................. 27

3.2 Interviews with news organisations ……........................................................ 30

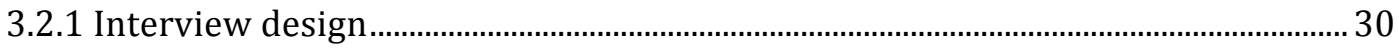

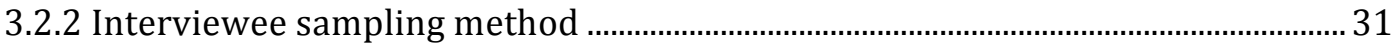

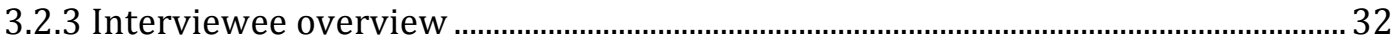

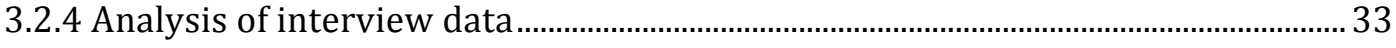

3.2.5 Limitations of qualitative data from interviews .......................................................... 34 
3.3 Human ethics 35

3.4 Key differences between Appendix B, and data analysis within thesis. 35

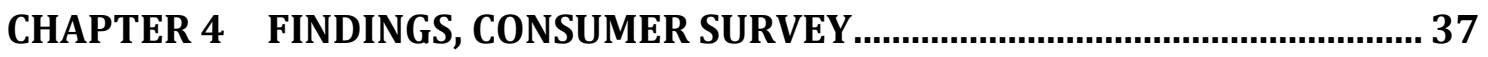

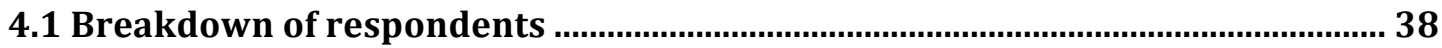

4.2 Global bundling compared to alternative monetisation strategies.................... 39

4.3 Standalone subscriptions versus bundling: overall findings............................... 41

4.4 Standalone subscriptions versus bundling: 18-30 year olds ............................... 43

4.5 Factors that influence consumers' preference for bundling ...............................45

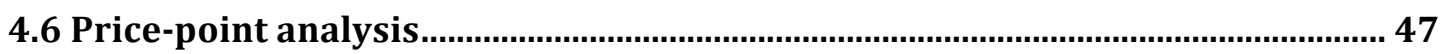

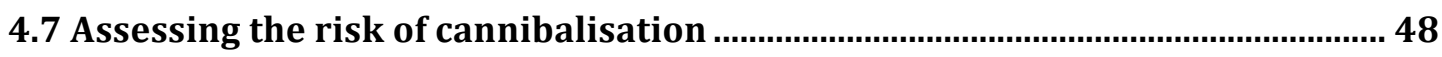

CHAPTER 5 FINDINGS, INTERVIEWS WITH NEWS ORGANISATIONS............. 51

5.1 Positive feedback about global bundling .................................................................. 51

5.2 Assessing existing research, and exploring opportunities for future studies. 53

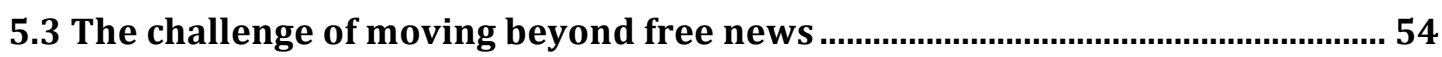

5.4 The challenge of moving beyond standalone subscriptions ............................... 55

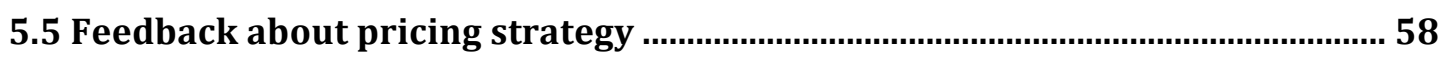

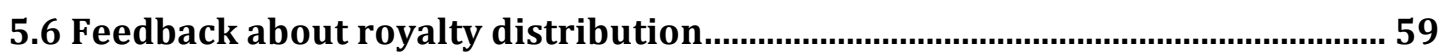

5.7 Feedback about commission structure ...................................................................61

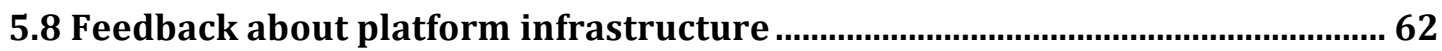

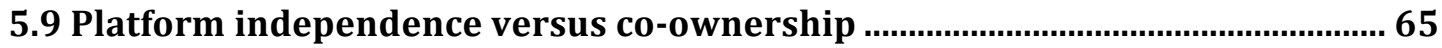

5.10 Developing a partnership strategy and preparing for launch ..........................67

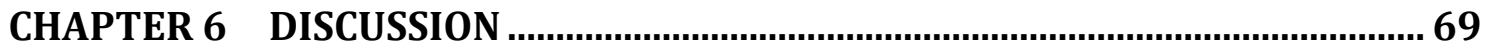

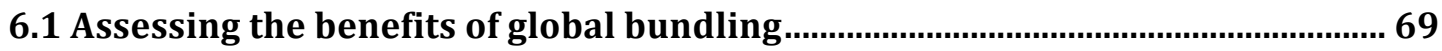

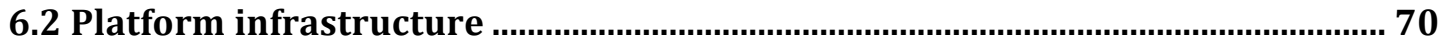

6.2.1 PressPass 1.0: universal login account .......................................................................... 71

6.2.2 PressPass 2.0: aggregation platform …………............................................................... 73

6.2.3 PressPass 3.0: content clearinghouse ………………………………….................. 75

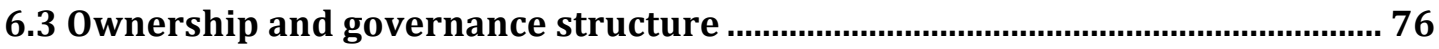

6.3.1 Assessing a Kirkpatrick cooperative ……………............................................................ 77

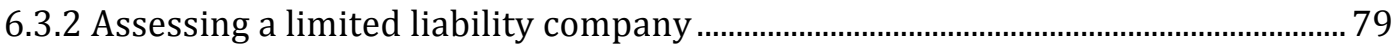

6.4 Pricing strategy

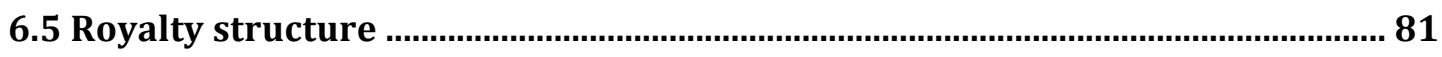

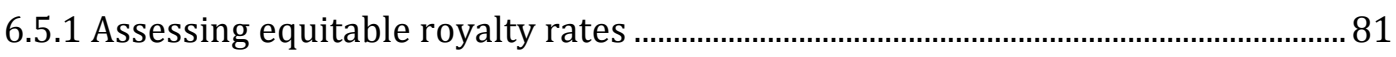

6.5.2 Assessing tiered packages and premium royalty rates ............................................. 83 


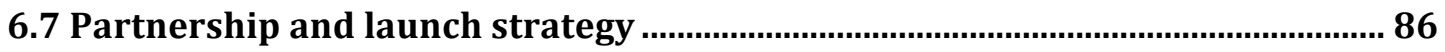

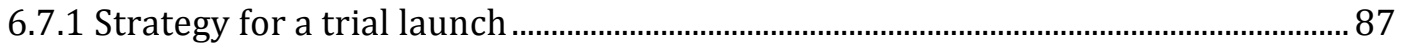

6.7.2 Establishing partnerships with conditional contracts................................................ 88

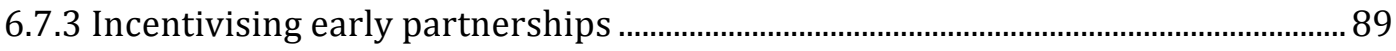

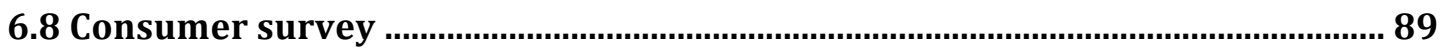

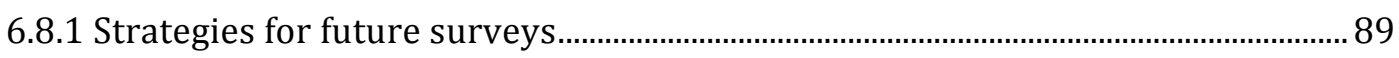

6.8.2 Assessing potential survey instruments ...................................................................... 91

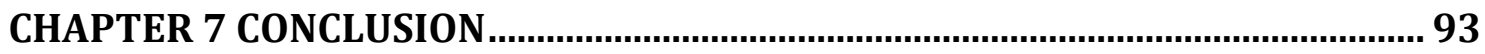

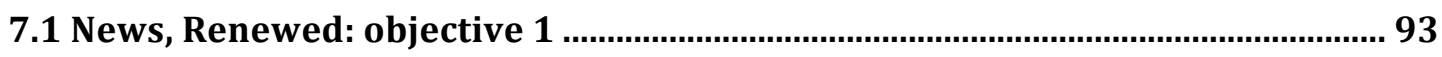

7.1.1 Evaluating the benefits of global bundling ............................................................... 93

7.1.2 Evaluating strategies for future studies.................................................................... 95

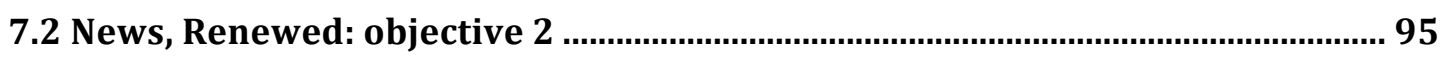

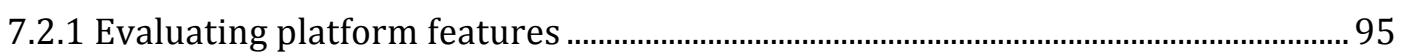

7.2.2 Evaluating ownership and governance structures........................................................ 97

7.2.3 Evaluating pricing and revenue distribution models.................................................... 98

7.2.4 Evaluating partnership and launch strategies ............................................................ 98

REFERENCES ..................................................................................................101

Appendix A: News, Renewed: Survey Questions ……......................................105

Appendix B: Enterprise Case Study …….....................................................113 


\section{TABLES}

Table 1: Monetisation strategies explored within survey …………………............................................21

Table 2: AC Nielsen 'BASES' Predicted Purchase Intent, values ..............................................................................2 26

Table 3: Margin of error for sample size of 416 …………………................................................................... 28

Table 4: Employment positions of interviewees within news organisations................................................... 33

Table 5: Age distribution of respondents $(n=416)$.................................................................................... 38

Table 6: Income distribution of respondents $(n=416)$.................................................................................... 38

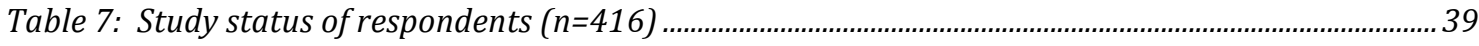

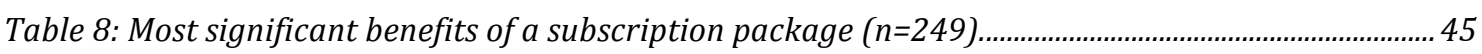

Table 9: Hypothetical commission discounts for early partnerships.............................................................. 89 


\section{FIGURES}

Figure 1: All monetisation strategies: Willingness to definitely pay $\$ 10$ or more per month (NZD)...... 39

Figure 2: All monetisation strategies: Willingness to 'probably' or 'definitely' pay $\$ 10$ or more per month (NZD).

Figure 3: All monetisation strategies: Estimated proportion of consumers who would pay $\$ 10$ or more per month (NZD). Estimates calculated using PPI values (see Section 3.1.5).

Figure 4: Proportion of respondents willing to 'definitely' pay $\$ 10$ or more per month (NZD).

Standalone subscriptions versus bundling.

Figure 5: Aggregate of respondents willing to 'probably' or 'definitely' pay $\$ 10$ or more per month (NZD). Standalone subscriptions versus bundling.

Figure 6: Estimated proportion of respondents who would pay at a price of $\$ 10$ per month (NZD), using PPI values. Standalone subscriptions versus bundling.

Figure 7: Proportion of 18-30 year old respondents willing to 'definitely' pay $\$ 10$ or more per month (NZD).

Figure 8: Proportion of 18-30 year old respondents willing to 'probably' or 'definitely' pay $\$ 10$ or more per month (NZD).

Figure 9: Estimated proportion of 18-30 year old respondents who would pay at $\$ 10$ per month (NZD), using PPI values.

Figure 10: Standalone subscription strategy: estimated conversion rate and annual revenue at different price points.

Figure 11: Global news package: estimated conversion rate and annual revenue at different price points.

Figure 12: Standalone subscription strategy: estimated conversion rates for different subgroups at $\$ 10$ per month (NZD). Values calculated using Predicted Purchase Intent. 


\section{CHAPTER 1 INTRODUCTION}

How will journalism be funded when the business models that sustained it for centuries are crumbling?

(Kaye and Quinn, 2010, p. 1)

\subsection{Project background}

The journalism industry is in crisis, and needs to identify new business models that can sustainably fund journalism in an online environment. At the heart of journalism's crisis, is the failure of existing online business models to compensate for continued losses from traditional revenue sources (Doctor, 2015). The print journalism industry is a prime example. For the financial year ending in 2012, the Pew Research Centre estimated that $\$ 16$ was lost in print advertising for every $\$ 1$ gained online ${ }^{1}$ (2013). Meanwhile, news websites with digital subscriptions convert an average of just $0.5 \%$ of readers into paying subscribers (Ellis, 2014a).

The News, Renewed project was established with the goal of helping the journalism community overcome the crisis, in order to thrive within an online environment. The project is focused on two core objectives:

1) To identify the most promising business model for funding online journalism, through academic research.

2) To enable implementation of the most promising monetisation strategy, through the development of a technology enterprise.

\footnotetext{
${ }^{1}$ Within the US market.
} 


\subsection{The Master of Advanced Technology Enterprise}

The Master of Advanced Technology Enterprise (MATE) is an interdisciplinary research programme, focused on exploring the relationship between academic research and commercial product development. At the start of the programme, students establish enterprise teams and adopt disciplinary roles based on their own field of expertise. Within their chosen team, each student undertakes activities that contribute to enterprise development, while advancing knowledge within their own disciplinary field.

The thesis component of the Master of Advanced Technology Enterprise is a vehicle for each student to synthesise knowledge and insights derived from their disciplinary role within the enterprise team. The process of enterprise development provides a wealth of academic insights and practical experience, which students are encouraged to use as the basis for reflective critique of prevailing practices within their discipline, as well as critically evaluating their own role.

In addition to writing a thesis, each team member contributes to an enterprise development case study (Appendix B). The case study is submitted as an appendix common to the theses of all team members, and is an assessment item marked separately by the Programme Director. The case study serves as a narrative of the enterprise development process, providing background information about each team's entrepreneurial journey and a high-level snapshot of strategic thinking.

The team appendix for PressPass was submitted in March 2015, and therefore contains some analysis and strategy that is superseded by material within this thesis (see Methodology, Section 3.4).

\subsection{Enterprise role}

My disciplinary role within the News, Renewed project has evolved throughout the process of enterprise development. My primary roles, to be explored within this thesis, are outlined below: 
1) At the start of the Master's programme, my core disciplinary role was to identify the most promising monetisation strategy for online journalism.

2) Once I had identified a monetisation strategy, I was responsible for coordinating development of a platform prototype.

3) Once a prototype had been developed, my role was to establish relationships with potential news partners, to gain feedback about my proposed monetisation strategy and platform design.

4) After gaining feedback from potential news partners, my role has been to refine our enterprise strategy in regards to: platform features, partnership development, pricing, revenue distribution, and governance structure.

My first role was pursued through the creation of the News, Renewed survey, which explored consumers' willingness to pay for ten online monetisation strategies, including: pay-per-article, standalone subscriptions, national news package, global news package, news and multimedia package, crowdfunding, donations, mobile application, fee-to-remove advertising, (see Section 3.1.1).

After completion of preliminary survey analysis, I developed specifications for a platform prototype (PressPass 1.0) that enables the most promising strategy (global news package) to be implemented by the journalism community. While the technical process of prototype development is beyond the scope of this thesis, my high-level specifications are summarised within Section 6.2.1.

Once a functional prototype had been developed I established relationships with potential news partners, focusing on news organisations that are adapting their legacy operations to a digital environment. Within each news organisation, I interviewed a range of individuals to gain feedback about my proposals for the PressPass platform. The interview process is summarised within Section 3.2, and findings are summarised within Chapter 5. 
Insights from news organisations have been used to establish an ongoing feedback loop, which continues to refine the enterprise strategy for PressPass. As outlined within Section 6.2, PressPass is an evolving platform containing a diverse range of features that are contingent on ongoing feedback from the journalism community.

An overview of thesis scope and structure is outlined within Sections 1.4 and 1.5.

\subsection{Scope of thesis}

Academic theory is used within this thesis to better understand the factors that influence the monetisation strategies of news organisations, through insights provided by: media economics, collective action theory, and Clayton Christensen's Innovator's Dilemma (2003). Within the literature review, some brief industry examples are occasionally used to illustrate key points. However, the literature review is not intended to provide indepth case studies about specific companies or monetisation strategies. Within the body of the thesis, the practical application of academic theory has been used as a tool to gain contextual insights into the responses of interviewees, as well as evaluate the enterprise strategy of the PressPass platform.

In regards to survey findings within Chapter 4, a side-by-side analysis of each option is initially provided as a means to evaluate the most promising monetisation strategies within the survey. The analytical focus of Chapter 4 is then narrowed, to provide an indepth assessment of bundling. A standalone subscription strategy is utilised as a benchmark for comparisons throughout Chapter 4 , because it is currently the most widely adopted paid-content strategy for news. Data analysis is intended to provide exploratory insights, that identify promising strategies most worthy of further assessment.

The thematic analysis of interviews, within Chapter 5, focuses on identifying the key strengths and weaknesses of a global news package as a monetisation strategy, while also evaluating the enterprise strategy for the PressPass platform. The core focus is on assessing the cost/benefit trade-offs associated with specific platform features, while also evaluating strategies for ownership, governance, pricing, royalty distribution, and commission structure. 
The discussion contained within Chapter 6 focuses on outlining potential next steps for the PressPass platform. Propositions outline inductive insights gained from findings within Chapter 4 and 5, and are intended to serve as a synthesis of key findings as they relate to the enterprise strategy of PressPass. Furthermore, 'proposed approaches' are recommended enterprise strategies based on propositions. Propositions and 'proposed approaches' are exploratory in nature, and not intended to serve as steadfast conclusions or concrete plans.

\subsection{Structure of thesis}

Chapter 2 (literature review) is divided into four sections. Section 2.1 assesses the media economics that influence online monetisation strategies for journalism. Section 2.2 focuses on a subset of media economic theory, exploring the implications of economies of scale, scope and aggregation. Section 2.3 explores how collective action theory can be used to better understand the underlying tension between individual and collective interests when developing a paid-content strategy. Section 2.4 assesses the Innovator's Dilemma that faces news organisations, as they try to pursue new business models while preserving existing revenue streams.

Chapter 3 (methodology) provides an overview of the methods used for the consumer survey 3.1, as well as interviews with news organisations 3.2. This chapter covers the design of each study, the process of data analysis, and limitations.

Chapter 4 (findings, consumer survey) provides analysis of data from the consumer survey, identifying the most promising monetisation strategies for online journalism. Each of the ten strategies explored within the survey are assessed side-by-side, with a detailed analysis of strategies that involve bundling.

Chapter 5 (findings, interviews with news organisations) provides a thematic analysis of qualitative data gathered during interviews with potential news partners. Key sections include: feedback about global bundling (5.1), the challenge of moving beyond existing monetisation strategies $(5.3,5.4)$, as well as feedback about pricing (5.5), royalty distribution (5.6) commission structure (5.7) platform features (5.8), ownership structure (5.9), and partnership development (5.10). 
Chapter 6 (discussion) explores how my findings have shaped the enterprise strategy of the PressPass platform. This chapter is structured with a high-level summary of preliminary propositions derived from my findings, as well as a 'proposed approach' for exploring potential enterprise strategies.

Chapter 7 (conclusion) synthesises my recommended next steps for the PressPass platform. Furthermore, I provide a critical analysis that weighs up the strengths and weaknesses of my proposed enterprise strategy, as well as selected strategies recommended by interviewees.

My references are listed on page 101. Appendix A is on page 105, and contains all questions featured within the News, Renewed survey. Appendix B is on page 113, and features the team enterprise case study for PressPass. 


\section{CHAPTER 2 LITERATURE REVIEW}

\subsection{The economic landscape of online journalism}

Quantifying the value of journalism is a challenging task that pushes the limits of conventional economic theory. As Robert Babe explains, "economists have not quantified and cannot quantify information" (2011, p. 31). At the heart of the problem, is that "information stands outside of neoclassical modelling," with a value that is highly subjective and contingent on contextual factors (Ibid, p. 31). In the case of journalism, valuations of news are shaped by: the technology of production and distribution, the business practices of producers, the laws that govern information, and consumer perceptions of value.

Many of these factors are neither fixed nor predetermined. The technology of digital distribution can have a range of characteristics depending on the rules and protocols embedded within its framework, and the business practices adopted by individual actors. In the case of online journalism, news organisations can choose to freely share their stories, or to tightly control distribution using Digital Rights Management (DRM) tools that restrict access. Furthermore, copyright law creates a legal framework that outlines the rules of redistribution, with significant impact on the economic value of information. Lastly, subjective consumer perceptions result in variable valuations based on a range of factors, such as opinions about the quality of a particular publication, and the usefulness of the information to the reader.

Of particular importance for the value of journalism, the Internet has caused a "radical reduction in the marginal costs of reproducing and distributing information goods" (Bakos \& Brynjolfsson, 2007, p. 314). The low costs of online distribution have resulted in extremely low barriers to entry, making it easy for news organisations and bloggers to distribute news for free to a global audience (Grueskin, Seave, \& Graves, 2011, p. 16). Consequently, a proliferation of free online news substitutes has emerged, resulting in a highly elastic demand curve that hinders the ability of individual news organisations to introduce prices for their online publications (Carveth, 2004, p. 272). 
The wide availability of free online news, however, was not an inevitable outcome of online technology. Instead, many news organisations made a conscious decision to freely distribute their content when first launching their websites (Kaye \& Quinn, 2010, p. 23). Often referred to as the "Original Sin" of online publishing, the decision to be free was largely motivated by the desire to gain audience share - and associated advertising revenue - at a faster rate than other news competitors (Ibid, p. 23).

Initially, it was believed that large online audiences would generate enough advertising revenue to sustainably fund journalism, without the need for online subscriptions (Kaye \& Quinn, 2010). The actual revenue generated by digital advertising, however, did not meet initial expectations. In 2010, McClatchy reported that while the number of unique users visiting news websites had grown by 17.3 percent over the previous year, digital advertising revenue had only risen by $2.4 \%$ (in Grueskin et al., 2011, p. 12). While the marginal costs of online distribution are now effectively zero, the profits that journalism can generate have also dropped significantly in an online environment.

Underpinning the low profitability of online journalism have been disparities in audience growth rates relative to other online platforms. Although many news organisations have increased the size of their online audiences, other Internet platforms have done so at a much faster rate. For example, the world's most popular Englishlanguage newspaper website - The Daily Mail - has 55.8 million monthly unique

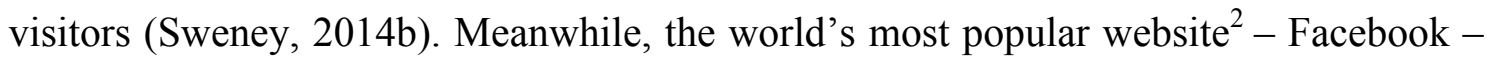
is more than 25 times larger, with 1.44 billion monthly active users (Facebook Newsroom, 2015).

Even when viewed as a collective, the entire online news industry has a small share of audience engagement compared to social networking giants such as Facebook. A 2014 report by GfK and the Interactive Advertising Bureau found that American internet users spent just $2.7 \%$ of their daily time (five minutes) reading online newspapers (GfK \& IAB, 2014). Social networking, however, was more than seven times more popular, accounting for 19.8 percent (37 minutes) of daily time spent online (Ibid).

\footnotetext{
${ }^{2}$ Global website ranking provided by similarweb.com (5 May 2015)
} 
Consequently, social networks have been able to accumulate a far greater proportion of online advertising revenues than all news websites combined.

The five minutes that consumers spend reading online newspapers, is a significant drop from the estimated 30 minutes spent reading the daily paper in 2005 (Grueskin et al., 2011 , p. 23). Furthermore, this five minutes of attention is spread between several online news websites, by readers who "flit from site to site [...] keep numerous sites open, and don't focus on any one for very long" (Ibid). Consequently, the news industry's already small slice of the online advertising pie is shared between a large number of competing websites, making the economics of purely ad-supported journalism untenable for many news organisations.

In the early days of free online news, the costs of production were entirely subsidised by print operations. Even today, free online content is heavily subsidised by revenues generated by print newspapers. In the USA, it is still common for news organisations to generate 80 to 90 percent of all revenues from their print operations (Ibid, 2011, p. 129). In New Zealand, it has been estimated that Fairfax Media still generates between 80 and 90 percent of revenue from print, despite their flagship website (stuff.co.nz) having the largest audience share of any New Zealand news site (Fahy, 2015).

Meanwhile, print revenue is declining at a much faster rate than online revenue is growing. In the USA, it has been estimated that $\$ 16$ in advertising revenue is lost, for every \$1 gained in digital revenue (Pew Research Center, 2013). In New Zealand, the Standard Media Index has estimated that \$19 in print advertising revenue is lost for every $\$ 1$ gained online (Fahy, 2014). As the subsidy provided by print revenue erodes, the sustainability of free online journalism is significantly undermined (Grueskin et al., 2011).

A report by the Tow Centre for Digital Journalism provides useful insights into the economies of scale required for free online journalism to be profitable. At one end of the scale, low barriers to entry have opened up opportunities for low-cost news sites to reach profitability with a small audience in the tens of thousands. Typically operated by a single blogger, these sites are characterised by low content creation costs. For such operations, modest advertising income is sufficient to cover modest expenses (Ibid). 
At the other end of the spectrum are large-scale news producers, with global audiences in the tens of millions. These websites have audiences large enough to generate sufficient advertising revenue to cover costs (Grueskin et al., 2011). The vast majority of legacy news organisations, however, fall within the "difficult middle of the cost curve" (Ibid, p. 98). Even though the costs of distribution are significantly lower than their existing print operations, online advertising revenue alone is not sufficient to fund their newsroom.

Eric Rowe, a former digital strategist at New Zealand's APN Online, has predicted that widespread consolidation will be required if news organisations choose to rely on a free model funded solely by online advertising. In order to achieve the economies of scale required under a free model, he predicts that the global news market would need to consolidate into 4 or 5 media companies. For the Australian and New Zealand market, he predicts that existing news companies will need to merge into a single Australasian conglomerate ("Media Take," 2014).

It is highly questionable whether an Australasian news monopoly would be legal, yet alone desirable. These issues aside, it is still doubtful whether a regional monopoly would have sufficient scale to be profitable if funded only by online advertising. A combined Australasian audience of 11 million $^{3}$ still skirts the difficult middle of the cost curve,' and would be unlikely to generate advertising revenues that could support existing newsrooms at both the local and national level.

Many news organisations now recognise the unsustainability of free online news, and have begun adopting paid-content strategies. The most popular strategy has been the introduction of online subscriptions, with news organisations introducing 'paywalls' that allow full access to paying subscribers only ${ }^{4}$. In the USA, an estimated $50 \%$ of news websites require payment for full access (Doctor, 2012). In New Zealand, online subscription plans are being considered by the country's two largest news websites (Gray, 2015; Pullar-Strecker, 2014). New Zealand Media and Entertainment (NZME), has announced plans for online subscriptions to nzherald.co.nz (APN News and Media,

\footnotetext{
${ }^{3}$ Calculated using Nielsen audience data, which estimates a unique news audience of 2.1 million for New Zealand (2014a) and 8.9 million for Australia (2014b).

${ }^{4}$ A paywall is a form of Digital Rights Management used to prevent non-subscribers from gaining full access to articles.
} 
2014), while Fairfax is considering subscriptions for specialist business content within stuff.co.nz (Pullar-Strecker, 2014).

Paywalls have had very low levels of success in overseas markets, suggesting that most consumers are unwilling to pay for standalone subscriptions to individual news websites. A study into the conversion rates of more than 500 news websites, has shown that the average paywall converts just $0.5 \%$ of unique visitors into paying subscribers (Ellis, 2014a). Even the highest performing websites within the sample converted between just one and two percent of their readers. The New York Times, which has one of the world's most successful paywalls, converts just $1.5 \%$ of its readers and has reached a point where subscriber growth is plateauing (New York Times, 2014).

While a standalone subscription is the primary paid-content strategy adopted by news organisations, a wide range of alternative business models are being explored to generate income from readers. To date, none have yet achieved widespread uptake or generated sufficient revenue to offset print losses. These include:

- Pay-per-article: micropayments to view each article (Kaye \& Quinn, 2010). Example: Blendle (www.blendle.com).

- Crowdfunding: contributors provide funds towards the creation of specific stories (Kaye \& Quinn, 2010). Example: Spot.Us (www.spot.us).

- Donations: contributors provide funds towards the operational costs of specific news organisations (McChesney \& Nichols, 2010). Example: NPR (www.npr.org/stations/donate).

- National news package: readers pay one monthly fee for a package containing several news websites within a specific country (Phelps, 2012). Example: Piano Media in Slovenia, Slovakia and Poland (www.pianomedia.com).

- Global news package: readers pay one monthly fee for a package of news websites from throughout the world (Lomas, 2014). Example: Inkl is attempting to create a global package, and currently includes seven mastheads (www.inkl.com).

- Multimedia package: bundling a news subscription with a subscription to online content, such as music or video (Sweney, 2014a). Example: The Times of London was bundled with a Spotify subscription ${ }^{5}$ (spotify.thetimes.co.uk).

\footnotetext{
${ }^{5}$ Promotional offer has now ended.
} 
- Fee to remove advertising: users contribute micropayments to remove advertising (Ellis, 2014b). Example: Google Contributor (www.google.com/contributor/welcome).

\subsection{Economies of scale, scope and aggregation}

The low marginal costs of online distribution have created strong production-side economies of scale, resulting in greater profitability and efficiency at larger scales of operation (Bakos \& Brynjolfsson, 2007). Furthermore, network externalities have fuelled demand-side economies of scale, with consumers finding online platforms more valuable when they offer a greater scope of content and community interaction (Ibid). Of particular importance for online media, are the 'economies of aggregation' that arise within a digital environment of low marginal costs.

Economies of aggregation are a "distinct source of demand-side economies [created by] strategies that bundle access to large numbers of information goods" (Ibid, p. 314). While the economics of bundling were unfavourable in a print media environment, "the effects can be decisive" with online media (Ibid, p. 315). Economies of aggregation provide a strong competitive edge to producers who embrace bundling as a strategy, by enhancing both profitability and efficiency (Ibid). Consequently, bundling has become "an essential component of internet marketing strategy for information goods" (Ibid, p. $339)$.

Another advantage of bundling is that it significantly enhances the pricing strategy of information producers. As demonstrated by Bakos and Brynjolfsson, "the law of large numbers makes it much easier to predict consumers' valuations for a bundle of goods, than their valuations for individual goods when sold separately" (1999, p.1613). Therefore, the "predictive value of bundling" enables information producers to "achieve greater sales, greater economic efficiency, and greater profits per good [...] than can be attained when the same goods are sold separately" (Ibid). Consequently, bundling is a valuable strategy that can help overcome the difficult task of quantifying the value of information.

Bakos and Brynjolfsson recommend embracing pricing strategies that maximise revenue for the overall bundle, rather than applying additive valuations that discount the 
standalone price of each information good (Bakos \& Brynjolfsson, 2007). Specifically, they recommend undertaking pricing surveys that identify the ideal price for the bundle itself, rather than applying a discount to the cumulative price of each publication within the bundle. They illustrate that additive valuations are impractical when bundling thousands of information goods into a single package, quickly resulting in a price that is beyond the reach of most consumers (Ibid).

Although economies of scale and scope provide media organisations with promising opportunities for greater efficiency and profit, they also unleash economic forces that can enable monopolisation. As Bakos and Brynjolfsson explain, "technological economies of scale [favour] large producers, and can lead to winner-take-all markets" (2007, p. 314). Low marginal costs are the driving force behind monopolisation in a digital environment, allowing per-unit costs of production to continually decrease as scale increases. This results in a dynamic where "an efficient large scale producer will be able to drive out other competitors [...] and become a monopolist" (Alexander, Owers, \& Carveth, 2004, p. 25).

There is a substantial body of literature ${ }^{6}$ exploring how bundling can be utilised as a strategy to obtain monopoly power (Bakos \& Brynjolfsson, 2007). The risk of monopolisation is strongest when content is aggregated under exclusive licensing arrangements (Ibid). Specifically, because the financial benefits of bundling continue to accrue with scale, the largest aggregator is able to accumulate resources that empower it to outbid smaller competitors (Ibid). Consequently, a virtuous cycle is created where the largest bundler with the best content continues to grow at a faster rate than competitors, allowing them to "foreclose entry, even when a competitor's products are [...] superior" (Ibid, p. 315).

In order for bundling to be a successful strategy for the journalism community, news organisations need to actively embrace economies of scale, scope and aggregation on terms that are favourable to the overall industry. To achieve this will require a high level of coordination within the journalism community - a significant challenge. Section 2.3 explores how collective action theory can be used to better understand the

${ }^{6}$ See: Burstein 1960, Bork 1978, Whinston 1990, Choi 1998, Nalebuff 1999, cited in Bakos \& Brynjolfsson, 2007. 
collective action problems faced by the journalism industry, and assesses some strategies that could allow these problems to be overcome.

\subsection{Collective action theory}

Mancur Olson's seminal work, The Logic of Collective Action, explores a wide range of circumstances where "rational, self-interested individuals will not act to achieve their common or group interests" (1971, p. 2). Collective action problems typically involve a high level of interdependency among participants, resulting in scenarios where individual contributions to collective goals are heavily contingent on the actions of other individuals (Sandler, 1995). Furthermore, collective action problems are characterised by situations where the pursuit of self-interest can lead to inferior collective outcomes (Ibid).

Olson's theory of collective action primarily relates to the provision of public goods, which have a degree of non-rivalry and/or non-excludability (Ibid). Perfectly rival goods arise when the act of consuming one unit of the good depletes all of the available benefits. A good is non-rival, however, when "a unit of the good can be consumed [...] without detracting, in the slightest, from the consumption opportunities still available for others from that same unit" (Ibid, p. 6). Perfectly non-rival goods have zero marginal costs, making them easy to share with others. Collective action issues arise, however, when trying to meet the high costs of producing the first unit of the good.

Information is an interesting example of a good that can be rival or non-rival, depending on the technology of distribution. In the case of a print newspaper, a copy can be shared with others, but there is an upper limit on how many can read a copy before diminishing the consumption opportunities of others. Consequently, a newspaper is a partially rival good. On the Internet, however, information becomes a non-rival good that can be consumed by millions of individuals, without minimising opportunities for consumption by others ${ }^{7}$.

\footnotetext{
${ }^{7}$ Apart from rare situations where excessive traffic can hinder website performance. 14
} 
Perfectly excludable goods provide benefits that can be withheld by the owner or provider without any additional cost (Sandler, 1995). Conversely, non-excludable goods involve a cost of exclusion so prohibitive that it is impractical to restrict consumption (Ibid). Consequently, perfectly non-excludable goods are freely available to anyone once they have been created. Collective action issues arise with non-excludable goods due to free-riding behaviour, where individuals enjoy the benefits of the good without contributing resources to its creation (Ibid).

Once again, information is a good that can be either excludable or non-excludable, depending on the technology of distribution. A print newspaper is an excludable good that can be restricted to paying readers. An online news site, however, requires a large investment of resources to develop Digital Rights Management (DRM) tools that can restrict access and reuse. Without the use of DRM, digital information is almost perfectly non-excludable. Even with DRM, methods exist to remove restrictions and redistribute digital content. Consequently, digital information is only partially excludable.

The formation of 'clubs' is a prominent institutional solution to help overcome collective action problems. Within collective action theory, clubs are voluntary groups containing members who derive mutual benefits from the sharing of impure public goods that are non-rival, yet characterised by a degree of excludability (Sandler, 1995). Clubs utilise the payment of membership fees or subscriptions to subsidise the provision of the club good, and use a method of exclusion to restrict nonpayers from free-riding (Ibid). In the case of online journalism, online subscriptions can be viewed within the lens of club theory to describe a collective of readers who pool their resources to fund the provision of news content.

The subscription strategies of individual news organisations are heavily shaped by the decisions of their competitors. Under a standalone subscription strategy, success is highly contingent on the availability of free substitutable alternatives. From a collective perspective, it would be rational for all news organisations to launch paywalls. The additional revenue generated by subscriptions would help fund newsrooms more sustainably than online advertising alone. From an individual news organisation's perspective, however, a rational strategy is to remain free while a competitor launches a 
paywall, in order to gain audience share and earn additional advertising revenue. Consequently, individual self-interest creates strong incentives to remain free, resulting in an inferior outcome for the collective.

In situations where scale economies exist, the underlying incentive structure of collective action is fundamentally altered, becoming more favourable towards outcomes of mutual cooperation (Sandler, 1995). Specifically, the financial benefits that can be accrued through increased scale create a strong incentive for collective action between group members, allowing personal self-interest to more directly align with collective action. As described within Section 2.2, bundling offers significant economies of scale, scope and aggregation, which could create financial rewards conducive to collective action.

Collective action theory provides some valuable strategies that could be embraced by the journalism community to help maximise the success of bundling. Of particular importance, Olsen recommends the provision of private inducements that encourage collective action, through financial self-interest (Ibid). In the case of online journalism, financial benefits derived from bundling could provide powerful private inducements that help align the self-interest of news organisations, with the collective interests of the journalism community.

Another institutional tool that is useful to overcome collective action problems, is the creation of a joint product, "in which collective activity yields multiple outputs" for a collective of producers (Sandler, 1995, p. 11). Outputs can be standalone products in a conventional sense, or can facilitate the production or distribution of other products. Joint products do not necessarily need to be owned directly by producers, but are instead enabled by their collective input. In the case of online journalism, a joint product is an essential tool for enabling bundling; without a shared platform, it will not be possible to create a global package.

Olson emphasises the importance of carefully crafted institutional design to facilitate collective action (Ibid). Cooperative business structures can be particularly conducive to collective action, with ownership creating a direct financial incentive that encourages membership and collaboration (Ibid). A conventional cooperative structure, however, 16 
may be unstable within the journalism industry due to high levels of rivalry and competition.

The model of the 'Kirkpatrick' cooperative is a governance structure that might help facilitate stability. Rather than being controlled directly by the patrons that own it, a Kirkpatrick cooperative involves the transfer of voting stock to a legally separate organisation that is responsible for governance in the interests of the collective (Ibid). This model may help overcome strong rivalries between news organisations, which otherwise threaten to hinder collective decision-making.

For collective action to successfully enable bundling, it will require news organisations to overcome the institutional inertia that is embedded within their current business models and practices. Section 2.4 explores the dynamics of the Innovator's Dilemma in greater depth, and provides some recommended strategies to help overcome barriers.

\subsection{The Innovator's Dilemma}

Christensen's Innovator's Dilemma describes how businesses often pursue strategies aimed at maximising the success of existing products, while failing to fully embrace new technology with more promising long-term prospects (2003). At the heart of the Innovator's Dilemma, is the difficult transition from 'sustaining technology' to 'disruptive technology.' Christensen defines 'sustaining technology' as incremental innovations that seek to improve the profitability of established products (Ibid). On the other hand, 'disruptive technology' offers a new value proposition that was previously unavailable to consumers (Ibid). The core challenge is finding ways to successfully maintain the profitability of existing product offerings, while pursuing disruptive substitute products that generate new revenue streams (Ibid).

In the case of the news industry, the Internet has fuelled several Innovator's Dilemmas. When the Internet was first introduced, the major challenge was transitioning from profitable print operations to less profitable digital operations. Once digital operations became firmly established, news organisations were faced with another dilemma: risk sacrificing existing digital advertising revenues, to develop a new revenue stream from standalone online subscriptions. For news organisations that have implemented 
paywalls, they now face the possibility of losing existing revenue from standalone subscriptions, in order to pursue revenues made possible by global bundling.

Christensen, Allworth and Skok emphasise that it is important for news organisations to embrace disruptive innovation: "The question of how to best survive in the new world will not be answered by hoping for a return to the past [...] now is the time for news managers to aggressively experiment with new distribution efforts" (2012). One of the new distribution techniques that they recommend, is bundling: "A consumer may find it difficult to justify the purchase price for each of a number of publications, but a subscription package that gives a consumer access to [...] multiple outlets is a compelling and unique proposition" (Ibid).

Another important strategy for news organisations, is to "always consider the audience first" by embracing products and strategies that enable the best possible customer experience (Christensen et al., 2012). Christensen recommends looking at every product from a consumer-centric perspective, identifying key pain points, and exploring ways to enable the 'job' customers want to achieve (Ibid). Christensen warns that unless companies embrace strategies that maximise consumer satisfaction, they risk losing their customers to companies that do.

In the case of online journalism, one of the core consumer 'jobs' is to access journalism. On the one hand, standalone subscriptions create multiple pain points by introducing numerous barriers to news content. Bundled subscriptions, however, solve this problem by reducing barriers to information and empowering consumers to access news from multiple sources.

Christensen posits several assumptions about the nature of disruptive technology. These include the belief that disruptive technologies generally:

- Underperform established products in mainstream markets

- Offer lower margins, not greater profits

- Are first commercialised in emerging or insignificant markets

- Are embraced by the least profitable customers on the fringes of a market

- $\quad$ Are not wanted by a leading firm's most profitable customers

(Christensen, 2003, p. xx) 
One of the core challenges created by disruptive technology, is the threat of cannibalisation. Specifically, new innovative products are often substitutes, which some consumers will adopt while abandoning previous products. Within the context of digital subscriptions, there is the possibility that some consumers will cancel their existing standalone subscription and switch to a bundled subscription. Even if bundling has the potential to generate more revenue in the long-term, the potential loss of short-term revenue creates a strong incentive for news organisations to resist the transition.

Christensen, Allworth and Skok strongly encourage businesses to embrace cannibalisation, regardless of the risk involved: "If a company is going to cannibalise your business, you'll almost always be better off if that company is your own, instead of a competitor" (2012). In the case of bundling, it is useful to consider this statement from a collective perspective. Specifically, it is better for the news industry to collectively embrace bundling as a core strategy on their own terms, rather than abdicating their autonomy and having bundling controlled by large centralised Internet companies such as Facebook, Google, Apple or Amazon.

As explored within Section 2.4, the Innovator's Dilemma is closely intertwined with the collective action problem facing the news industry. If the news industry proactively embraces bundling, it will have an opportunity to collectively establish protocols that are fair and equitable for the journalism community. If prominent Internet companies manage to establish bundling within their own closed platforms, however, they will have the upper hand in establishing rules for profit allocation and content distribution.

One of the strategies that Christensen recommends to help overcome the Innovator's Dilemma, is to create autonomous organisations responsible for commercialising the disruptive technology (2003). Autonomous organisations provide an environment where businesses can focus on maximising the success of the disruptive technology, without having a dual mandate to also preserve existing revenues.

Within the context of online news, this could result in a strategy where standalone subscriptions are maintained as the core strategy within the news organisation, while a bundling platform is developed at an arms-length and targeted at non-subscribers. 
Although such a strategy would help minimise the risk of cannibalisation, it could also undermine the prospects of success by failing to fully align bundling with each news organisation's core subscription strategy.

Another strategy recommended by Christensen, is to conduct a trial launch. A trial launch is an important strategy to help overcome resistance from cautious managers, who will often "demand quantification of market sizes and financial returns before they can enter a market" ( 2003 , p. xxvi). In the case of online journalism, small-scale trials could help news organisations to assess the benefits of a bundling, prior to a full launch within other markets. 


\section{CHAPTER 3 METHODOLOGY}

Data were collected for the News, Renewed project through an online consumer survey (Section 3.1), as well as interviews with individuals from news organisations (Section 3.2). This chapter explains the methodology involved with data collection and analysis, while also summarising the limitations that arose.

\subsection{Consumer survey}

\subsubsection{Survey design}

The News, Renewed survey was designed to assess consumers' willingness to pay for online journalism. Respondents were presented with ten online monetisation strategies, each of which is described within Table 1. The full News, Renewed survey can be viewed within Appendix A.

Table 1: Monetisation strategies explored within survey

\begin{tabular}{|l|l|}
\hline STRATEGY & DESCRIPTION \\
\hline Pay-per-article & A small fee to access each article. \\
\hline Standalone subscription & $\begin{array}{l}\text { A monthly subscription for unlimited access to one New } \\
\text { Zealand news website. }\end{array}$ \\
\hline National news package & $\begin{array}{l}\text { A monthly subscription for access to all news websites in } \\
\text { New Zealand. }\end{array}$ \\
\hline Global news package & $\begin{array}{l}\text { A monthly subscription for access to all news websites in } \\
\text { the world. }\end{array}$ \\
\hline package & $\begin{array}{l}\text { A monthly subscription for access to all news websites in } \\
\text { the world, as well as music, television and movies. }\end{array}$ \\
\hline Crowdfunding & $\begin{array}{l}\text { Journalists pitch story ideas, and readers donate funds } \\
\text { towards the creation of a specific story. }\end{array}$ \\
\hline Donations & $\begin{array}{l}\text { Readers donate funds to a specific journalist or news } \\
\text { organisation to support their operational costs. }\end{array}$ \\
\hline Mobile application & $\begin{array}{l}\text { A monthly subscription for access to a mobile news } \\
\text { application, available on phones or tablets. }\end{array}$ \\
\hline $\begin{array}{l}\text { Fee to remove } \\
\text { advertising }\end{array}$ & \begin{tabular}{l} 
A fee to remove advertising from news websites. \\
\hline Premium content
\end{tabular} \\
$\begin{array}{l}\text { A 'freemium' model, where general news articles remain } \\
\text { free but readers pay a monthly fee for access to premium } \\
\text { stories. }\end{array}$ \\
\hline
\end{tabular}


An online survey was chosen as my data collection instrument, so that I could sample a larger and more geographically dispersed range of respondents than would be possible if solely relying on face-to-face interviews (Pickard, 2007). Furthermore, a survey was useful for standardising question format and data collection, increasing the accuracy and efficiency of data analysis.

The survey was organised into three sections. Section 1 asked respondents to provide background information about themselves, including age, income, and study status. This data was important to help identify trends within each demographic group, and also to assess how representative the sample was of the general population (see Section 4.1). Section 2 of the survey asked questions about online news habits, as well as details about general media consumption. These questions were selected to assess the extent to which media consumption habits may impact respondents' propensity to pay.

Section 3 of the survey asked respondents to indicate their willingness to pay for each monetisation strategy. Monetisation options were selected by assessing a range of online strategies discussed within literature (Section 2.1), or encountered through personal experience. Furthermore, a global news package and multimedia package were initially personal ideas, developed prior to an extensive literature review. Data collected within Section 3 of the survey was of central importance for answering my core research goal: to assess the most promising monetisation strategies for online journalism.

Within Section 3 of the survey, respondents were provided with background information about the news industry and its search for new revenue models. This introductory section was created to establish the context of the study for each respondent.

Within Section 3 (Part A), respondents were asked to "Imagine a scenario where all your favourite news sites started charging for full online access." This hypothetical scenario was used to establish a point-of-reference for evaluating the following paidcontent strategies: pay-per-article, standalone subscription, national package, global package, news + multimedia package. 
Within Section 3 (Part B), respondents were asked to "Imagine a scenario where general news stories remained free, but you had the option to pay for extras." This hypothetical scenario was used to assess the following monetisation strategies, which co-exist alongside free content: fee to remove advertising, mobile application, premium content, donations, crowdfunding.

When designing the survey, several survey techniques were considered for assessing willingness to pay and pricing, including the Gabor-Granger method, Van Westendorp's Price Sensitivity Meter, and discrete choice modelling (see Section 6.8.1). These techniques, however, involve multiple steps of questioning for each option presented to respondents. Due to the large number of monetisation strategies being explored, it was impractical to utilise these methods. Instead, I gathered data using a combination of Likert scale ratings, in combination with stated price preferences, as outlined below.

For each monetisation strategy, respondents were asked "How likely are you to pay for each of the following options," and were provided with a 5-point Likert scale ranging from 'definitely not' through to 'definitely.' Immediately after answering, respondents were asked "How much would you be prepared to pay?" Respondents then selected a monthly price from the following price scale: $\$ 0, \$ 1-3, \$ 4-6, \$ 7-9, \$ 10-12, \$ 13-15$, More than $\$ 15$, and unsure.

Respondents were subsequently given the opportunity to provide qualitative insights into their funding preferences, with the question, "Please feel free to share your thoughts about the payment options above, and to explain the reasons for your answers within this section." Answers to this question were useful for gaining qualitative insights into respondents' preferences.

\subsubsection{Pilot testing of the survey instrument}

Early versions of the survey underwent a limited pilot test with four individuals over a two-day period in March 2014. The survey also received feedback from project mentors and advisors.

The most significant changes during the pilot were alterations to the pricing questions. Originally, respondents were asked to state a price within an empty text box. Pilot 
respondents had difficulty naming a price from scratch, leading to the development of pre-determined price ranges, and addition of the option to select "unsure."

Other alterations included:

- The addition of "other," "none of the above," or "prefer not to disclose," as options for questions whenever appropriate (such as income).

- Improved descriptions for monetisation strategies.

- The addition of questions that allowed for open-ended responses.

- The addition of follow-up questions for bundling, to explore the reasons why respondents selected it as an option.

\subsubsection{Respondent sampling method}

The News, Renewed survey was conducted in person, as well as via an online survey. A total of 25 respondents were interviewed face-to-face, while the remaining 432 took the survey online. Both face-to-face and online respondents were selected using convenience sampling, so that I could efficiently sample a large number of respondents within a short timeframe, using the networks and resources available to me.

Face-to-face respondents were surveyed at a number of locations, including common areas within Victoria University's Kelburn campus, Wellington's central business district, and at Wellington Airport. These respondents used my laptop to complete the same survey questions as online respondents, but were given the opportunity to discuss their open-ended answers with me. These two-way conversations were useful for gaining in-depth qualitative insights that were not possible within the static format of the online survey.

The online survey was distributed using several channels. Within Victoria University of Wellington, it was distributed via email to staff and students within the School of Information Management, as well as the School of English, Film, Theatre, and Media Studies. The survey was also sent to members of the 'NZ-Libs' email discussion group, a forum for those with a background in library and information services. Furthermore, the survey was distributed via personal, professional and community networks on Facebook and Twitter. 
Online respondents were allowed to take the survey anonymously, without unique identifiers assigned to each distribution list. Consequently, it is not possible to ascertain the exact number of respondents from each online distribution method.

\subsubsection{Assessing missing data and outliers}

Of the 457 respondents who participated in the News, Renewed survey, 33 did not complete the questions about monetisation strategies assessed within Section 3. These respondents were removed from analysis.

All of the remaining 424 respondents completed Part A of Section 3, and were included in data analysis of monetisation strategies contained within this section of the survey (Appendix A, p. 109). Eight respondents did not complete Part B of Section 3 due to attrition, resulting in only 416 respondents being included in the data analysis of monetisation strategies contained within Part B (Appendix A, p. 111).

All remaining survey data were assessed to identify potential abnormalities within answers, such as respondents providing the exact same answer for all responses. Analysis revealed that 22 respondents selected 'definitely not' for all options presented within Section 3 of the survey. Another three respondents answered 'unlikely' for all options. Nobody selected 'maybe', 'probably' or 'definitely' for all options.

I decided to include these answers within analysis, as they represent legitimate answers by respondents. While it is possible that some respondents may have selected these responses to save time when completing the survey, it is reasonable to assume that these individuals are simply opposed to paying for any of the options presented to them.

\subsubsection{Analysis of survey data}

Survey data from each monetisation strategy was analysed using three different techniques. Firstly, the proportion of respondents who answered 'definitely' at a price point of $\$ 10$ or more per month was assessed (i.e. respondents who selected: $\$ 10-12$, $\$ 13-15, \$ 16+)$. A value of $\$ 10$ was chosen for analysis, so that all options could be compared side-by-side at the same price point. Percentages were calculated by dividing the 'definitely' responses by the cohort total (including 'unsure' responses). 
Because the proportion of 'definitely' responses was very low for most options, the margin of error (see Table 3) reduced the reliability of side-by-side comparisons. To provide a higher level of certainty about the pattern of relative preference for each option, the second stage of data analysis calculated the aggregate proportion of respondents answering either 'probably' or 'definitely'. These findings were useful for evaluating the consistency of consumers' relative preferences.

The third data analysis technique was to assign a Predicted Purchase Intent (PPI) value to the Likert responses of each respondent. The PPI is a translation scale developed by AC Nielsen, to estimate the proportion of consumers who would purchase a product at different levels of stated intent (see Table 2). For example, a PPI value of 0.75 is applied to consumers who select 'definitely,' and predicts that $75 \%$ will actually purchase a product. AC Nielsen developed these predicted conversion rates through comprehensive studies that measured the stated purchase intentions of consumers, and compared them to actual purchases (Chandon, 2005; Risen \& Risen, 2008).

Table 2: AC Nielsen 'BASES' Predicted Purchase Intent, values

\begin{tabular}{|l|l|l|}
\hline SCALE & DESCRIPTION & $\begin{array}{l}\text { AC NIELSEN 'BASES' } \\
\text { PREDICTED PURCHASE INTENT }\end{array}$ \\
\hline 5 & Definitely & 0.75 \\
\hline 4 & Probably & 0.25 \\
\hline 3 & Maybe & 0.1 \\
\hline 2 & Unlikely & 0.05 \\
\hline 1 & Definitely not & 0.02 \\
\hline
\end{tabular}

For the first step of analysis, PPI values were calculated for all respondents who selected a price-point of $\$ 10$ or more per month for each option (i.e. $\$ 10-12, \$ 13-15$, $\$ 16+)$. These values estimate the likelihood of each respondent purchasing at the pricepoint selected. For the second step of analysis, a cumulative PPI value was calculated by adding all of these responses. This value estimates the total number of respondents who would actually purchase at the price-point selected. Lastly, an estimated conversion rate was calculated, by dividing the cumulative PPI value by the total number of respondents ${ }^{8}$.

\footnotetext{
${ }^{8}$ Respondents who answered 'unsure' were excluded from calculations, as they could not be assigned to a price. 
To illustrate this process, imagine a simplified scenario where eight respondents indicated they would 'probably' purchase option $\mathrm{X}$ at $\$ 10$ or more per month. In this situation, the PPI method would estimate that each respondent had a 0.25 probability of actually purchasing (i.e. one in four would convert). The cumulative PPI values would then total 2.0, estimating that two of these eight respondents would purchase. If 100 respondents had answered the question, the cumulative PPI value of 2.0 would be divided by 100 , for an estimated conversion rate of $2 \%$.

For the price point analysis in Figures 10 and 11, estimated conversion rates were calculated for every price point within the survey. For example, to estimate the conversion rate at $\$ 1$ per month, PPI values were added from all respondents who answered at $\$ 1$ or above (i.e. $\$ 1-3, \$ 4-6, \$ 7-9, \$ 10-12, \$ 13-15, \$ 16+$ ), and divided by the total number of respondents. This same process was then used to estimate the conversion rates at $\$ 4, \$ 7, \$ 10, \$ 13$ and $\$ 16+$. Estimated conversion rates were then used to calculate the estimated revenue per $\$ 1000$ respondents (i.e. conversion rate $\mathrm{x}$ 1000 x monthly price x 12 months).

\subsubsection{Limitations of survey data and methods of analysis}

This section outlines some of the limitations encountered with: the survey instrument, data collected, and methods of analysis.

Margin of error values were determined using an online calculator, provided by Creative Research Systems (CRS) ${ }^{10}$. The CRS online calculator allows the user to enter the confidence level desired, the sample size, the population size, and the survey finding (as a percentage value). The user is then provided with the margin of error based on the values entered. For my calculations, I used: a confidence level of 95\%, a sample size of 416, and an estimated New Zealand population of 4.4 million (Statistics New Zealand, 2014a).

For survey sections with the minimum number of responses (416), the margin of error is $4.80 \%$ for a $50 \%$ figure, at a confidence level of $95 \%$. Uncertainty levels become lower

\footnotetext{
${ }^{9}$ Within this simplified scenario, all other respondents answered 'definitely not', and were not assigned a PPI value. Within my own analysis, all responses were coded with the PPI values outlined within Table 2.

${ }^{10}$ Margin of error calculator available at: www.surveysystem.com/sscalc.htm
} 
as survey results get closer to zero, as illustrated within Table 3. Throughout Chapter 4, error bars are used within graphs to indicate the margin of error. These margins of error have been calculated separately for each survey result, based on the sample size of respondents for each question.

The findings within Section 4.7 contain subgroups of the overall survey, and therefore have a much higher margin of error than calculations made for the entire sample ${ }^{11}$. Consequently, findings within this section of the thesis identify interesting trends within the sample, but cannot be applied to the general population of New Zealand consumers.

Table 3: Margin of error for sample size of 416

\begin{tabular}{|c|c|}
\hline SURVEY RESULT & MARGIN OF ERROR \\
\hline $50 \%$ & $4.80 \%$ \\
\hline $40 \%$ & $4.71 \%$ \\
\hline $30 \%$ & $4.40 \%$ \\
\hline $20 \%$ & $3.84 \%$ \\
\hline $10 \%$ & $2.88 \%$ \\
\hline $5 \%$ & $2.09 \%$ \\
\hline $4 \%$ & $1.88 \%$ \\
\hline $3 \%$ & $1.64 \%$ \\
\hline $2 \%$ & $1.35 \%$ \\
\hline $1 \%$ & $0.96 \%$ \\
\hline $0 \%{ }^{12}$ & $0.72 \%$ \\
\hline
\end{tabular}

In regards to respondent selection, the survey distribution methods described in Section 3.1.3 are weighted towards students, as well as respondents with a background in media and information studies, or the library sector. Furthermore, survey participation was not compulsory so there may be a self-selection bias towards respondents with a preexisting interest in news media. As a result, survey results may not reflect the preferences of the general population of New Zealand. It is also important to note that the responses of consumers within other countries, such as the USA, may be different to the responses of New Zealand consumers.

\footnotetext{
${ }^{11}$ An exact margin of error could not be calculated, because calculations require the total size of each subgroup within the general population. Since this information was not available for all subgroups, a margin of error was not included.

${ }^{12}$ For a $0 \%$ figure the upper margin of error was manually calculated, dividing 3 by the margin size (Lumley, 2011). This technique was used because the online margin of error calculator did not calculate values for figures below $1 \%$. 
In regards to survey design, there are several factors that may impact the validity of results:

- The technique used for price-point analysis (see Section 3.1.1 and 3.1.5) may not be as accurate as more comprehensive market research techniques, such as the Gabor-Granger method and Van Westendorp's Price Sensitivity Meter.

- For questions about subscriptions, survey respondents were asked to predicate answers based on a hypothetical scenario where all of their favourite news sites had begun charging for full access. Responses may be different in a scenario where some of a respondent's favourite sites remain freely accessible.

- Within the survey, no specific news publications are mentioned. Responses may vary within a survey that asks respondents to express their propensity to pay for specific publications.

- For a global news package and multimedia package, respondents were asked to imagine scenarios where they could access all news websites in the world. If a global package is eventually created, propensity to pay will be dependent on the specific publications it includes.

- Monetisation options were assessed side-by-side within the survey, allowing respondents to make direct comparisons between each strategy. It is possible that findings may be different when strategies are assessed in isolation.

In regards to survey analysis, side-by-side analysis of certain monetisation options was not accurate when percentage values were low. Specifically, for some findings the margin of error range was within the percentage value of alternative strategies, making it difficult to assess the relative preferences of consumers. This was only an issue for the least popular monetisation options. For the most popular monetisation options, the percentage gap between alternative options sat outside the margin of error in most instances.

Another limitation of my survey analysis relates to the use of Predicted Purchasing Intent values. There is a possibility that the PPI scale (Table 2) has different values for different types of product, or for products that do not exist yet. Furthermore, research by Chandon suggests that the very act of measuring consumer intent can impact purchasing 
outcomes (2005), making it difficult to create a translation scale that perfectly predicts actual purchasing behaviour.

\subsection{Interviews with news organisations}

\subsubsection{Interview design}

For my qualitative data collection with news organisations, I chose to generate insights through semi-structured interviews rather than a survey. The key advantage of the interview format is that it provides an opportunity to obtain qualitative insights on complex topics, through a flexible format that can adapt to the expertise, interests and responsibilities of each interviewee (Pickard, 2007).

Most interviews were informal one-on-one meetings, usually conducted in person within the premises of the interviewee's news organisation. Some interviewees were met within the context of a boardroom meeting with 3-6 individuals, where I would conduct a presentation before a question and answer session. One meeting was conducted over Skype, as a face-to-face meeting could not be organised. Interview length ranged from brief 20-minute meetings through to discussions that lasted more than an hour, depending on the availability of the interviewee.

In regards to my note taking method, I would compose handwritten notes within a notebook, or would type notes using my laptop. During meetings, brief shorthand notes were primarily used to summarise the responses of each interviewee. In situations where an interviewee said something particularly noteworthy, a full phrase was noted in its original form. Immediately after each meeting, I would review all shorthand notes and add additional details based on feedback obtained during the interview. None of the interviews were recorded, providing interviewees with an environment where they could freely discuss confidential information.

The interview format adopted was semi-structured and open-ended, exploring a set of core topics and themes while allowing conversations to flow naturally depending on time constraints, as well as the interests and background of each interviewee. As recommended by Kvale, interviews were based on an interview guide, "with a reflective approach to the knowledge sought and the interpersonal relation of the interview 30 
situation" (in Pickard, 2007). Whenever time allowed, interviewees were asked for their opinions about the following core topics:

- The strengths and weaknesses of standalone subscriptions.

- The strengths and weaknesses of bundled subscriptions.

- The potential of alternative monetisation strategies (guided by the interests of the interviewee).

- Existing monetisation strategies within the interviewee's news organisation.

- $\quad$ Primary concerns about bundling, and challenges to overcome.

- The business logistics of bundling, with a focus on pricing, royalty distribution, commission structure, and partnership development.

- The technical logistics of bundling, using the PressPass prototype as a starting point before exploring a range of alternative platform strategies.

\subsubsection{Interviewee sampling method}

Interviewees were selected using a purposive sampling method. Specifically, expert elicitation was utilised as a method to gain insights from individuals with specialised institutional knowledge, and with a degree of input into the monetisation strategies of target news organisations. As outlined within Section 3.2.3, each of the 25 respondents had managerial responsibility within the news organisations approached, including one CEO.

Selection of interviewees was primarily focused on established journalism organisations, with sizeable newsrooms and large online audiences. The primary focus of my analysis was on established news organisations trying to adapt their legacy operations to an online environment. Furthermore, I predominantly focused on journalism outlets that created content for a consumer audience, rather than specialist publications aimed at professionals (such as financial and trade publications). Whenever a publication was owned by a chain, I reached out to upper management from the parent organisation so that relationships could be established with decision-makers. 
In New Zealand, I focused my efforts on connecting with the country's largest and most recognisable online news organisations, reaching out to: NZME (nzherald.co.nz), Fairfax (stuff.co.nz), TVNZ (tvnz.co.nz/news), and MediaWorks (3news.co.nz). In the USA, I focused on journalism outlets that have brand name recognition in New Zealand, reaching out to: National Geographic (nationalgeographic.com), New Scientist (newscientist.com), New York Times (nytimes.com), Rolling Stone (rollingstone.com), The Economist (economist.com), and Time Magazine (time.com). The journalism organisations that agreed to interviews are outlined within Section 3.2.3.

Once journalism organisations had been identified, I conducted background research to create corporate maps of upper management using publically available resources such a LinkedIn and company websites. This contact information was also complemented with recommendations from employees within each organisation. Once interviewees were identified, I reached out to them via email with a high level summary of preliminary findings from the News, Renewed survey, and offered to discuss the PressPass platform in more depth. Interviews were pitched as an opportunity to: discuss my survey findings, view the PressPass prototype, explore the potential for partnerships, and provide feedback about the strategy of bundling.

\subsubsection{Interviewee overview}

Between June and November 2014, I conducted interviews with senior employees within NZME (nzherald.co.nz), TVNZ (tvnz.co.nz/news), MediaWorks (3news.co.nz), the New York Times (nytimes.com), the Economist (economist.com), and National Geographic (nationalgeographic.com). I interviewed a total of 25 individuals who held senior management positions, and had varying levels of input into each news organisation's monetisation strategy. Interviewees had responsibility for a range of roles, including: strategy, marketing, revenue, consumer research, digital content, new products and technology. Table 4 provides a full overview of each employee's role, seniority and primary responsibility within their organisation. 
Table 4: Employment positions of interviewees within news organisations

\begin{tabular}{|c|c|c|c|}
\hline ROLE & SENIORITY & PRIMARY RESPONSIBILITY & \# \\
\hline $\begin{array}{l}\text { Research and } \\
\text { Insights; Strategy } \\
\text { and Analytics; } \\
\text { Research and } \\
\text { Analytics; Strategy }\end{array}$ & Head; Director & $\begin{array}{l}\text { Conducting consumer } \\
\text { research, and using insights to } \\
\text { inform strategy. }\end{array}$ & 4 \\
\hline $\begin{array}{l}\text { Digital Content; } \\
\text { Digital Media; Online } \\
\text { Content; Digital }\end{array}$ & $\begin{array}{l}\text { Head; Group } \\
\text { Director; General } \\
\text { Manager; } \\
\text { Executive } \\
\text { Producer; Group } \\
\text { Editor }\end{array}$ & $\begin{array}{l}\text { Coordinating and maintaining } \\
\text { digital content. }\end{array}$ & 5 \\
\hline $\begin{array}{l}\text { Marketing; Digital } \\
\text { Marketing; } \\
\text { Circulation } \\
\text { Innovation }\end{array}$ & Head; Director & $\begin{array}{l}\text { Promoting the uptake of } \\
\text { content offerings and } \\
\text { subscription products. }\end{array}$ & 4 \\
\hline $\begin{array}{l}\text { News and/or Current } \\
\text { Affairs }\end{array}$ & $\begin{array}{l}\text { Head; Editor of } \\
\text { Content; Director; } \\
\text { Deputy Director }\end{array}$ & $\begin{array}{l}\text { Coordinating the creation of } \\
\text { editorial content. }\end{array}$ & 4 \\
\hline $\begin{array}{l}\text { Technology; Product; } \\
\text { Product } \\
\text { Management, Digital } \\
\text { Solutions; New } \\
\text { Initiatives; Business } \\
\text { Development and } \\
\text { Innovation }\end{array}$ & $\begin{array}{l}\text { CTO; Executive } \\
\text { Director; Vice } \\
\text { President; } \\
\text { Assistant } \\
\text { Managing Editor }\end{array}$ & $\begin{array}{l}\text { Coordinating the creation and } \\
\text { implementation of new } \\
\text { products and innovations. }\end{array}$ & 5 \\
\hline $\begin{array}{l}\text { Revenue; Finance } \\
\text { and Operations }\end{array}$ & $\begin{array}{l}\text { Group Head; } \\
\text { Vice President }\end{array}$ & $\begin{array}{l}\text { Oversight of organisational } \\
\text { revenue strategy. }\end{array}$ & 2 \\
\hline \multirow[t]{2}{*}{$\begin{array}{l}\text { Chief Executive } \\
\text { Officer }\end{array}$} & CEO & $\begin{array}{l}\text { Decision-making responsibility } \\
\text { for organisation. }\end{array}$ & 1 \\
\hline & & TOTAL & 25 \\
\hline
\end{tabular}

\subsubsection{Analysis of interview data}

Interview data was analysed using a process of thematic analysis, to assess key ideas and topics that emerged (Lapadat, 2010). Once all interviews had been completed, notes were initially grouped within deductive categories based on interview questions. I then undertook a process of inductive analysis, using open coding to label responses with key themes that emerged from the data. A process of selective coding was then used to group responses into refined thematic categories, which became the basis for the analysis detailed within Chapter 5. 
The key purpose of my analysis was to identify the most important themes that emerged from data, not to quantify the relative strength of each theme. The following system, however, has been used to provide a broad insight into the number of respondents who discussed specific themes:

- Exact numbers are outlined when one or two interviewees expressed a particular view.

- 'Several' is used when three or more interviewees shared similar views.

- 'All' is used when every interviewee shared similar views.

As outlined within Section 3.2.1, not all interviewees were presented with the exact same set of questions. Therefore, references to numbers are only exploratory insights into the strength of each theme.

\subsubsection{Limitations of qualitative data from interviews}

Due to the semi-structured and open-ended nature of interviews, not all interviewees were asked the same set of questions. Consequently, qualitative analysis can only summarise the responses of interviewees who discussed each specific topic. A different range of responses may have arisen if interviews had a more structured format, such as a guided questionnaire with a fixed set of questions for all interviewees.

In regards to respondent selection, interviews were not compulsory resulting in the possibility of a self-selection bias. Specifically, interviewees who responded to my request for a meeting may have had a higher interest in paid content strategies than individuals who did not respond.

Furthermore, interviewees were selected using a non-random method with subjective criteria. Of particular importance, a focus on established news organisations means that findings will likely be different for bloggers and independent journalists. Findings are not representative of the wider journalism community, nor are interviewee responses necessarily indicative of the official position held by their employer.

Instead, qualitative analysis provides insights into the thoughts and rationale of individuals placed within complex and multifaceted organisations. Consequently, 34 
themes that emerge within analysis should be viewed as exploratory starting points for future research, rather than conclusive findings applicable to the entire journalism community.

\subsection{Human ethics}

The Programme Director for the Master of Advanced Technology Enterprise programme, Dr. Paul Smith, provided course-level permission for teams to conduct interviews and surveys related to their enterprise projects. As such, human ethics approval was not specifically obtained for the consumer survey or for interviews with news organisations. However, the principles and practices outlined within Victoria University of Wellington's Human Ethics policy were followed when conducting research (2015).

In regards to the consumer survey, responses were anonymous unless respondents chose to provide their contact details. Survey data were anonymised for analysis, and no personally identifiable information has been included within survey findings. In regards to interviews with news organisations, all qualitative analysis has been presented in anonymised form without identifying individual interviewees or news organisations. No interviews were recorded, and all interviewees were given the opportunity to go 'offthe-record' if they wished to provide confidential insights.

\subsection{Key differences between Appendix B, and data analysis within thesis}

Appendix B was completed as a team assessment, submitted in March 2015. Therefore, it only contains preliminary data analysis that differs from the analysis within this thesis.

In regards to survey analysis, Chapter 4 within Appendix B provides the percentage of all respondents who answered 'definitely' and 'probably,' at all price points. As discussed within Section 3.1.5, data analysis within the thesis focuses on respondents who answered 'probably' and 'definitely' for a price of $\$ 10$ or more per month. 
Furthermore, the thesis provides additional data analysis using Predicted Purchase Intent values.

In regards to the analysis of interviews, Chapter 5 within Appendix B provides only a preliminary analysis for a handful of high-level themes. Analysis within Chapter 5 of this thesis is more comprehensive, and supersedes any propositions made within Appendix B. Furthermore, 'proposed approaches' within Chapter 6 of this thesis superseded any recommendations outlined within Appendix B. 


\section{CHAPTER 4 FINDINGS, CONSUMER SURVEY}

Chapter 4 provides key insights from the News, Renewed survey. A total of 416 respondents completed the survey in its entirety ${ }^{13}$, providing both quantitative and qualitative insights into consumer willingness to pay.

As outlined within Section 3.1.5, data were analysed using three methods:

1) The number of respondents who said they would 'definitely' purchase at a price of $\$ 10$ or more per month.

2) An aggregate of respondents who said they would 'probably' or 'definitely' pay at a price of $\$ 10$ or more.

3) An estimated conversion rate at $\$ 10$ or more per month, using Predicted Purchase Intent values applied to all responses.

Method 1 is useful for gaining insights into the number of respondents with the highest level of consumer purchase intent. Low numbers of 'definitely' responses, however, resulted in a relatively high margin of error, reducing the reliability of side-by-side comparisons (see Section 3.1.6).

Method 2 analyses an aggregate of 'probably' and 'definitely' responses, which is useful for reducing the margin of error relative to findings. The drawback of this this metric, is that it provides less granular insight into levels of consumer purchase intent.

Method 3 is useful for creating an estimated conversion rate, through calculations that assess every answer from all respondents. The drawback of this metric is that estimated conversion rates are subject to limitations, outlined within Section 3.1.6.

When used together, these three methods provide multifaceted insights that indicate the strength of relative preferences through various analytical lenses.

Note: graphs contain margin of error bars, with values calculated separately for each survey result (see 3.1.6).

\footnotetext{
${ }^{13} 416$ respondents completed both Section 3 A and B. 424 completed Section 3A only (see Section 3.1.4 for further explanation).
} 


\subsection{Breakdown of respondents}

Tables 5 and 6 illustrate that the News, Renewed survey was completed by respondents from a diverse range of age and income brackets.

The median age-bracket of respondents was 41-50, compared to a median age of 38 years for the New Zealand population ${ }^{14}$ (Statistics New Zealand, 2013). The median income-bracket of respondents was $\$ 40,0001-\$ 80,000$, compared to a median income of $\$ 31,200$ for the New Zealand population ${ }^{15}$ (Statistics New Zealand, 2014b). Consequently, respondents are slightly older and have slightly higher incomes than the general population.

Table 7 shows that $26.9 \%$ of respondents were students. Ministry of Education figures estimate that $10.3 \%$ of the population aged 15 and above was enrolled in formal tertiary education in 2013 (Ministry of Education, 2013). This indicates that students were overrepresented within the sample.

Table 5: Age distribution of respondents $(n=416)$

\begin{tabular}{|l|l|l|}
\hline AGE & \% & n \\
\hline Under 18 & $0.5 \%$ & 2 \\
\hline $18-24$ & $13.5 \%$ & 56 \\
\hline $25-30$ & $18 \%$ & 75 \\
\hline $31-40$ & $16.8 \%$ & 70 \\
\hline $41-50$ & $24.8 \%$ & 103 \\
\hline $51-60$ & $18.8 \%$ & 78 \\
\hline $61+$ & $7.7 \%$ & 32 \\
\hline
\end{tabular}

Table 6: Income distribution of respondents $(n=416)$

\begin{tabular}{|l|l|l|}
\hline INCOME (NZD) & $\%$ & $\mathbf{n}$ \\
\hline$<\$ 15 \mathrm{k}$ & $9.4 \%$ & 39 \\
\hline$\$ 15-40 \mathrm{k}$ & $19.2 \%$ & 80 \\
\hline$\$ 40-80 \mathrm{k}$ & $47.6 \%$ & 198 \\
\hline$\$ 80 \mathrm{k}+$ & $15.9 \%$ & 66 \\
\hline Undisclosed & $7.9 \%$ & 33 \\
\hline
\end{tabular}

\footnotetext{
${ }_{15}^{14}$ March 2012 quarter.

${ }^{15}$ June 2014 quarter. 
Table 7: Study status of respondents $(n=416)$

\begin{tabular}{|l|l|l|}
\hline STUDY STATUS & $\%$ & $\mathbf{n}$ \\
\hline Student & $26.9 \%$ & 112 \\
\hline Non-student & $73.1 \%$ & 304 \\
\hline
\end{tabular}

\subsection{Global bundling compared to alternative monetisation}

\section{strategies}

Monetisation strategies that provide bundling at a global scale were substantially more popular than all other options explored within the survey. Figure 1 shows the proportion of respondents who said they would 'definitely' pay $\$ 10$ or more per month for each of the options surveyed ${ }^{16}$. A global news package $(5.4 \%, n=23)$ was between $3 \mathrm{x}$ and $23 \mathrm{x}$ more popular than all other options, while a global multimedia package $(10.8 \%, n=46)$ was between $6 \mathrm{x}$ and $43 \mathrm{x}$ more popular.

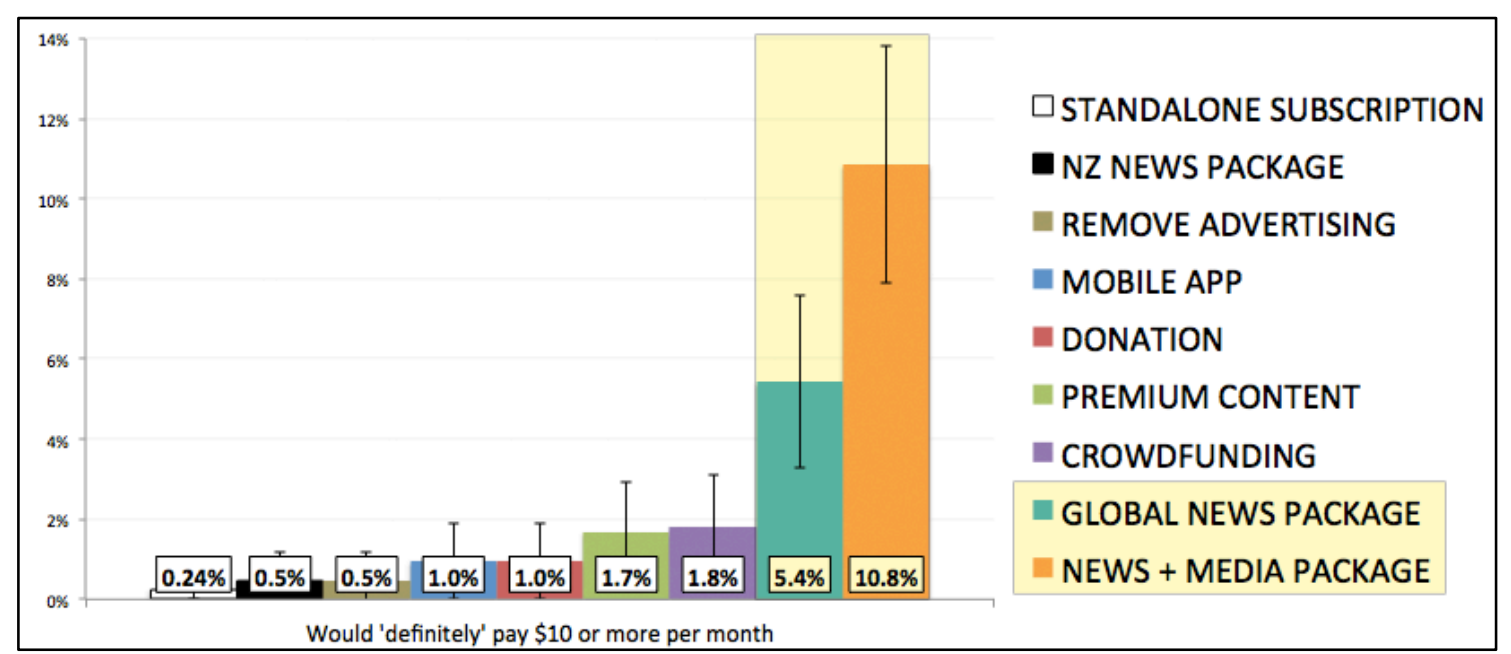

Figure 1: All monetisation strategies: Willingness to definitely pay $\$ 10$ or more per month (NZD).

\footnotetext{
${ }^{16}$ Fee-per-article not included, due to lack of pricing data. A total of 3 respondents $(0.7 \%$, 2 nd lowest ranking) said that they would 'definitely' pay a small fee to access each article, while an aggregate of 11 respondents $(2.6 \%$, lowest ranking) said that they would 'probably' or 'definitely' pay. No pricing data was collected for this question, because the monthly amount consumers are willing to pay is dependent on the per-article cost. To ascertain the ideal per-article cost as well as monthly demand would have required a multi-step market research technique, which was not possible due to the number of strategies being assessed within the survey.
} 
Figure 2 shows the aggregate of respondents willing to 'probably' or 'definitely' pay $\$ 10$ or more each month. The global news package and global multimedia package remained strong favourites at this level of analysis. A global news package $(14.9 \%$, $\mathrm{n}=63$ ) was between $1.9 \mathrm{x}$ and $10.6 \mathrm{x}$ higher than all other alternatives, while a multimedia package $(26.4 \%, \mathrm{n}=112)$ was between $3.3 \mathrm{x}$ and $18.9 \mathrm{x}$ higher.

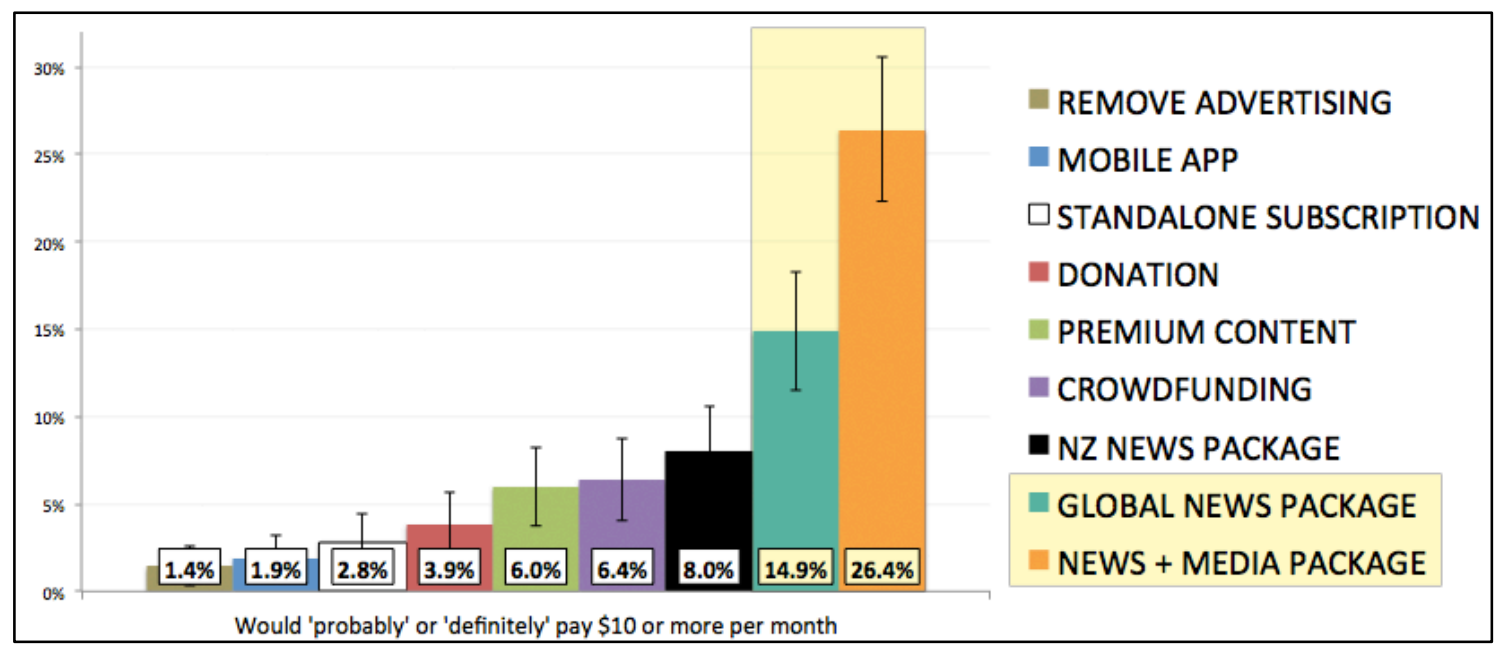

Figure 2: All monetisation strategies: Willingness to 'probably' or 'definitely' pay \$10 or more per month (NZD).

Figure 3 shows an estimate of consumers who would pay $\$ 10$ or more per month for each option, calculated by assigning a Predicted Purchase Intent (PPI) value to the answers of each respondent (see methodology, Section 3.1.5). A global news package $(8.6 \%, n=36)$ was between $2.3 \mathrm{x}$ and $10.8 \mathrm{x}$ more popular than all options without global bundling, while a multimedia package $(15.9 \%, \mathrm{n}=67)$ was between $4.2 \mathrm{x}$ and $19.9 \mathrm{x}$ more popular. 


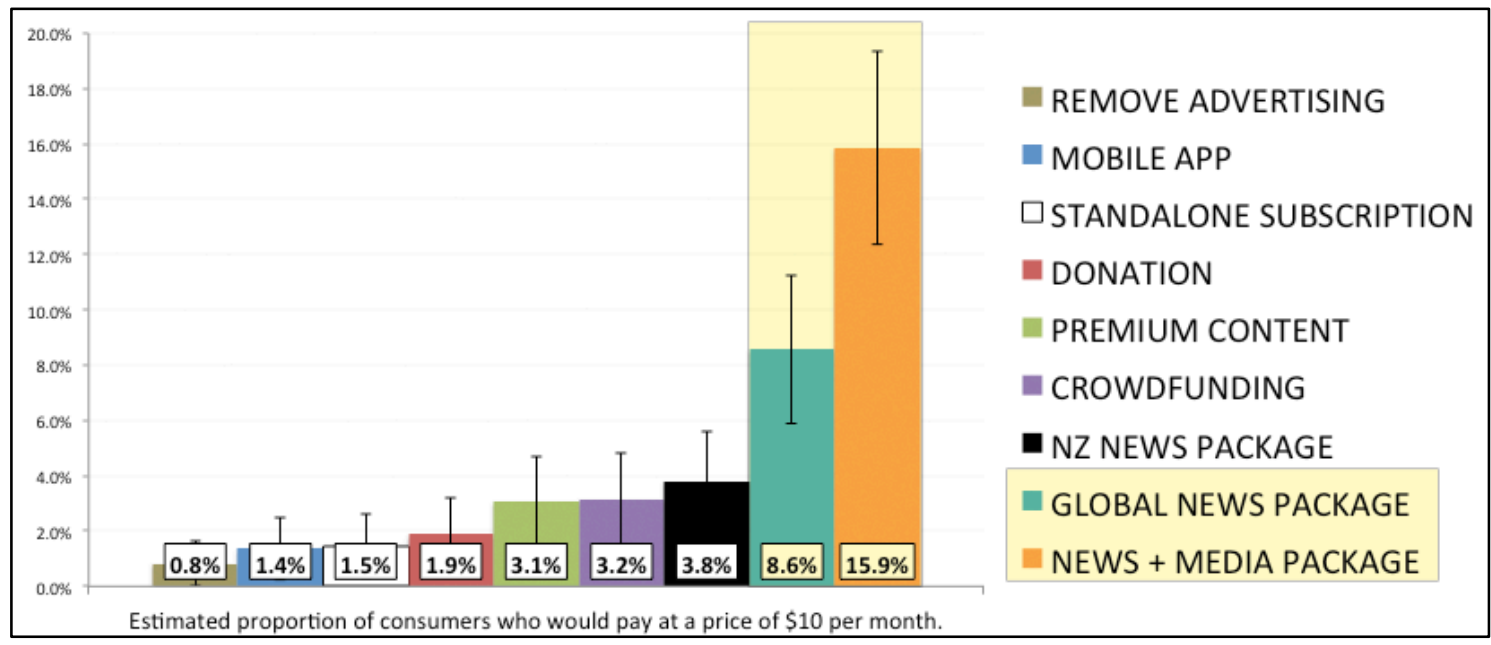

Figure 3: All monetisation strategies: Estimated proportion of consumers who would pay $\$ 10$ or more per month (NZD). Estimates calculated using PPI values (see Section 3.1.5).

\subsection{Standalone subscriptions versus bundling: overall findings}

This section contains a close analysis of the same data presented within Section 4.2, providing more granular insights into how bundling at different scales increased respondents' propensity to pay. A standalone subscription has been chosen as a benchmark for comparison, as it is the most prevalent paid-content strategy within the news industry.

Analysis of survey data revealed that as the size of the news package increased, so did respondent's willingness to pay. As shown within Figure 4, only one respondent $(0.24 \%)$ said that they would definitely pay $\$ 10$ or more per month for a standalone subscription to a New Zealand news website. For a package containing all New Zealand news websites, the number of respondents doubled to two $(0.47 \%)$. For a global package containing all news websites in the world, the number increased to $23(5.4 \%)$. For a multimedia package (containing all news websites, as well as TV shows, movies and music), the number increased to $46(10.8 \%)$. 


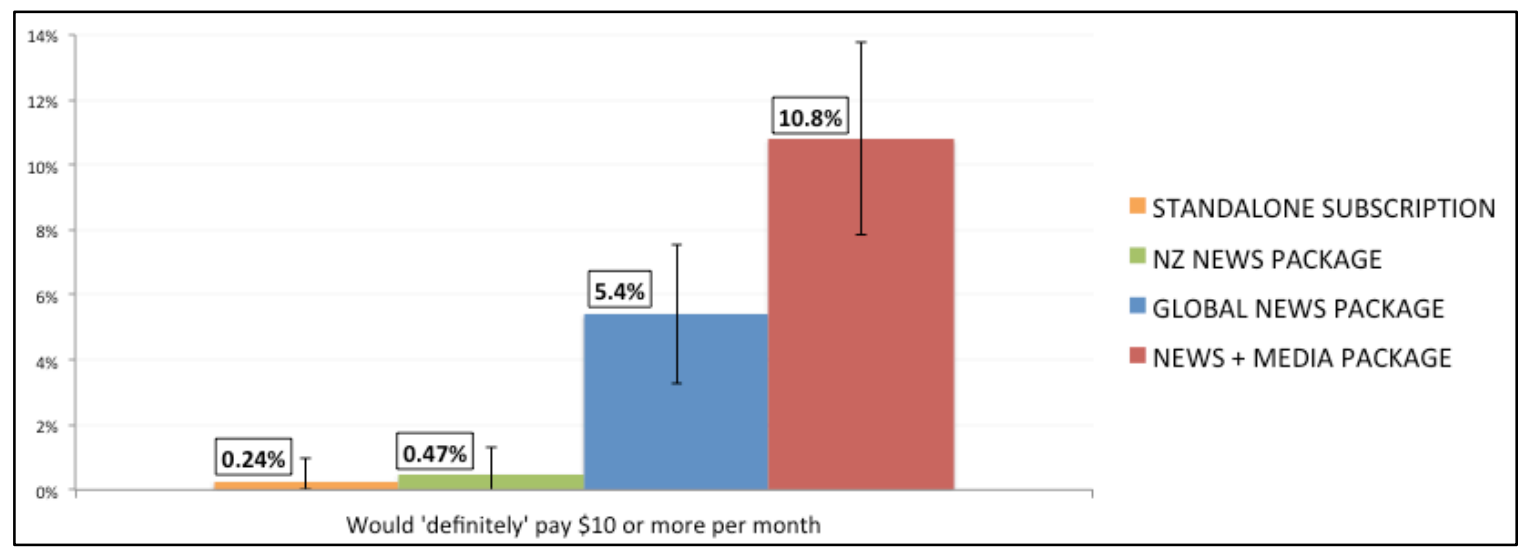

Figure 4: Proportion of respondents willing to 'definitely' pay $\$ 10$ or more per month (NZD). Standalone subscriptions versus bundling.

Figure 5 shows an aggregate of respondents who said they would 'probably' or 'definitely' pay $\$ 10$ or more per month for each option, and further confirms the strength of respondents' preference for bundled subscriptions. For a global package, the proportion willing to 'probably' or 'definitely' pay increased $5.3 \mathrm{x}$ to $14.9 \%(n=40)$. For a multimedia package, the proportion increased $9.4 \mathrm{x}$ to $26.4 \%$.

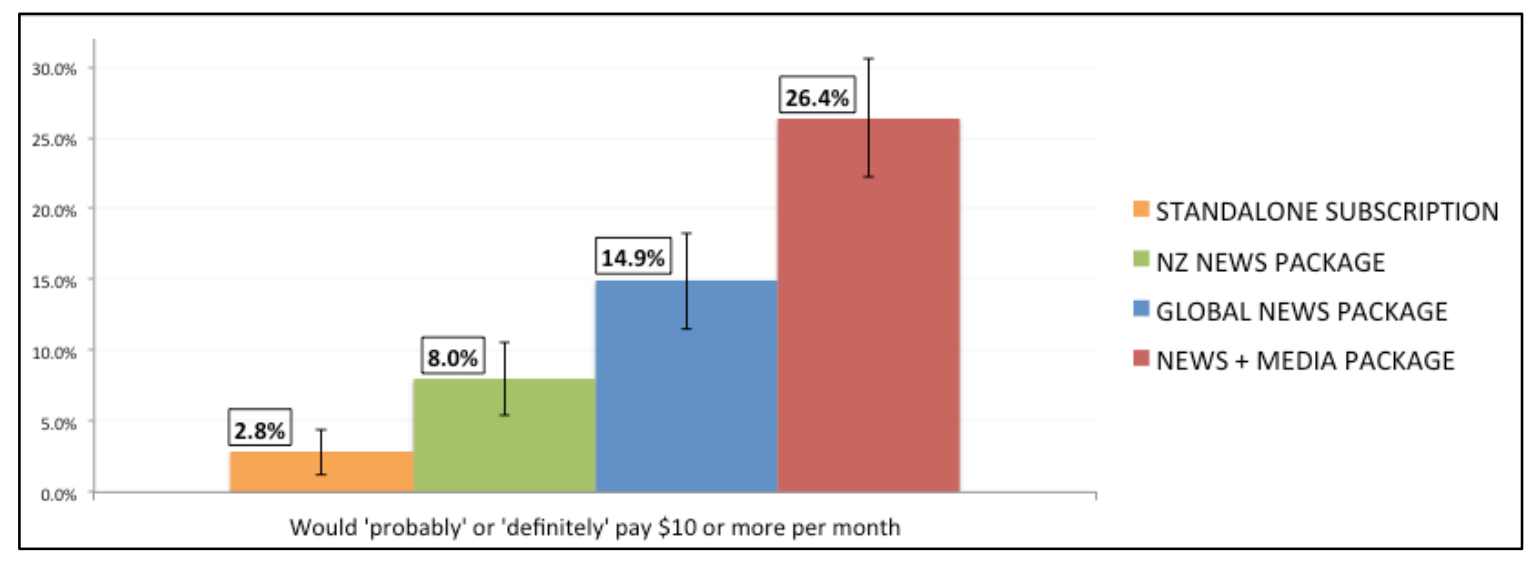

Figure 5: Aggregate of respondents willing to 'probably' or 'definitely' pay $\$ 10$ or more per month (NZD). Standalone subscriptions versus bundling.

To further explore the relative preferences of consumers, the answers of each respondent were coded with a Predicted Purchase Intent (see methodology, Section 3.1.5). The PPI values were then used as a tool to estimate the proportion of respondents who would actually purchase a subscription at each given price point. Figure 6 shows the estimated proportion of respondents willing to pay at a price of $\$ 10$ per month for each option. 
For a standalone subscription, an estimated $1.5 \%$ of respondents would pay at a price of $\$ 10$ per month. For a New Zealand news package, this value increases to $3.8 \%(2.5 \mathrm{x})$. For a global news package, this value increases to $8.6 \%(5.7 \mathrm{x})$. For a news and multimedia package, this value increases to $15.9 \%(10.6 \mathrm{x})$.

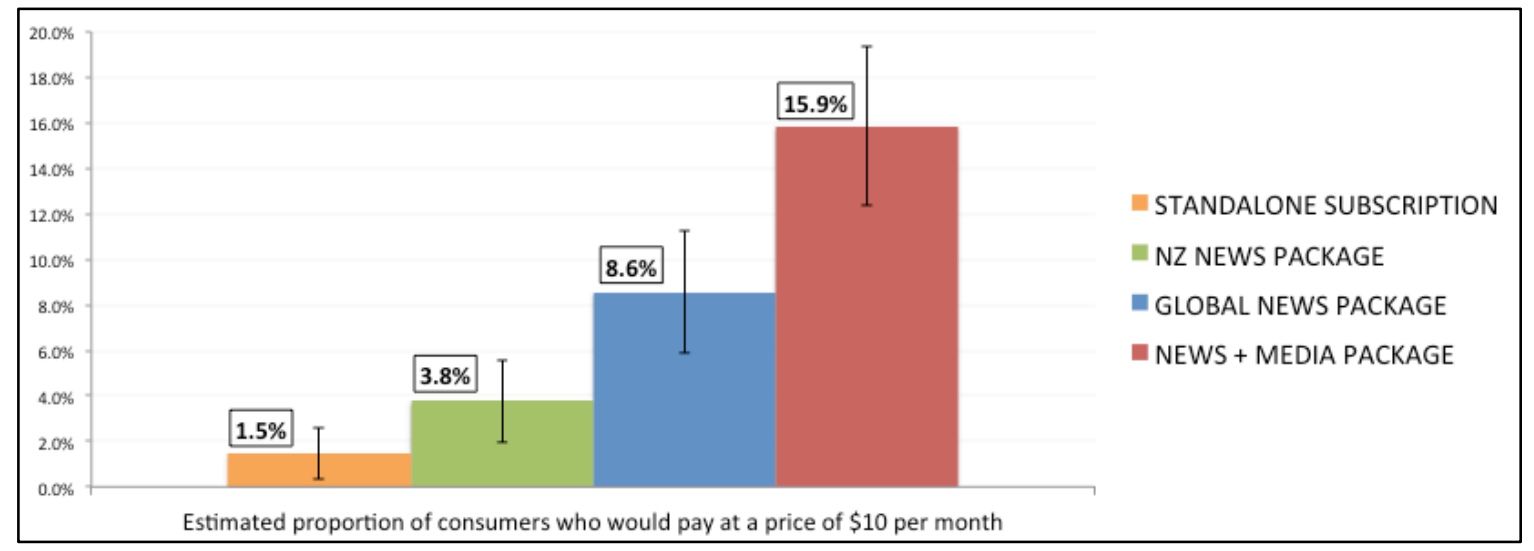

Figure 6: Estimated proportion of respondents who would pay at a price of $\$ 10$ per month (NZD), using PPI values. Standalone subscriptions versus bundling.

\subsection{Standalone subscriptions versus bundling: 18-30 year olds}

Under a standalone subscription strategy, respondents between 18-30 years old $(n=134)$ are the least likely age group to pay for news. However, when presented with a global news package, 18-30 year olds became twice as likely to 'definitely' purchase news than the overall consumer average. They are also twice as likely as the overall average to 'definitely' purchase a global multimedia package.

As shown within Figure 7, none of the respondents between 18-30 said that they would definitely pay $\$ 10$ or more for a New Zealand news websites by itself. For a global news package, the proportion increases to $11.2 \%(2.1 \mathrm{x}$ overall average, $\mathrm{n}=15)$. For a global multimedia package, the proportion is $21.8 \%$ ( $2.0 \mathrm{x}$ overall average, $\mathrm{n}=29)$. 


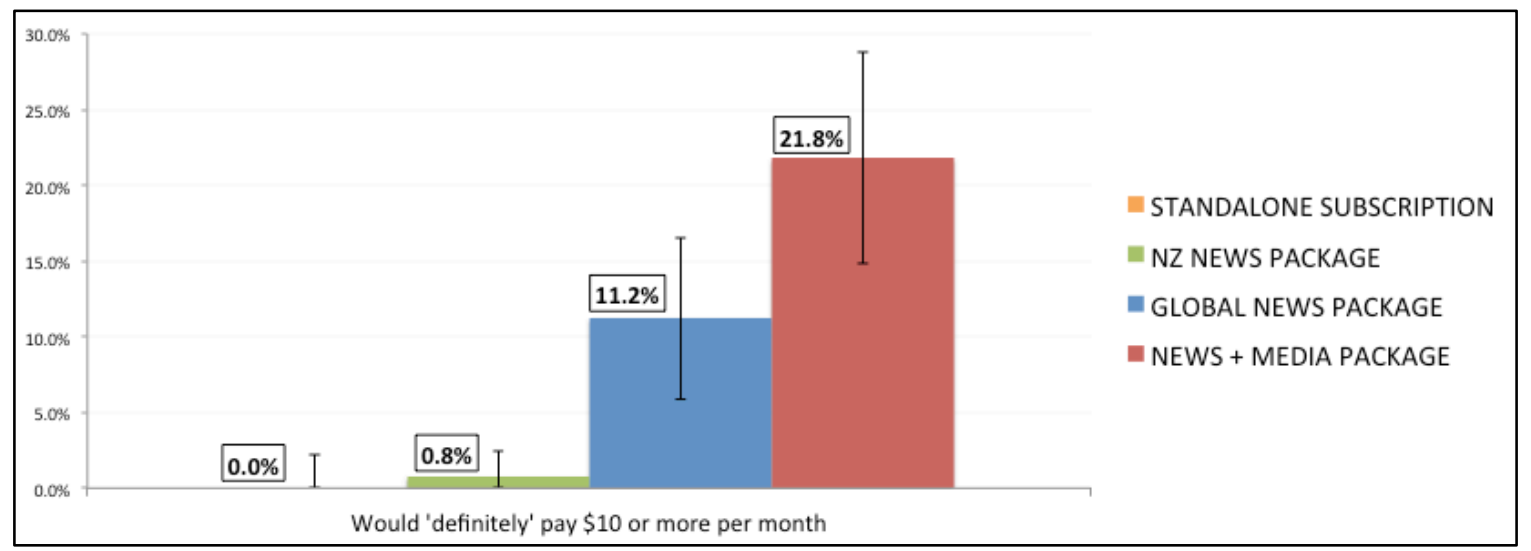

Figure 7: Proportion of 18-30 year old respondents willing to 'definitely' pay $\$ 10$ or more per month (NZD).

An aggregate of 'probably' and 'definitely' responses (Figure 8) confirms the strength of 18-30 year olds' preference for global packages. Only $2.3 \%(n=3)$ of respondents said that they would 'probably' or 'definitely' pay for a standalone subscription. For a global news package, the proportion increases to $21.6 \%(n=29), 45 \%$ higher than the overall average. For a global multimedia package, the proportion is $42.7 \%(n=57), 62 \%$ higher than the overall average.

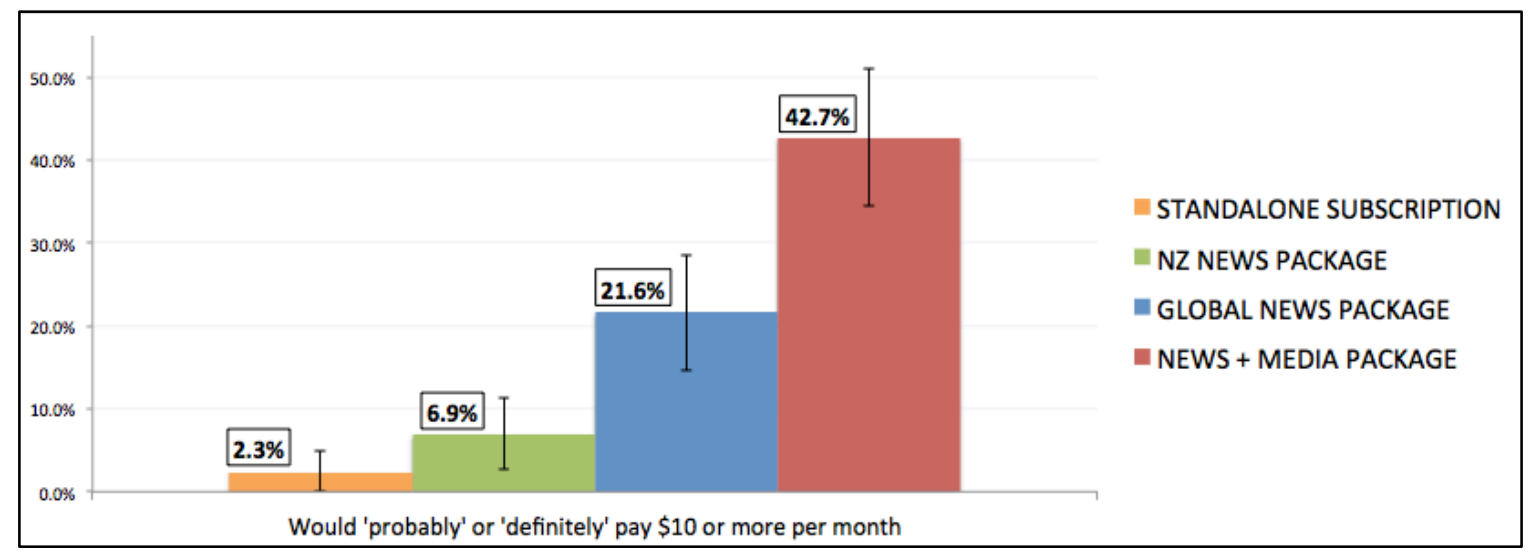

Figure 8: Proportion of 18-30 year old respondents willing to 'probably' or 'definitely' pay $\$ 10$ or more per month (NZD).

Predicted Purchase Intent values were also used to estimate the proportion of 18-30 year old respondents who would pay $\$ 10$ or more per month (Figure 9). For a standalone subscription, an estimated $0.7 \%(n=1)$ of $18-30$ year olds would pay $\$ 10$ or more per month (51\% lower than overall average). For a New Zealand news package, the estimated conversion rate increased to $2.5 \%$ (34\% lower than overall average, $n=3)$. For a global news package the conversion rate reached $11.4 \%(n=15)$, exceeding the overall 
average by $33 \%$. For a global multimedia package the conversion rate increased to $22.6 \%(n=30)$, exceeding the overall average by $42 \%$.

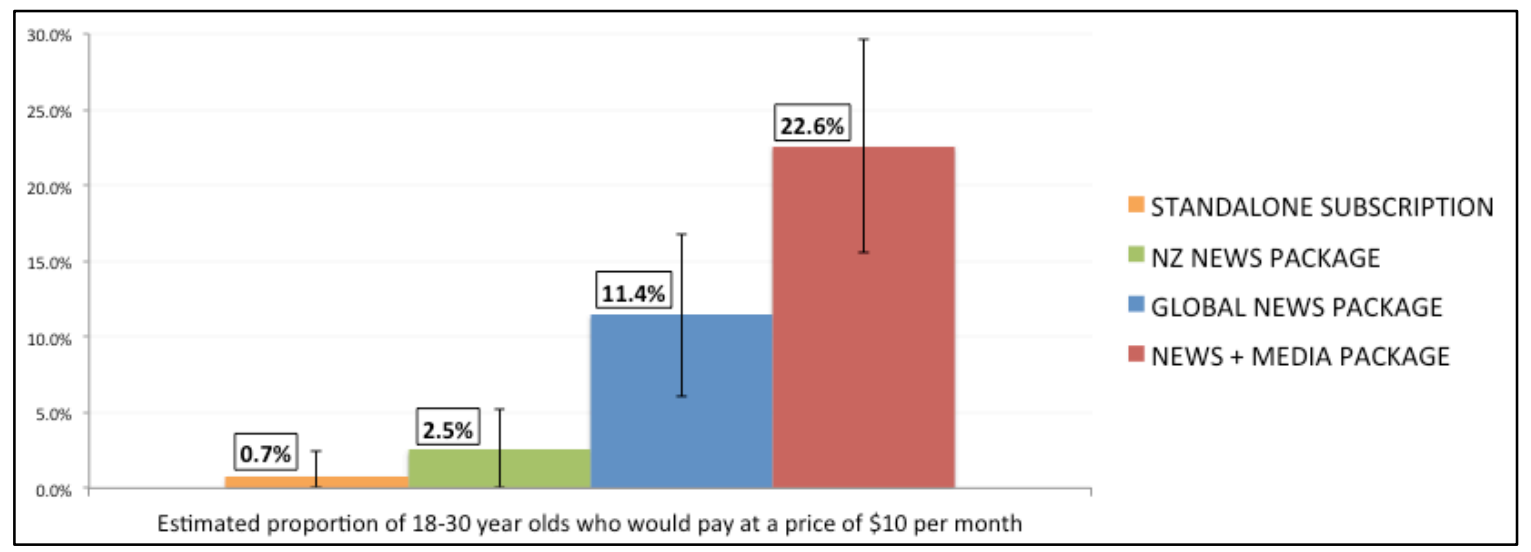

Figure 9: Estimated proportion of 18-30 year old respondents who would pay at \$10 per month (NZD), using PPI values.

\subsection{Factors that influence consumers' preference for bundling}

Respondents who answered 'maybe', 'probably' or 'definitely' for a New Zealand news package or a global news package, were given an opportunity to provide further insights into their preference for a bundle of news websites ( $n=249$, inclusive of all age groups). First, respondents were asked to select the biggest benefits of bundling from a selection of four choices (see Table 8). Respondents were then given an opportunity to provide open-ended responses that explained their preference in more depth.

Table 8: Most significant benefits of a subscription package $(n=249)$.

\begin{tabular}{|l|l|}
\hline Response & $\begin{array}{l}\text { Proportion of } \\
\text { respondents }^{17}\end{array}$ \\
\hline $\begin{array}{l}\text { It provides access to a diverse range of opinions and perspectives } \\
\text { from multiple sources. }\end{array}$ & $80 \%(\mathrm{n}=199)$ \\
\hline It is more convenient than creating multiple subscriber accounts. & $78 \%(\mathrm{n}=193)$ \\
\hline $\begin{array}{l}\text { It provides access to a variety of news websites that specialise in } \\
\text { different topics. }\end{array}$ & $60 \%(\mathrm{n}=149)$ \\
\hline It is cheaper than paying for multiple subscriptions. & $49 \%(\mathrm{n}=123)$ \\
\hline
\end{tabular}

The most popular benefit of bundling, was the ability to "access a diverse range of opinions and perspectives from multiple sources." This option was selected by $80 \%$ $(n=199)$ of respondents, and was further supported by a range of open-ended answers:

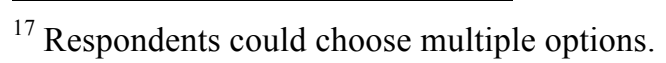


- "I prefer to have access to a wide range of opinions, especially if it's a topic or issue I don't know much about."

- "I read a number of different articles about the same news story to try and create a more whole picture of the event."

- "I don't like the idea of being tied to just one source."

- "I like choice and a range of perspectives."

- "I wouldn't want to restrict my coverage to a single website or news source."

- "I visit a few sites to attempt to avoid the filter bubble."

- 'I wouldn't be wanting to pay a subscription to receive access to a bunch of publications from the same company!"

The convenience of a bundled subscription was the second most popular benefit, selected by $78 \%(n=193)$ of respondents. Several responses provided further insight into the benefits of convenience provided by bundling:

- "It would be annoying to want to switch between a few sites only to find each one had to be separately paid for."

- "It's discouraging to have to set up logins, subscriptions etc. which might involve yet another login and password, filling out a yet another online [form] with personal details."

- "Paying individually is a nonsense - no one will do it."

- "The convenience of one subscription would be my main motivator."

- "I would favour [combining] all those services in one package for a standard fee. I am not interested in making endless choices about alternatives."

The third most popular benefit of bundling, was the ability to "access a variety of news websites that specialise in different topics. This option was selected by $60 \%(n=149)$ of respondents, and was further elaborated upon within several open-ended answers:

- "Different publications have different focus points, strengths in particular areas and political/topical/geographical leanings, so I believe it's really important to access a range of sites to gather information."

- "Not one site will cover everything you want to know" (sic).

The potential cost savings associated with bundling were a primary benefit for $49 \%$ $(n=123)$ of respondents. As one respondent articulated, "Financially, I suspect 
subscribing to multiple sources [individually] would become a bigger burden than I'd be willing to accept."

\subsection{Price-point analysis}

As detailed within Section 6.1, a global news package has been chosen as the initial focus of the PressPass platform. This section provides a price-point analysis for a global bundling strategy, compared with a standalone subscription strategy.

Predicted Purchase Intent values were used to estimate the proportion of respondents who would purchase a standalone subscription at different price points (Figure 10). Maximum revenue was generated at a price point of $\$ 10$ per month $(\$ 1,764$ per 1000 respondents ${ }^{18}$ ), with an estimated conversion rate of $1.5 \%$.

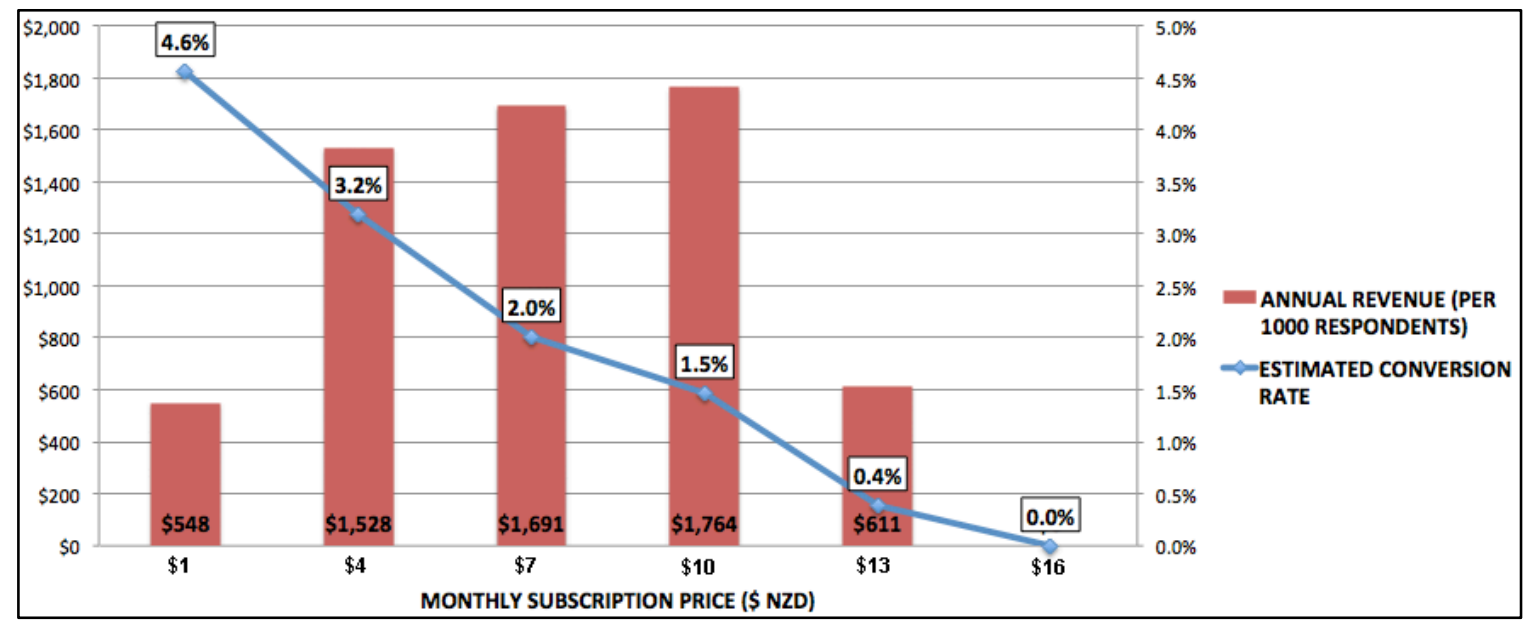

Figure 10: Standalone subscription strategy: estimated conversion rate and annual revenue at different price points.

For a global subscription, estimated conversion rates and annual revenue increase significantly (Figure 11). Maximum revenue was generated at $\$ 10$ per month $(\$ 10,272$ per 1,000 respondents), with an estimated conversion rate of $8.6 \%$. Compared to a standalone subscription, a global subscription strategy resulted in revenue estimates that were 5.8x higher, with an additional $\$ 8,508$ per 1,000 respondents.

\footnotetext{
${ }^{18}$ Calculations do not account for respondents who might buy more than one standalone subscription. Data were not available to quantify this metric.
} 


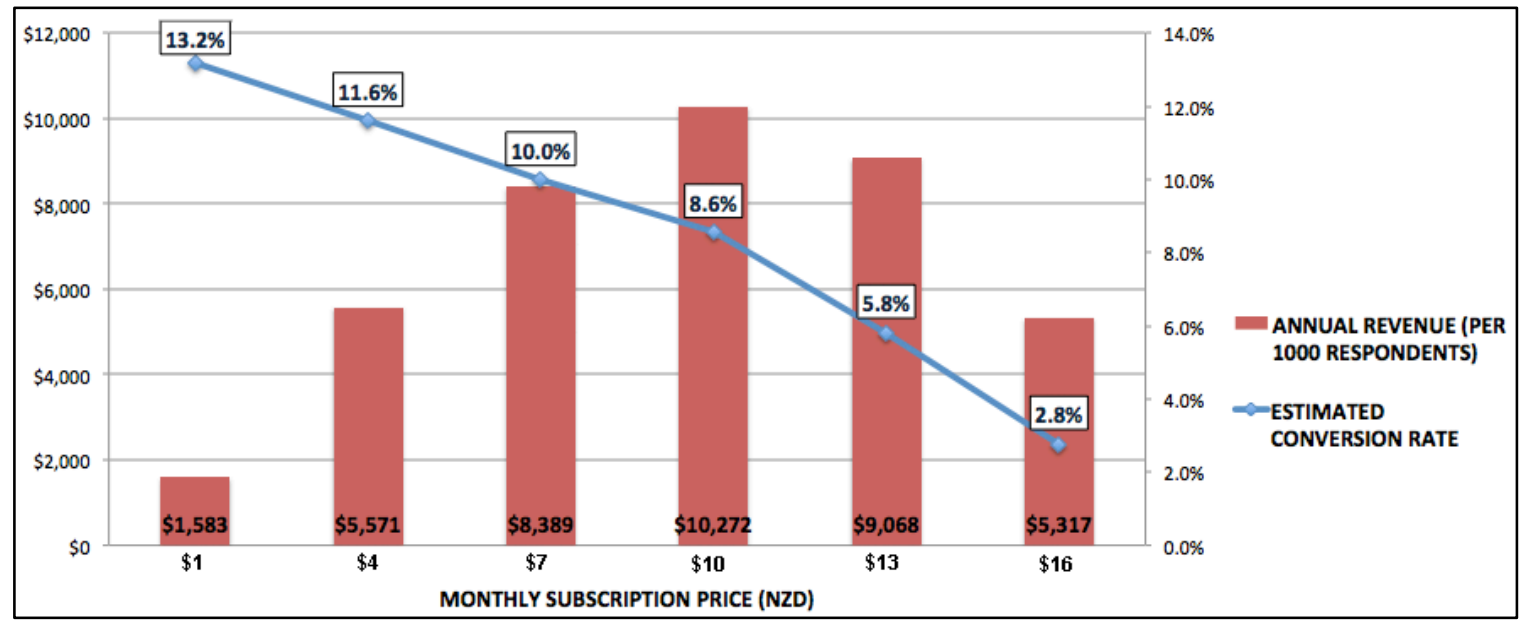

Figure 11: Global news package: estimated conversion rate and annual revenue at different price points.

\subsection{Assessing the risk of cannibalisation}

As described within Section 2.4, cannibalisation is the process by which consumers switch to new 'disruptive' products, resulting in lost revenues from legacy product offerings. A preliminary analysis was conducted to assess the risk that global news subscriptions could cannibalise a standalone subscription strategy. Trends identified within the survey data suggest that standalone subscriptions and a global news package might be two distinct markets, which can be pursued as complementary strategies.

Of the two respondents $(0.5 \%)$ who said that they would 'definitely' purchase a standalone subscription ${ }^{19}$, both had a higher preference for a standalone subscription than for a bundled subscription. Of the 26 respondents $(6.1 \%)$ who said that they would 'probably' purchase a standalone subscription, only three (11.5\%) indicated that they were more likely to purchase a global subscription. Another six (23.1\%) indicated the same level of likelihood. Consequently, the majority of survey respondents who indicated a high level of purchase intent for a standalone subscription, are unlikely to switch to a global subscription.

Quantitative analysis of subgroups within the survey sample revealed some additional trends that help explain why certain respondents prefer a standalone subscription (see Figure 12). Of particular interest, survey respondents were more likely to pay $\$ 10$ for a

\footnotetext{
${ }^{19}$ All price ranges included.
} 48 
standalone subscription if they were: older than 61 years of age (2.3x overall average), had an existing print subscription (1.9x overall average), and visited only one news website regularly $(1.5 \mathrm{x}$ overall average). Those aged $61+$, were $7 \mathrm{x}$ more likely to purchase a standalone subscription than 18-24 year olds. Those with a print subscription were $3.2 \mathrm{x}$ more likely than those with an online music or video subscription. Those who visited only one news website, were $1.3 \mathrm{x}$ more likely than respondents who visited more than 4 websites per month.

The qualitative trends within Figure 12 suggest that standalone subscriptions are more strongly preferred by older respondents, as well as those who have developed a very strong brand relationship with a specific news organisation. Consequently, it is unlikely that these respondents would readily abandon a standalone subscription in favour of a global subscription.

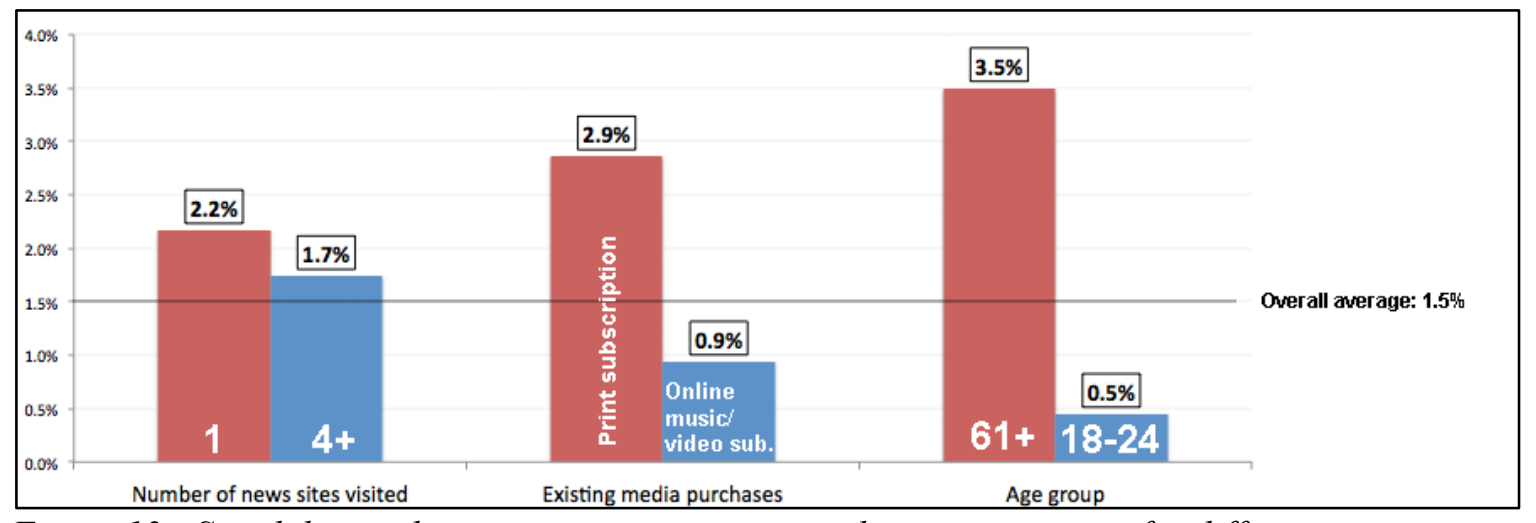

Figure 12: Standalone subscription strategy: estimated conversion rates for different subgroups at \$10 per month (NZD). Values calculated using Predicted Purchase Intent.

Due to the small sample size of the subgroups analysed, it is not possible to draw steadfast conclusions from the trends identified within the sample. If these trends can be confirmed with a larger sample, however, then the risk posed by cannibalisation is low. Consequently, news organisations might be able to pursue revenues generated by standalone subscriptions, while also pursuing new revenue streams from global bundling. 


\section{CHAPTER 5 FINDINGS, INTERVIEWS WITH NEWS ORGANISATIONS}

This section provides a thematic analysis of interviews with 25 individuals within the following news organisations: NZME, TVNZ, MediaWorks, The New York Times, The Economist and National Geographic. As outlined within Section 3.2.2, interviewees were selected using a purposive sampling method, with a focus on individuals with specialised institutional knowledge relevant to the News, Renewed project and PressPass. Themes explored within this section should be viewed as preliminary starting points to guide future research and negotiations.

Within each section of analysis, the following system has been used to provide a broad insight into the number of respondents ${ }^{20}$ who discussed specific themes:

- Exact numbers are outlined when one or two interviewees expressed a particular view.

- 'Several' is used when three or more interviewees shared similar views.

- 'All' is used when every interviewee shared similar views.

\subsection{Positive feedback about global bundling}

All interviewees expressed an interest in the potential of global bundling as a possible subscription strategy. The strongest value proposition identified by interviewees was the potential of bundling to enable a new marketplace of subscribers, who would not otherwise pay for news. Several interviewees highlighted the potential of global bundling to facilitate an easier channel to market, generating new revenue streams while also increasing the audience size for premium content.

Several interviewees emphasized that one of the biggest benefits of global bundling is to increase customer satisfaction and the perceived value of a news subscription. The convenience and value created by unlimited access was seen as a powerful marketing

\footnotetext{
${ }^{20}$ As outlined within Section 3.2.1, not all interviewees were presented with the exact same set of questions. Therefore, references to numbers are only rough insights into the strength of each theme.
} 
message to promote the uptake of news subscriptions. As one interviewee emphasised, "If readers are happy, we'll be able to generate more revenue from them."

Several interviewees highlighted the improved balance that bundling achieves between over-restrictive barriers created by standalone subscriptions, and the challenging prospect of remaining completely free. As one interviewee noted, "bundling helps us to reach a new equilibrium that better reflects the low marginal costs of digital distribution." As another interviewee emphasised, "bundling helps the news community shift back to the ideal of unlimited access to [online] information."

There was strong interest in my finding that global bundling increases the propensity to pay amongst 18-30 year olds, and several interviewees were enthused about the prospects of attracting younger subscribers with bundling. As one interviewee commented, "it's absolute gold once you convert a young subscriber. It's income for a lifetime."

Several interviewees confirmed that younger demographics have been the hardest to convert into paying subscribers under a standalone strategy, and that it is predominantly older readers who are currently paying for standalone subscriptions. One interviewee believed that standalone subscriptions do not align with the online expectations of younger readers: “There's a perception among digital natives that they're being ripped off by [standalone] paywalls. We need a better model."

Several interviewees believed that the journalism industry would eventually shift from the existing standalone model to a bundled ecosystem. One subset thought that the transition should be actively embraced immediately, while another thought that it should be a more gradual 'evolution' that occurred within the next five to ten years. Those advocating for a slower transition were concerned that the immediate adoption of bundling could undermine their standalone subscription strategy, indicating a strong Innovator's Dilemma (see Section 5.4). 


\subsection{Assessing existing research, and exploring opportunities for future studies}

Several interviewees expressed a desire for further surveying to be conducted, to confirm the extent to which trends identified within the survey are replicable. None of the news organisations interviewed had specifically assessed the merits of global bundling, resulting in an institutional blind-spot that interviewees were keen to overcome. Several interviewees were open to the prospect of collaborating on future surveys, and discussed the possibility of contributing resources, having input into survey design, and directly surveying their own readers; one interviewee formally expressed their interest in writing. All discussions about survey collaboration are still at an early stage. Possible strategies for future surveys are discussed within Section 6.8.

Despite the lack of internal research that directly assessed the potential of a global news package, several interviewees discussed proprietary studies that strengthen the case for global bundling. One interviewee highlighted an internal study which showed that many readers are willing to pay for 'journalism' as a broad concept, yet unwilling to pay for one specific publication by itself.

This interviewee also shared research insights into the willingness to pay amongst different reader archetypes. Within their news organisation, readers are categorised into four distinct groups, based on different levels of engagement. 'Super-heavy' readers accumulate more than 300 page views per month, and are most likely to pay for a standalone subscription. These readers had extremely high levels of brand loyalty, and a tendency to read 'hard news' articles.

Next are the 'heavy' readers ${ }^{21}$. These readers are still highly engaged, but regularly visit several news brands through a process labelled as 'triangulation'. While 'heavy' users still have respect for the brand of news websites they visit, they do not have an unwavering loyalty to any one specific publication. Typically they are heavily engaged with the overall news ecosystem, but are not very willing to commit to a standalone subscription for a specific publication.

${ }^{21}$ This interviewee did not provide an exact number of page views for 'heavy', 'medium' and 'light' readers. Instead, he chose to describe these reader archetypes according to the characteristics outlined. 
'Medium' readers visit the publisher's website on a regular basis, but engage with a limited range of content such as lead stories and general interest content focused on lifestyle and entertainment. Lastly, 'light' readers only visit occasionally through avenues such as social media, and have low loyalty to specific news brands. Both 'medium' and 'light' readers were highly unlikely to purchase a standalone subscription.

This interviewee emphasised that a standalone subscription strategy is most successful at converting their 'super heavy' users. However, he was concerned with the finding that a standalone subscription strategy fails to convert many readers who are 'heavy' or 'medium' readers. He pointed out that although these readers may not be the most heavily engaged with his own news website, they are probably 'super heavy' users of the entire news ecosystem. He articulated a firm belief that the process of triangulation is "massively underestimated" by the news industry, and that news organisations should embrace readers doing their own curation and exploration beyond our own brand: "We should be encouraging them to explore, rather than trying to lock them in."

This interviewee was particularly interested in surveying their readers to find out the relative preferences of each customer archetype. From his perspective, the biggest potential of global bundling is to convert the large number of readers who heavily engage with the overall news ecosystem, rather than concentrating efforts on the small proportion of readers who are narrowly focused on one specific publication.

\subsection{The challenge of moving beyond free news}

Within all news organisations without a paywall, at least one interviewee expressed a strong desire to have a paid content strategy. All interviewees, however, were apprehensive about the challenge of shifting from a free model to a paid content offering. The primary concern amongst interviewees was the fear of losing audience share to competitors who remained free.

Several interviewees emphasised their current focus on building audience share, so that they could "close the gap" with larger competitors: "We don't want to put up any barriers as we grow our audience." These same interviewees, however, were concerned 
that it would be difficult to fund their newsrooms from online revenues under a free model. As one interviewee emphasised, "We haven't figured it out yet." Interviewee concerns were symptomatic of the collective action problem facing news organisations under a standalone subscription strategy (Section 2.3).

Several interviewees identified that a bundled subscription strategy would help overcome the collective action problem that is facing news organisations. As one interviewee noted, bundling helps facilitate "safety in numbers." He emphasised that if PressPass is able to accumulate a critical mass of partners, the platform will help create a reduced sense of risk for the news industry.

Within all news organisations without a paywall, at least one interviewee highlighted the risk of losing advertising revenues while pursuing a paid content strategy. One interviewee noted that there is strong pressure from advertising sales teams to remain free, due to the fear that paywalls would undermine their primary form of online revenue. This interviewee noted that there is also external pressure from advertisers to pursue strategies that maximise audience growth, so that businesses can better target their products to readers. These comments highlight the complex Innovator's Dilemma that news organisations face, as explored within Section 2.4.

Within one news organisation, an interviewee lamented that some colleagues were "waiting for the magic holy grail of free." From his perspective, the decision to make news available for free online was the "Original Sin" of the publishing industry. He was convinced that news organisations could not sustain newsrooms without the support of reader subscriptions. With print revenues continuing to plummet, he warned: "free news is no news."

\subsection{The challenge of moving beyond standalone subscriptions}

The inertia from existing business models is perhaps the biggest obstacle to the success of PressPass. News organisations have invested substantial resources into their standalone subscription strategies, in both print and online. Participation in a global news package is a paradigm shift from existing practices, and several interviewees 
identified concerns about the impact that bundling could have on their standalone strategy.

Resistance to bundling was underscored by a powerful Innovator's Dilemma, with several interviewees concerned about the risk of cannibalising existing revenues from standalone subscriptions. All interviewees wanted to have robust reassurances that revenue generated by a global package would exceed revenue generated from standalone subscriptions, and several wanted a follow up survey to confirm the validity of my findings (see Section 5.2).

One interviewee believed that global news packages would emerge "as the market evolves," yet was resistant against bundling's immediate implementation. When I asked if I could present my research to the wider team, he was extremely reluctant. He emphasised that the paywall had been a "challenging project," and that he wanted his team focused on their standalone strategy: "I don't want to divert their attention." A management reshuffle eventually resulted in this interviewee being replaced with someone more receptive to the prospects of bundling. His comments, however, highlight the strong institutional inertia that needs to be overcome for a bundled subscription strategy to be successful.

An interviewee from another news organisation emphasised that their current monetisation strategy revolves around the maximisation of standalone subscription revenues. He warned that there could be internal resistance from his colleagues, even if bundling does have the potential to generate additional revenue: "It's outside our current realm of thinking, and could be seen as a distraction to our current goals." This was despite this interviewee being personally interested in the prospects of global bundling.

Several interviewees also expressed fears that a global bundling strategy could dilute their brand and diminish the strength of their customer relationships, when compared to standalone subscriptions. One interviewee asserted that standalone subscriptions are a powerful strategy to create reader 'lock-in', and cited internal research showing that paying subscribers become more loyal readers after purchasing a subscription. Another interviewee emphasised that a standalone strategy provides direct control over their 56 
marketing strategy, allowing them to nurture stronger brand loyalty. Furthermore, one interviewee feared that readers could develop a stronger brand relationship with the intermediary than with individual news organisations. Strategies to uphold the importance of brand are assessed within my proposed features for PressPass (Section $6.2)$.

As highlighted within Section 5.2, there was a strong bias towards standalone paywalls within the internal studies undertaken by publishers. While several news organisations had undertaken extensive proprietary studies to assess willingness to pay for their own standalone subscription product, none had assessed the financial benefits of crosspublisher bundling with their competitors. For several interviewees, this had reinforced their resistance to a global bundle.

One interviewee asserted that their internal research had already proven the viability of their standalone strategy, and were confident that they could successfully launch by themselves without any partnering. It appears that a narrow emphasis on research related to their own specific brand, has fuelled an institutional blind-spot within some news organisations. Unless efforts are made to further explore consumer trends highlighted within Chapter 4, there is a risk that news organisations will overlook more lucrative financial opportunities available through global bundling.

Despite the scepticism and resistance expressed by several interviewees, there was generally strong support for global bundling. Of particular importance, every news organisation had at least one interviewee who thought that global bundling was the best strategy to pursue. Within one group meeting, the contrasting views of interviewees was particularly evident. While one interviewee expressed scepticism about bundling throughout the discussion, another was enthused, stating: "This is exciting. We could be looking at the future of journalism."

Two of the news organisations interviewed had launched their paywalls several years earlier. Within one of these organisations, two interviewees independently discussed how growth to their standalone subscriptions had plateaued, and that new strategies were needed to enable further growth of paid subscriptions. These interviewees had concluded that standalone subscription strategies are extremely difficult to scale, since 
they only appeal to a small proportion of readers. All interviewees within this organisation expressed an openness to experiment with bundling if other partners could be brought on board.

Even in situations where interviewees expressed a preference for a standalone subscription, there was often an acceptance that it was unsustainable. As one interviewee noted, "Personally, I'd prefer a one-on-one relationship with our readers," and explained how standalone subscriptions make it easier to control their marketing and revenue strategy. However, she also understood that the new media ecosystem involves "multiple brands and diverse sources," conceding that, "publishers need to adapt to this evolving ecosystem."

Despite the fact that several interviewees were hesitant about participating in a global news package, it was encouraging that nobody rejected the potential of global bundling outright. Consequently, there are some promising foundations upon which partnerships can be built if concerns about bundling's risks can be allayed.

\subsection{Feedback about pricing strategy}

Participation in a global package will require news organisations to relinquish some of their control over pricing, so it is important to develop an acceptable pricing strategy alongside potential partners. Several respondents emphasised that publishers place a high value on their ability to control pricing, and will be extremely cautious to relinquish power: "It'll be a huge leap of faith." During interviews, I discussed possible pricing strategies with interviewees. In addition to the strategies that I proposed, interviewees made their own recommendations about how pricing should be determined for a global package.

As outlined within Section 6.4, my core proposal is to use consumer research to identify a price-point within each market that maximises overall revenue for the global package. Respondents who agreed with my proposal, saw it as an ideal strategy to maximise the success of global bundling. Respondents who disagreed with my proposal were concerned that pricing focused on maximising the success of bundling, could undermine 
the pricing strategy for their standalone subscriptions. Some of the alternative pricing strategies proposed by interviewees are outlined below.

One interviewee was particularly concerned about the risk of cannibalisation. To reduce the risk, they proposed that pricing for a global package should be structured significantly higher than existing standalone subscriptions so that readers don't readily substitute. Another interviewee suggested that pricing should be determined by applying a discount to the cumulative standalone price of each publication within the bundle. The implications of these strategies are weighed up within Section 6.4.

Within another news organisation, an interviewee discussed how digital subscriptions have been used by some organisations as a strategy to drive print subscriptions. Under this line of reasoning, publishers believe that readers will be less likely to abandon the print edition if access to the online edition is restricted to paying subscribers. As such, pricing levels are set at levels very close to the cost of the print edition, in the hopes that readers will simply opt to stick with print (which also generates higher advertising rates than online).

In contrast to this print mentality, another interviewee highlighted the importance of adopting digital pricing strategies distinct from their print: "Each subscription product is fundamentally different, even though we perceive them to be the same. We need to price them accordingly." This interviewee emphasised the importance of adopting a pricing strategy that maximises revenue streams for each subscription product independently, rather than developing strategies that attempt to promote one subscription product at the expense of the other. A print-focused pricing strategy is assessed in more depth within Section 6.4.

\subsection{Feedback about royalty distribution}

To enable the creation of a global bundle, news organisations will need to agree upon a system of royalty distribution for allocating subscription revenues amongst publishing partners. During interviews, I proposed putting all subscription revenue from a global package into a royalty pool that would be equitably distributed between publishing partners using readership metrics. For the purposes of discussion, I proposed having 
$50 \%$ of the royalty pool allocated based on page views, with the other half being allocated according to time spent reading.

Several interviewees believed that it was extremely important to have an equitable distribution of royalties between news partners, based on a transparent system applicable to all news partners. As one interviewee emphasised, "You'll need to facilitate a relationship of trust by having a fair and even playing field [for all publishing partners]." If rates are different for specific publishers, he warned that PressPass would have difficulty establishing partnerships and overcoming competitive rivalries.

Smaller news organisations within my sample were particularly concerned that an ecosystem of global bundling could be structured to favour news organisations with the most power and market share. Several interviewees from these organisations were strong advocates of equitable royalty distribution, and were reluctant to join a package if the system rewarded some publishers at a higher rate relative to others. The tension between equitable and premium royalty rates is further explored within Section 6.5.

There was widespread support for developing royalty metrics that reward quality content, rather than populist content focused on generating 'clicks'. Interviewees who supported time spent reading as a metric, liked the idea of rewarding engagement after a reader had clicked an article, discouraging the practice of 'click-baiting'. Interviewees who supported page views as a metric, liked the idea of rewarding popularity using an industry-standard metric that is easy to measure. Interviewees who supported a mixed method liked the prospect of a system that equitably rewards different types of reader behaviour, allowing news organisations to compete on both popularity and engagement.

Star ratings were also discussed as a possible royalty distribution metric with some interviewees, in addition to social networking metrics such as 'shares' and 'likes'. Several respondents saw appeal in the use of these metrics, however, there was also some concern that star ratings and social metrics could be erratic and inconsistent measures of engagement. Specifically, not every reader will take the time to rate, share or like an article. Consequently, these metrics may not be representative of overall reader engagement. If these metrics become more widely used and standardised, 60 
publishers may have a stronger desire to include them within royalty calculations. Each of the engagement metrics mentioned within this section are discussed in more depth within Section 6.5.1.

Several interviewees warned that each news organisation may have conflicting opinions about the value of the journalism they create, and the remuneration rate that they are entitled to. As one interviewee warned, "You're going to get tangled up in the egos of each publisher." He quipped that some publishers "might only get $10 \%$ of audience engagement, but think that they provide $50 \%$ of the value." Section 6.5 weighs up the implications of premium royalty rates for PressPass' partnership strategy.

The conflicting egos of some publishers became evident during interviews, particularly with larger publications. One interviewee asserted that "our news is better than anyone else's," and suggested that his publication should be entitled to a higher royalty rate. He further stated a belief that, "these partnerships are more important to [other news organisations], than they are to us." Meanwhile, another interviewee within this news organisation was more sympathetic to my proposed system of equitable royalty metrics.

Rather than creating a universal news bundle, several interviewees recommended a tiered strategy for different content niches. These interviewees highlighted that some types of content might not be easily included within a universal news package, especially 'professional' news content such as financial journalism and trade publications. These interviewees emphasised that content aimed at professionals already commands a high market price, and could be difficult to reconcile within a package alongside lower value consumer news content. Several interviewees recommended the creation of tiers for each specific content niche. A tiered bundling strategy is explored within Section 6.5.2.

\subsection{Feedback about commission structure}

During interviews, I explained my desire for PressPass to have a low commission structure, so that a high proportion of revenue can be returned directly to news partners (further details, Section 6.6). 
There was considerable positive feedback about my proposal, with one interviewee commenting, "That's very generous [...] I think that's quite a noble approach." Several interviewees expressed a strong desire for an intermediary that would redistribute profits to the journalism community, without taking an excessive commission in the process. Several interviewees believed that my proposed strategy would help establish trust with the journalism community, and could provide a key competitive advantage over other platforms that might attempt to create a global news package. Interviewees emphasised that it would be difficult for PressPass to form partnerships if our commission structure was perceived to be unfair.

Consistently, interviewees expressed a strong belief that existing Internet platforms were generating excessive profits at the expense of content creators. Interviewees were particularly concerned by the 'industry standard' commission rate of $30 \%$, which platforms such as Apple, Amazon and Google charge when dividing revenues from content sales or advertising. Several interviewees had negative comments about intermediaries, complaining that they "cream profits" and "have a reputation for eating everybody else's lunch". Considering that revenues from subscriptions are already low, there were concerns that a news platform with an unfair commission structure could prevent the journalism community from achieving financial sustainability.

The large amount of negativity around existing Internet platforms reinforced the importance of having a commission structure that is fair and equitable for the journalism industry. The commission structure of PressPass is discussed in more depth within Chapter 6.6.

\subsection{Feedback about platform infrastructure}

There is a strong tension between having global bundling enabled by a centralised aggregation platform, or having a decentralised platform that is integrated within each partner news website. Each strategy has its own inherent strengths and weaknesses, and it appears that each approach may be appropriate at different stages of the PressPass project. A full discussion of the pros and cons of each stage is contained within Section 6.2 , while a summary of interviewee feedback is provided below. 
For the first stage of the PressPass platform (version 1.0), I have proposed a decentralised platform that integrates with existing news websites. Under this model, PressPass would provide news partners with paywall technology that is hosted within each website, as well as authentication protocols that allow paying subscribers to view premium content (see Section 6.2.1).

Several interviewees gave positive feedback about the decentralised nature of PressPass 1.0, and liked the way that the platform empowers news partners with independent control over editorial, design and advertising decisions. Furthermore, interviewees were enthusiastic about the prospect of maintaining a direct relationship with their readers.

In regards to the alternative strategy of a centralised news platform, several interviewees expressed a high level of concern about the risk of an intermediary gaining excessive control over the journalism ecosystem. Interviewees were particularly concerned about the prospect of a centralised platform dictating the way that all news stories are curated and prioritised within the ecosystem. These interviewees believed that PressPass 1.0 would be a good way to achieve the benefits of universal access provided by a global package, without the loss of curatorial control that could occur under a centralised model.

Despite the strong advantages of PressPass 1.0, several interviewees were concerned that it could be difficult getting final approval for direct integration with their website. The primary concern was the risk of cannibalising their existing standalone strategy, with these interviewees suggesting that it might be easier to gain approval for a bundling strategy if it was trialled at an 'arms length' from their website. Another interviewee raised concerns that direct integration could require more technical resources, than provision of news content to a centralised third-party application. The pros and cons of PressPass 1.0 are discussed within Section 6.2.1.

To explore the possible advantages of a centralised application, I discussed possible features that could be included within a second version of PressPass (version 2.0). Specifically, I proposed providing readers with a streamlined 'all-in-one' platform, allowing readers to easily browse the articles of all publishing partners by category, while also providing article recommendations (Section 6.2.2). 
Several interviewees expressed an interest in providing readers with a streamlined platform to browse news stories. Interviewees who supported an aggregation component believed that news organisations should be making it easier to consume news from multiple sources, so that readers can efficiently find the articles they are most interested in. Interviewees highlighted the potential to improve reader satisfaction, while also increasing the volume of news stories that are discovered and read.

Several interviewees, however, had strong concerns about the way that articles would be curated and prioritised within a centralised platform. These interviewees wanted reassurance that the methods of curation used within PressPass 2.0 would be fair and transparent. As outlined within Section 6.2.2, my proposals for PressPass 2.0 include mechanisms to uphold publisher independence and editorial autonomy, while enabling each news partner to establish a direct relationship with their readers. Furthermore, I have outlined possible strategies for an open and transparent system of algorithms to prioritise aggregated content. These proposals are still under development, and will be used as starting points within future discussions.

Another concern about aggregation was that readers could easily flow to their competitors, resulting in less brand loyalty and more transient customer relationships. Despite these fears, several interviewees recognised that recommended articles and aggregation would enable a multidirectional and reciprocal flow between publishers. One interviewee viewed aggregation through a pragmatic lens: "it's the way that readers already behave online, it's just not streamlined yet." As another interviewee highlighted: "We need to be realistic, people are going to channel surf."

Further to my plans for PressPass 1.0 and 2.0, Section 6.2.3 outlines my recently developed proposals for PressPass 3.0, a content clearinghouse that aims to streamline the provision of global news partners' content to a decentralised ecosystem of aggregators. Many details contained within proposals for PressPass 3.0 were refined after my interviews, and feedback will be sought from news organisations in the future. 


\subsection{Platform independence versus co-ownership}

Several interviewees showed a strong interest in having PressPass operate independently from news organisations, by avoiding direct investment from specific news partners. Interviewees expressed a belief that independence would help facilitate partnerships that overcome competitive rivalries. As one interviewee highlighted, "If direct ownership is involved, natural competition will prevent the development of partnerships with [competing] publishers."

Interviewees in favour of independence, expressed concern that direct ownership could result in conflicts of interest. Specifically, publishers with ownership stakes could operate the platform in a manner that favours their own content, at the expense of their competitors. Furthermore, there were concerns that direct ownership by a handful of publishers would result in a concentration of market power, with owners gaining excessive control over the flow of information. For these interviewees, platform independence was seen as an extremely important strategy to help maintain the operational integrity of the bundling ecosystem.

Several interviewees were also concerned that direct ownership by publishers could contribute to instability when trying to make pivotal decisions. There was a strong belief that bundling should be operated under an independent governance structure, to help overcome the possible deadlock that could occur during collective decision-making between rival publishers. There was interest in the possibility of establishing an independent governance structure that considers the individual desires and concerns of each individual publisher, while also having a mandate to make decisions that benefit the collective interests of the journalism community.

Several interviewees also highlighted the potential anti-trust implications of direct ownership by competing publishers. Of particular concern, the New Zealand media ecosystem is already a highly concentrated duopoly, and direct ownership could trigger antitrust proceedings. I discussed these concerns with a representative of the Commerce Commission. While he could not give specific legal advice on proposed business models, he warned that direct ownership would likely trigger an extremely high level of 
legal scrutiny. While he noted that there are some limited exemptions provided within the Commerce Act for joint ventures, he advised that the provisions are very narrow in scope and may not apply in the case of PressPass. As he emphasised, "The devil is in the details."

Despite widespread concerns about the implications of direct ownership by news partners, several interviewees indicated that their news organisation would likely want an ownership stake in PressPass if they came on board as publishing partners. Furthermore, one interviewee emphasised that his news organisation had "always gone down a proprietary approach" when developing its news products, and stated that if his news organisation were to adopt a bundling strategy, it would want to build the platform itself and own the ecosystem. Interviewees who expressed an interest in ownership, highlighted concerns that non-ownership could result in a loss of power, either to the intermediary itself or to competitors who might obtain an ownership stake.

One interviewee pointed out that he had personally recommended against having an ownership stake in emerging news platforms, due to issues such as perceived conflicts of interest and barriers to partnership development with competitors. However, he pointed out that there was strong pressure from business colleagues to have an investment stake in the platforms they contributed content to. Following my interview, his news organisation moved forward with investment in an emerging news platform. This interviewee suggested that co-ownership with a range of competing publishers could be the best way to balance the interests of multiple stakeholders. However, he also conceded that collective governance could be unstable when making contentious decisions between rival owners

Interviewee feedback suggests that some form of co-ownership arrangement might be important for PressPass' success, but comes with some significant risks. The pros and cons of the different ownership and governance structures are explored in more depth within Section 6.3. 


\subsection{Developing a partnership strategy and preparing for launch}

A number of interviewees recommended possible strategies that might help facilitate partnerships with publishers. One interviewee recommended the use of preferential rates for the first publishing partners who come on board, such as a discounted commission rate for the first 12 months after launch. This interviewee emphasised that this strategy would help create a strong first-mover advantage, incentivising risk-averse publishers to come on board at an early stage.

Several interviewees expressed interest in the potential of conditional contracts that would become activated once milestones with partnership development had been met. Under this strategy, each publishing partner would sign a contract agreeing to basic principles related to pricing, royalty distribution, commission structure and a provisional launch date. The contract would not become activated, however, until several other publishing partners had signed the same agreement. Interviewees in favour of conditional contracts thought that it would be an ideal mechanism to spread the risk of participation within a global bundle. Of particular importance, it would help overcome the fear of launching first by allowing news organisations to move forward together.

Several interviewees emphasised that once partnerships are established, they would like to obtain robust metrics from a trial launch before fully embracing global bundling as their primary strategy. This was particularly true for publishers who already had paywalls in place, and were concerned about cannibalising standalone subscriptions. As one interviewee expressed, "I want to see if this is a model that might make a difference. If it does, then we can apply it everywhere." Interviewees were particularly concerned about shifting their subscription strategy, based solely on insights from consumer surveys. One interviewee provided an anecdote about a subscription product they had recently launched, pointing out that consumer uptake was significantly lower than projections derived from surveys. He emphasised that, "You can't really understand anything until you actually do it." 
Several interviewees within the USA had a strong interest in conducting a trial launch of PressPass within the New Zealand market. As one interviewee explained, "One of the biggest advantages that [PressPass] has over potential competitors, is the possibility of trialling this in New Zealand.” Interviewees highlighted that the New Zealand market was small enough to minimise potential losses from cannibalisation, while being large enough to assess whether global bundling is financially viable: "It provides us with a safe environment to conduct a live experiment, and see if bundling works."

Several New Zealand interviewees saw a trial as a positive way for news organisations to launch their paid content strategy with a world-leading strategy, while working alongside prestigious international publications. Furthermore, interviewees were enthused by the prospect of launching with a strategy with the potential to generate more revenue than a standalone subscription. Other interviewees were more sceptical about the prospect of a trial, and wanted firmer reassurances that participation in a global package would generate higher revenues than a standalone subscription, or advertising revenue alone.

I also discussed possible timeframes for a trial launch, proposing a trial period of between 18 to 24 months. Several interviewees, however, indicated a preference for a much shorter period of time. As one interviewee noted, "We don't have two years to wait. Even 12 months is a lifetime in our world." This interviewee indicated that a trial would ideally be between three to six months, with a longer period if initial metrics were promising.

Each of the partnership and launch strategies mentioned within this section are discussed in more depth within Section 6.7. A number of advantages and disadvantages are assessed, as well as strategies to address the concerns raised by interviewees. 


\section{CHAPTER 6 DISCUSSION}

This chapter discusses my recommended next steps for PressPass, by synthesising insights from my literature review, consumer survey and interviews with news organisations. This chapter is structured by first establishing core propositions and 'proposed approaches' for each key aspect of PressPass' enterprise strategy, before providing a more in-depth discussion. Propositions and 'proposed approaches' are constantly evolving, and are intended to serve as exploratory starting points for future research, discussion and negotiation.

\subsection{Assessing the benefits of global bundling}

\section{Proposition:}

- A global news package is the most promising strategy for news organisations to pursue in the short term.

- Although a multimedia package was the most popular option amongst respondents, further work is required to assess the logistics and economic viability of multimedia bundling.

Proposed approach:

- $\quad$ PressPass should first focus on the logistics of enabling a global news package.

- As a secondary priority, PressPass should conduct further research into the prospects of multimedia bundling.

As discussed within Chapter 4, monetisation strategies that enable bundling at a global scale were the most popular of all ten options explored within my survey. While only one respondent said they would 'definitely' pay for a standalone subscription ${ }^{22}, 23$ respondents said they'd definitely pay for a global news package, and 46 said they'd definitely pay for a news and multimedia package. Consumer preference for global bundling remained relatively strong when viewing survey data through alternative analytical lenses, such as an aggregate of 'probably' and 'definitely' responses, as well as estimated conversion rates calculated using PPI values.

Although a news and multimedia package was the most popular option within the News, Renewed survey, a global news package was chosen as the initial focus of the PressPass

${ }^{22}$ At $\$ 10$ or more per month 
platform for a number of pragmatic reasons. As illustrated within Chapter 5, there are significant hurdles to overcome before news organisations will be willing to participate in a global news package. It is already a substantial challenge trying to establish agreement upon pricing, commission structure and royalty rates for bundled news content, yet alone trying to simultaneously do the same for music, movies, and television.

In addition to pragmatic reasons, a global news package was chosen because further research is needed to assess whether a multimedia bundle is an economically viable strategy for news organisations. Firstly, market research is needed to assess the value that consumers assign to news within a multimedia package relative to other content. Furthermore, research is needed to assess the proportion of media engagement that would be spent on news relative to other content. From a partnership perspective, negotiations are needed with existing media platforms to determine the proportion of revenue assigned to news. If existing music and video platforms demand a high share, there might not be sufficient revenue for news organisations to make multimedia bundling economically viable.

\subsection{Platform infrastructure}

\section{Proposition:}

- If platform infrastructure for bundling is designed poorly, there is a strong risk of market capture by a centralised intermediary that could gain significant power over the journalism ecosystem.

\section{Proposed approach:}

- Design a platform that minimises the risk of market capture, by designing technical features that empower each news organisation with significant autonomy.

Designing the technical infrastructure of bundling is a complex task, with many variables that have significant implications for the journalism community. Section 2.2 describes how economies of scale, scope and aggregation involve a significant risk of monopolisation. Poorly designed technical infrastructure could enable a centralised intermediary to gain pervasive control over the flow over information as well as the profits derived from bundling. It will be important to design a platform with technical features that allow the journalism community to embrace the substantial benefits of bundling, while actively militating against the concomitant risk of market capture. 
A key disadvantage of handing over content to a centralised aggregator at arm's-length, is that it risks abdicating editorial control to a centralised aggregation platform with full power over curation and distribution. If news organisations wish to pursue a global bundling strategy with third-party aggregators, I would encourage them to develop partnerships with platforms that provide a level of autonomy and curatorial control within the platform, with transparent practices around the algorithmic prioritisation of news content. My proposed infrastructure for PressPass 2.0 explores features that could make this possible (Section 6.2.2).

The risk of market capture can be minimised if content is provided under non-exclusive arrangements to many distributors (Section 2.2). I would strongly recommend the development of protocols that standardise the provision of content to multiple competing platforms. My proposed infrastructure for PressPass 3.0 explores how a content clearinghouse could be established to help achieve this goal for PressPass partners (Section 6.2.3).

Each of the features outlined within the following sections provide a high-level conceptualisation of functionality that could help uphold the editorial independence of each news organisation. It is likely that particular features will need to be prioritised based on the level of technical complexity involved, and the extent to which features are desired by publishers and readers.

\subsubsection{PressPass 1.0: universal login account}

\section{Propositions:}

- A decentralised platform directly integrated with each news website, will uphold editorial independence by providing news organisations with operational autonomy.

- Direct integration increases consumer awareness of a global bundle, by making PressPass a prominent feature of every partner website. Direct integration with news websites, however, also increases publisher fears of cannibalisation.

\section{Proposed approach:}

- PressPass 1.0 provides subscribers with a universal login account, that unlocks premium news content hosted natively within each partner website.

- For news partners, PressPass 1.0 provides paywall infrastructure, user authentication, reader analytics and payment collection.

- PressPass 1.0 integrates with partner news websites, through the addition of our JavaScript code. No changes are required in regards to existing content management systems. 
- Note: Screenshots of the prototype for PressPass 1.0 can be viewed within pages 811 of Appendix B.

The first stage of the PressPass platform (version 1.0) is focused on providing subscribers with a universal login account, that unlocks premium news content hosted natively within each partner website (6.2.1). PressPass 1.0 has been purposefully designed to uphold the operational independence of each news partner, by empowering them with complete control over editorial curation, design and advertising. Consequently, PressPass does not have any centralised control over the way that stories are curated and presented to readers.

It was encouraging to get positive feedback from news organisations about the editorial independence enabled by PressPass 1.0 (Section 5.8). It was clear, however, that fears of cannibalisation could hinder uptake. Specifically, some interviewees were fearful that actively promoting a global news package directly within their website could cannibalise their existing standalone strategy. They suggested that participation in a global news package might be easier if they could provide their content to a centralised aggregator at an arm's-length to their website.

Survey findings (Chapter 4) indicate that global bundling should be embraced as a core strategy, rather than being explored on the margins. Section 4.6 indicates that news organisations are likely to convert more readers and generate higher revenues under global bundling, even if all standalone subscribers were to switch to a global news package. Furthermore, analysis within Section 4.7 suggests that bundling may pose a low risk of cannibalisation for standalone subscriptions, with distinct groups of respondents preferring each option. If news organisations are able to overcome their fears of cannibalisation, the direct integration facilitated by PressPass 1.0 would allow news organisations to actively promote global bundling to all their readers, maximising uptake rates and subsequent revenues. 


\subsubsection{PressPass 2.0: aggregation platform}

\section{Propositions:}

- An 'all-in-one' aggregation platform will create an improved reader experience, by allowing readers to easily engage with news from all publishing partners and enabling personalised recommendations.

- An improved reader experience is likely to result in higher conversion rates, and a higher level of engagement with news.

- Aggregation platforms should be designed with features that uphold publisher's independence and autonomy.

Proposed approach:

- Within PressPass 2.0, each news partner would be provided with a branded 'Masthead' home.

- A 'News Stand' interface would allow readers to browse the 'Masthead' homes of each news partner.

- A 'Follow' button would allow readers to opt-in for content updates from each 'Masthead', or specific journalists.

- A 'News Feed' interface would allow readers to view an aggregated stream of content from all entities they 'Follow.'

- Content within the 'News Feed' would be organised within a range of standardised categories.

- Readers would be able to create their own additional categories, by entering keywords for topics of interest.

- 'Open Algorithms' would be used to prioritise content, based on variables that can be adjusted by each reader.

- An 'Unfiltered Feed' would provide a raw stream of stories from all 'Followed' entities, in chronological order.

To complement the infrastructure created by PressPass 1.0, I proposed creating a standalone aggregation platform that streamlines the way readers consume news from all PressPass partners (PressPass 2.0). Several interviewees expressed a strong interest in the improved reader experience enabled by aggregation. However, there were also significant concerns around the loss of curatorial control that could arise within an aggregated platform. With these concerns in mind, I have proposed platform features that empower news organisations with significant autonomy, while also providing transparency around the methods used to prioritise content.

To enable autonomy, each news organisation would be provided with their own branded 'Masthead' home within the aggregation platform, with full control over how their news is presented to readers within this space. This same functionality would be offered to independent journalists who wish to establish their own editorial space within PressPass 2.0. A 'News Stand' interface would allow readers to browse through 
'Mastheads,' and select a reading experience that is fully curated by their news organisation of choice. Furthermore, readers would be able to 'Follow' specific news organisations and journalists, empowering news partners to maintain direct reader relationships.

For the aggregation component of PressPass 2.0, all readers would be provided with a 'News Feed' interface for viewing an aggregated stream of content from all news partners they 'Follow'. Content could be organised within a range of standardised categories, based on geography (e.g. World, National, Local), topic (e.g. Politics, Technology, Sport), popularity (e.g. Top Stories), social metrics (e.g. Shared By Friends), and personalisation (e.g. Recommend Articles). Furthermore, readers could create their own subcategories by entering keywords related to a specific topic of interest (e.g. "Rugby World Cup", "Ponytail-gate"). PressPass would then search the content of all news partners, and create a curated feed of articles containing the chosen keywords.

'Open Algorithms' would be used to prioritise content within each category, in a manner transparent to both publishers and readers. Specifically, PressPass would create clear documentation and guidelines that describe how articles are ranked. Furthermore, our algorithms would contain variables that can be adjusted by the user, allowing them to choose the extent to which articles are prioritised according to factors such as: article popularity, personalisation based on individual interests, or curatorial decisions made by human editors. Readers would also have access to a raw 'Unfiltered Feed,' providing access to all stories in chronological order.

There is a risk that an open system of algorithms may increase the risk of publishers trying to 'cheat' the system, as they might identify ways to artificially boost prioritisation of their content. However, I believe that a multi-faceted system with multiple variables will be a useful strategy to help minimise this risk. Furthermore, many of the variables used to prioritise content will be very difficult to 'cheat,' especially variables that have been personalised by each reader. 


\subsubsection{PressPass 3.0: content clearinghouse}

\section{Proposition:}

- The streamlined provision of news content to multiple aggregation platforms, will help minimise the risk of market capture while also improving the reader experience.

Proposed approach:

- PressPass 3.0 would provide news partners with tools that enable them to feed their articles into an encrypted global content stream.

- PressPass would unlock the global content stream for any platform that wished to aggregate news articles, as long as they integrated standardised protocols for authenticating paying subscribers, collecting subscription payments, measuring engagement, and distributing royalties.

- Readers would be able to use their universal PressPass account, to unlock premium news content within any third-party platform integrated with PressPass 3.0.

- To incentivise integration with PressPass, aggregators could be provided with a conversion commission when readers subscribe within their platform, as well as a small royalty payment whenever subscribers engage with articles within their platform.

A global content stream would allow a global news bundle to be distributed and monetised within platforms as diverse as Flipboard, Facebook, Twitter, Google News, LinkedIn, or even platforms created by news organisations. By providing content on non-exclusive terms to a range of third-party platforms, PressPass 3.0 would allow content to be curated in a distributed and decentralised manner that minimises the risk of market capture by any one platform.

There are many other advantages of a global content stream, including that it:

- Allows the journalism community to establish an equitable commission structure and royalty scheme, consistent across a range of platforms, providing financial rewards to both creators and distributors.

- Facilitates a competitive and diverse ecosystem of aggregation platforms, each empowered with the freedom to create an innovative user experience using the same global content stream.

- Broadens the audience reach of content within the global package, by allowing articles to be distributed within a range of online environments.

- Minimises the high transaction costs involved when content rights are individually negotiated between a range of platforms and news providers.

- Has authentication protocols that allow readers to gain streamlined access to news content within a range of platforms, using a single login account. 
I am yet to present my full proposals for PressPass 3.0 to the journalism community, and will need to gain feedback from both news organisations and Internet platforms about the feasibility of my proposed approach. Most importantly, I need to assess the extent to which PressPass 3.0 would be embraced, and to assess the logistics of developing a global content stream that is interoperable with the infrastructure of existing platforms. I suspect that a global content stream will be logistically challenging, but will have significant benefits once established. At this stage, I believe that it would be best to pursue PressPass 3.0 after successful launch of versions 1.0 and 2.0 .

\subsection{Ownership and governance structure}

\section{Propositions:}

- $\quad$ From a collective perspective, co-ownership of PressPass by news organisations risks undesirable outcomes, such as: conflicts of interest, concentration of media power and unstable governance.

- From an individual perspective, news organisations have strong incentives to pursue an ownership stake in PressPass to maximise the financial rewards of participation and exercise control.

Proposed approach:

- $\quad$ PressPass will work with the journalism community, to explore whether there is an ownership and governance structure that might provide the benefits of coownership, while minimising the associated risks.

In regards to ownership and governance, feedback within Chapter 5 highlights a powerful tension between individual and collective goals. While several interviewees expressed concern about the implications of co-ownership, several conceded that an ownership stake could be a pivotal factor in deciding whether or not their news organisation joined PressPass. Finding a solution to overcome this tension has been one of my biggest challenges. Within this section, I assess the prospects of a Kirkpatrick cooperative (Section 6.3.1) and a limited liability company (Section 6.2.3). 


\subsubsection{Assessing a Kirkpatrick cooperative}

\section{Propositions:}

- Cooperative ownership provides strong financial incentives for news organisations, helping facilitate collective action and partnerships.

- A Kirkpatrick cooperative provides an independent governance structure, which could help minimise conflicts of interest and the risk of operational deadlock.

Proposed approach:

- PressPass would be collectively owned by news organisations that contribute content.

- Equity shares would be allocated according to each news organisation's level of patronage, as determined by their share of readership engagement.

- Equity shares would form the basis upon which dividends from profits are distributed.

- Voting stock of cooperative members would be transferred to a legally separate governance body, entrenched with an operational mandate to pursue the collective interests of the journalism community.

A Kirkpatrick cooperative is a promising ownership structure that would facilitate coownership while upholding operational independence. As discussed within Section 2.3, cooperative businesses can be highly conducive to collective action. By providing members with equity, cooperatives create strong financial inducements that allow individual self-interest to align with the goals of the collective.

In a Kirkpatrick cooperative, operational independence is upheld by transferring all voting stock to a legally separate governance body. In the case of PressPass, this governance body could be established with a mandate to pursue the collective interests of the journalism community, rather than being directly controlled by competing sectional interests within the cooperative.

Operational independence could help overcome organisational deadlock, a likely scenario if competitors with strong rivalries are forced to make decisions about divisive issues within a conventional corporate structure. The independent governance body could still include representation from a diverse range of news organisations, in the form of an advisory board. However, the governance body would have ultimate decision-making power.

One potential downside of a Kirkpatrick cooperative, is that it could be challenging to get agreement upon its structure prior to establishment. In particular, news organisations 
might have divergent views about the ideal framework for the independent governance body. Furthermore, some news organisations might be reluctant to participate within a cooperative that does not provide them with any voting rights.

Another possible issue is that the cooperative might need to gain regulatory approval, to ensure that it does not breach any anti-trust laws. This will be particularly relevant in media markets that are duopolies or oligopolies, such as New Zealand and Australia. Further research will be needed to determine the journalism community's support of the cooperative model, and to ensure that it is logistically feasible. 


\subsubsection{Assessing a limited liability company}

\section{Propositions:}

- A limited liability company will likely be easier to establish than a Kirkpatrick cooperative.

- Institutional design can be used to create similar benefits to those derived within a cooperative.

Proposed approach:

- Within the company's constitution and/or articles of association, create clauses that uphold operational independence and entrench core principles desired by the journalism community.

- Create an equitable system of royalty payments and rebates, to institutionalise financial rewards comparable to a cooperative company.

If a cooperative model is not feasible, then a limited liability company is a promising alternative. Specifically, clauses could be embedded within PressPass' constitution or articles of association, which bind the company to provisions intended to benefit the collective interests of the journalism community. For example, clauses could bind PressPass to maintain a fair distribution of revenue to news partners. Furthermore, clauses could require PressPass to treat all news partners in an equitable and nondiscriminatory manner. Under this model, news partners could potentially obtain an ownership stake, but would be bound to provisions that upheld operational independence.

\subsection{Pricing strategy}

Propositions:

- A global bundle is the most promising monetisation strategy for online news. Therefore, news organisations should support a pricing strategy that focuses on maximising the success of a global news package.

- Pricing strategies focused on preserving standalone subscription revenues, risk undermining the more lucrative revenues that could be generated by global bundling.

- It is not logistically feasible to determine bundled pricing based on the cumulative individual valuations of each news partner.

- $\quad$ Print newspapers and digital subscriptions are two distinct markets, and should have separate pricing strategies.

Proposed approach:

- Use market research to identify the price-point at which a global news package generates maximum overall revenue.

- After launch, pricing should be assessed on an ongoing basis to ensure that the price-point is maximising overall revenue. 
- $\quad$ Price elasticity should be assessed to determine the extent to which promotional discounts could encourage increased uptake.

Within each market that PressPass is launched, I propose using comprehensive market research to assess the price-point at which a global news package generates maximum overall revenue. Section 6.8 outlines a range of market research techniques that should be considered for assessing pricing. I would also encourage consideration of a promotional discount to get readers into the sales pipeline, and help shift consumers into the mindset of paying for news again.

As highlighted within Section 5.5, interviewees discussed some alternative pricing strategies. One reader suggested that a global subscription should be priced at a substantially higher rate than existing standalone subscriptions, to minimise the risk of cannibalisation. Unfortunately, such a strategy would come at the expense of undermining the more lucrative revenue streams that can be generated through the successful implementation of global bundling.

Based on survey analysis within Section 4.6, the ideal price-point to maximise overall revenue for a global subscription is $\$ 10$ NZD per month, with an estimated conversion rate of $8.6 \%$ and annual revenue of $\$ 10,272$ per 1,000 respondents $(5.8 \mathrm{x}$ higher than a standalone subscription strategy). If the news industry pushes to have global subscriptions priced significantly higher than standalone subscriptions, it will result in a substantial decrease in conversion rates and revenue. A 30\% increase in price to $\$ 13$ per month, resulted in a 33\% decrease in demand and a $12 \%$ decrease in revenues; a loss of $\$ 1,204$ per 1,000 respondents. A $50 \%$ increase in price to $\$ 16$, resulted in a $67 \%$ decrease in demand and a $48 \%$ decrease in revenues; a loss of $\$ 4,955$ per 1,000 respondents.

Another interviewee suggested that the price of the global package should be calculated by discounting the cumulative standalone price of each publication within the bundle. As discussed within Section 2.2, a cumulative pricing strategy is impractical when creating a bundle with potentially thousands of publications. Such a strategy would quickly result in a price point beyond the reach of readers, and far above the ideal price point to maximise overall industry revenue. Cumulative pricing would only make sense for extremely small packages containing a handful of partners. 
In regards to the practice of using digital subscriptions as a tool to drive print subscriptions, news organisations need to understand that they are undermining the prospects of digital subscription products. As one interviewee pointed out, news organisations should recognise that print and digital subscription products are "fundamentally different" and "we need to price them accordingly."

My survey findings appear to reinforce this statement. Of the 128 print subscribers within the sample, only eight (6.1\%) said that they would definitely pay $\$ 10$ or more per month for a global news subscription. Of the 23 respondents who said they would definitely pay $\$ 10$ or more per month for a global news subscription, $65 \%(n=15)$ did not have a print subscription. These findings indicate that print and digital subscriptions are distinct markets with only minimal overlap, and therefore need separate pricing strategies.

\subsection{Royalty structure}

\subsubsection{Assessing equitable royalty rates}

\section{Propositions:}

- From a collective perspective, equitable royalty rates establish a relationship of trust with news organisations, and help facilitate partnerships across competitive boundaries.

- From an individual perspective, it is rational for news organisations to pursue a premium royalty rate that is higher than rates paid to their competitors.

- PressPass should strive to establish an equitable royalty system that rewards high quality content, rather than assigning royalty rates based on subjective perceptions about the quality of a masthead.

- Multiple readership metrics should be used as the basis for distributing revenue, providing a comprehensive assessment of reader engagement and article quality.

Proposed approach:

- $\quad$ All revenue from sales of PressPass' global package would be accumulated into a royalty pool (minus any commission fees).

- PressPass would distribute the royalty pool equitably between news partners, using metrics that measure reader engagement.

- In the short term, reader engagement metrics would be derived from page views and time spent reading.

- In the long term, additional royalty metrics would be considered, such as star ratings and social networking metrics. 
Feedback about possible methods of royalty distribution highlighted another tension between individual and collective interests within the journalism community. Several interviewees expressed a desire for an equitable method of royalty distribution applicable to all news partners, and warned that the use of premium royalty rates could undermine trust in the PressPass platform and create barriers to the development of partnerships. Meanwhile, other interviewees believed that their publication deserved premium rates (Section 5.6).

I have found this to be a difficult tension to overcome. Personally, I believe that royalty distribution should be equitable, but I also appreciate the wide range of quality standards that exist across various publications. Rather than apply arbitrary content valuations based on subjective perceptions about the quality of specific mastheads, I would rather establish an equitable royalty system that successfully rewards the highest quality content. If higher quality content generates higher levels of revenue under a system of equitable royalty rates, then 'premium' publications will be sufficiently rewarded without the need for premium rates.

For an equitable system of royalty distribution to successfully reward quality content, careful consideration will be required to assess the best metrics. In the short term, I would recommend distributing the royalty pool according to page views (50\%) and time spent reading (50\%). The key advantage of this model is that it helps each partner create financial projections prior to launch, based on their existing engagement metrics (see Section 6.8.1 for proposed methods to create financial projections). Furthermore, page views and time spent reading are two firmly established metrics already used widely to measure reader engagement, which could make it easier to establish agreement across multiple news partners.

In the long term, I would recommend considering complementary metrics such as star ratings, article word-count, percentage read, social shares and social 'likes'. Multiple metrics allow quality to be assessed through a range of different lenses, painting a comprehensive picture of an article's quality. While each metric has its own strengths and weaknesses, it would be difficult to cheat the system because artificially maximising one metric would likely have negative impacts on another metric. 
For example, a publication may use 'click-bait' techniques within their headlines to maximise page views. However, if the article is low quality then readers: will not spend much time reading it, are likely to give it a low user rating, and unlikely to share it. Another publication may use photo galleries and 'listicles' in an attempt to maximise time spent reading, but these articles are also likely to have a very low word-count and lower quality ratings. Another publication might deliberately increase the length of their articles, but if the quality of writing is poor then readers are unlikely to spend much time reading or to give the article a high rating.

I would recommend that each additional metric be carefully weighed up before being used to distribute the royalty pool. As a method of evaluation, PressPass could implement the measurement of alternative metrics, without using them to distribute revenue. Data collected about these metrics could then be used to create revenue projections under different hypothetical scenarios. A list of articles that receive the highest remuneration, could then be assessed qualitatively to identify the types of stories that were rewarded. News organisations could then utilise this information to evaluate whether additional metrics should be used to better reward quality content.

\subsubsection{Assessing tiered packages and premium royalty rates}

\section{Propositions:}

- Future negotiations with potential news partners might reveal that some form of premium royalty rate is essential to establish important partnerships.

- Creation of a premium tier within the global package is a possibility that should be further investigated.

- For consumer news content, creation of a premium tier could undermine potential revenue for both 'premium' and 'general' news providers.

- For specialist news content, such as financial news and trade publications, a tiered bundling strategy might have more promising prospects.

Proposed approach:

- For specialist news content, global packages should be created containing as many publications as possible within each niche.

- Market research should be conducted with target consumers, assessing their propensity to pay for a bundle of niche content compared to standalone subscriptions.

Although my preference is to establish equitable royalty rates for all news organisations, it might be necessary to consider alternative scenarios. A possible compromise to accommodate news organisations that want a premium royalty rate, is to 
create a premium tier to the subscription package. Under this model, readers would pay an additional fee for access to publications within this premium tier. All money from this additional fee would create a premium royalty pool, that would be divided between premium publications based on readership metrics.

Each potential news partner would then need to weigh up the relative metrics of each package. On the one hand, the general package would have a larger audience and the potential for higher revenues through greater volume. On the other hand, a premium tier would have a smaller audience, but the potential for higher revenue due to more lucrative royalty rates.

I would recommend against a tiered bundling strategy for consumer news, since overall conversion rates and revenue are likely to be lower than an all-inclusive package. Not only will fewer consumers sign up for a global package that doesn't include premium publications, but an even smaller number of consumers will upgrade to a premium package. Consequently, both 'general' and 'premium' news organisations are likely to suffer financially under such a strategy.

Another disadvantage is that the creation of multiple tiers undermines the pricing efficiency that is achieved through bundling (see Section 2.2). Specifically, consumers will find it much easier to pay one price for a global bundle containing all news organisations, than assessing various tiers that each have different value propositions and prices. As one consumer highlighted in Section 4.5, "I am not interested in making endless choices about alternatives."

Although sceptical about the prospects of a tiered strategy for consumer news, I think that a tiered strategy is promising for high-value non-consumer news content. Specifically, there is a wide range of financial and trade publications that command a high market price, well beyond the reach of most consumers.

The specialist information contained within 'professional' publications is often essential for individuals who work within specific industries, resulting in valuations much higher than consumer news. Consequently, it is unlikely that PressPass could readily accommodate these niche publications within a consumer news package. 
For specialist packages, I would recommend bundling as many publications as possible relevant to each specific industry niche, such as agriculture, mining or finance. I suspect that bundles for non-consumer news will generate higher revenues and conversion rates than standalone subscription products. Further market research should be conducted to evaluate this value proposition.

\subsection{Commission structure}

\section{Propositions:}

- A low commission structure will help establish a relationship of trust with the journalism community, facilitating partnerships.

- A low commission structure results in a higher royalty rate, increasing the financial incentives that motivate news organisations to participate within a global bundle.

\section{Proposed approach:}

- $\quad 0 \%$ commission for standalone subscriptions sold through the PressPass platform.

- $20 \%$ commission for sales of the global news package.

- Additional rebates for news partners, once PressPass is profitable.

Several interviewees expressed negative opinions about the commission structures of existing Internet platforms (Section 5.7), reinforcing the importance of having a commission structure that is fair and equitable. From a practical perspective, news organisations might be apprehensive to join PressPass if our commission structure is perceived to be excessive. A low commission structure, however, will help facilitate a relationship of trust with the journalism community, and could form a key competitive advantage over alternative platforms. By keeping our commission structure low we would be able to increase royalty payments, further motivating news organisations to join the global package.

In addition to practical considerations, there are strong ethical reasons for returning as much revenue as possible to the journalism community. While a commission fee is important for maintaining the financial sustainability of the PressPass platform, it should not be used as a tool to siphon excessive profits from the news industry. Instead, journalists and news organisations should be fairly rewarded for their work, as it is their content that creates the most value within a global bundle. Furthermore, it would be unethical for PressPass to operate with high profit margins, when the journalism industry itself is struggling to fund the creation of quality journalism. 
With both practical and ethical considerations in mind, I propose a $20 \%$ commission fee for sales of the global news package. If PressPass is established as a cooperative (see Section 6.3.1), then profits derived from the commission fee would be redistributed to news partners as dividends. If PressPass is incorporated as a limited liability company, then I propose to establish a system of rebates once PressPass has achieved profitability. Under this model, news partners would receive a share of excess profits above a specified threshold of operational costs.

Although negotiations are still required to finalise the commission structure and rebate scheme, early feedback suggests that the core elements of my proposal align with the desires of the journalism community. My key challenge with implementing a fair and equitable commission structure, will be obtaining funding and investment from individuals and organisations who align with the altruistic mandate I am proposing. For philanthropic funding, the key to success will be outlining achievable outcomes that align with their altruistic mission. For private funding, it will be important to ensure that investors still have sufficient financial incentives to justify their investment.

\subsection{Partnership and launch strategy}

The development of partnerships for a global bundle is one of the most challenging aspects of the PressPass project. At its heart, the PressPass project faces a fundamental conundrum. On the one hand, news organisations want to see global bundling in action before they are willing to form a partnership with PressPass. However, PressPass needs partnerships with news organisations before a global bundle can be launched. Within this section, I explore three complementary strategies that help overcome this conundrum:

1) A trial launch to generate robust market data about actual conversion rates for a global package. (6.7.1)

2) Conditional contracts to help lower the risk of participation in a trial. (6.7.2)

3) Discounted commission rates to incentivise early partnerships. (6.7.3) 


\subsubsection{Strategy for a trial launch}

\section{Propositions:}

- A trial launch will provide news organisations with market insights into actual uptake rates for a global news package, relative to a standalone subscription strategy.

- If a trial launch confirms the benefits of a global news package, news organisations will be able to adopt bundling as their core subscription strategy.

Proposed approach:

- Identify trial markets that are large enough to assess consumer trends with high statistical certainty, while being small enough to minimise financial risk (between 1-5 million people).

- Use Internet Protocol (IP) address filtering to identify readers within trial markets. Within these markets, readers will see PressPass 1.0 integrated with partner news websites.

- Trials would be conducted for 12 months, with an opt-out clause for publishers who wish to leave after 6 months.

The importance of a trial was emphasised by several interviewees, and was seen as a critical milestone before committing their full resources into a global bundle. Within each country where bundling is being considered, I would recommend identifying a trial market of between 1 and 5 million people. A trial market of this size would allow news organisations to assess uptake rates with high statistical certainty, while minimising the financial risk involved.

In New Zealand, a trial across the entire country (4.5 million) would be an ideal scale to assess bundling. If New Zealand publishers are not prepared to take a risk across the entire market, however, it might be necessary to consider a limited trial just within the South Island (1.1 million). In Australia, the states of Queensland (4.6 million), Western Australia (2.5 million), and South Australia (1.7 million) are possible candidates for a trial launch. In the USA, there are $23 \operatorname{states}^{23}$ with a population of between 1 and 5 million, which could be suitable trial markets.

In regards to logistics, I recommend that readers within trial markets are targeted by identifying their Internet Protocol (IP) address. Under this scenario, any reader with an IP address within the target market would be redirected to a mirror version of each partner news website. This mirror version would have exactly the same content and

\footnotetext{
${ }^{23}$ Montana, Rhode Island, New Hampshire, Maine, Hawaii, Idaho, West Virginia, Nebraska, New Mexico, Nevada, Kansas, Utah, Arkansas, Mississippi, Iowa, Puerto Rico, Connecticut, Oklahoma, Oregon, Kentucky, Louisiana, South Carolina, and Alabama.
} 
layout as the original, except that it would have PressPass 1.0 integrated as a ribbon along the top of the page. Readers would then have the option of creating a subscription account that provides unlimited access to all partner news websites within the trial.

I would strongly advise news organisations to persevere with a trial for a minimum period of 12 months. Any subscription strategy, whether standalone or global, will need several months before significant consumer uptake is achieved. Still, I appreciate that some news organisations have expressed a reluctance to commit to a longer trial period. To accommodate these concerns, I plan to include an opt-out clause that would allow partners to leave after 6 months if specified revenue targets are not achieved.

\subsubsection{Establishing partnerships with conditional contracts}

\section{Proposition:}

- Conditional contracts are an important mechanism to facilitate partnerships, useful for establishing the logistical parameters of bundling while also helping to spread the risk of participation.

Proposed approach:

- $\quad$ Each news partner would sign a conditional contract, outlining policies related to: pricing, royalty distribution, commission structure and provisional launch date.

- Conditional contracts would become activated after reaching a specified threshold of partnerships.

To establish partnerships for a trial, I plan to use conditional contracts that are not activated until an agreed-upon threshold of partnerships has been achieved. Under this strategy, each publishing partner would sign a contract agreeing to basic principles related to pricing, royalty distribution, commission structure and provisional launch date. The contract would not become activated, however, until several other publishers had signed the same agreement. Activation could be predicated on reaching a particular number of partners, or a specific threshold of audience share within a market.

Conditional contracts will be extremely important from a logistical perspective, since a truly 'global' package can't be facilitated until a certain scale of partnerships has been achieved. Furthermore, a number of interviewees identified that conditional contracts could be a useful strategy to help create a reduced sense of risk. Consequently, it makes sense not to activate contracts until a satisfactory number of partnerships have been secured. 
Within each market, I would recommend achieving approximately 50\% market share before launch, with a mix of local, national and international publications that have brand recognition within the target market.

\subsubsection{Incentivising early partnerships}

Proposition:

- By offering discounted commission rates for our first news partners, PressPass will create a strong first-mover advantage that incentivises early partnerships.

Proposed approach:

- Discounted commission rates could be based on the order that news partners sign conditional contracts, or the timeliness of signing a contract after being offered a formal partnership proposal.

As recommended by one interviewee within Section 5.10, I think it will be beneficial to offer a discounted commission rate to the first news organisations that sign conditional contracts. Discounted commission rates will create a strong first-mover advantage, resulting in an additional financial incentive for publishers to become news partners. Table 9 presents a hypothetical scenario, with discounts based on the order that news partners sign the conditional contract. Alternatively, discounted commission rates could be offered to publishers who either sign up before specific dates, or within a specific timeframe after being offered a contract.

Table 9: Hypothetical commission discounts for early partnerships

\begin{tabular}{|l|l|}
\hline Order of signing contract & $\begin{array}{l}\text { PressPass commission rate } \\
\text { (for the first 12 months) }\end{array}$ \\
\hline First news partner & $0 \%$ \\
\hline $2^{\text {nd }} / 3^{\text {rd }}$ & $2.5 \%$ \\
\hline $4^{\text {th }} / 5^{\text {th }}$ & $5 \%$ \\
\hline $5^{\text {th }}-10^{\text {th }}$ & $10 \%$ \\
\hline Partnerships established pre-launch & $15 \%$ \\
\hline Partnerships established post-launch & $20 \%$ \\
\hline
\end{tabular}

\subsection{Consumer survey}

\subsubsection{Strategies for future surveys}

\section{Proposition:}

- A follow-up survey will allow potential news partners to weigh up the benefits of bundling with a higher level of certainty, while also gaining additional insights. 


\section{Proposed approach:}

- The focus of future surveys should be narrowed, so that questions are solely focused on comparing a standalone subscription strategy with a global news package.

- To reduce the margin of error to $2 \%{ }^{24}$, a minimum random sample of 2,400 respondents should be taken from the general population ${ }^{25}$.

- In addition to a random sample of the general population, news organisations should directly survey their own readers.

- Survey respondents should be presented with hypothetical packages containing actual news organisations.

- In order to create a revenue model and financial projections for each news organisation, news partners should provide PressPass with standardised readership metrics outlining current levels of engagement ${ }^{26}$.

Several interviewees from news organisations expressed a strong desire for a follow-up survey to be conducted, in order to gain additional insights into the potential of global bundling. There are a number of general strategies that I would recommend to help improve upon the News, Renewed study.

Now that bundling has been identified as the most promising monetisation strategy, I recommend that future surveys should focus on directly comparing a standalone subscription strategy with global bundling. Narrowing the scope of monetisation strategies would make it possible to get more granular insights that were not logistically possible when assessing ten monetisation strategies within a single survey.

I also recommend that news organisations survey their own readers. Direct reader surveying would allow potential news partners to gain insights into the preferences of their own readers, enabling them to create financial models and projections specific to their organisation. Of particular importance, news organisations would be able to assess the risk of cannibalisation with their existing subscribers, by asking whether they would switch to a global package.

In regards to survey design, it will be important for respondents to be presented with hypothetical packages that contain actual news organisations considering partnerships

\footnotetext{
${ }^{24}$ With confidence level of $95 \%$

${ }^{25}$ Value calculated for New Zealand (population: 4.4 million).

${ }^{26}$ Under confidentiality agreements. 
with PressPass. By creating tangible scenarios, news organisations will be able to gain more granular insights into the potential financial benefits of bundling.

Furthermore, I propose that potential news partners provide accurate readership metrics into current levels of website engagement. These metrics would remain confidential, but would allow me to create revenue projections that estimate future income from royalty payments. These projections would allow each news organisation to more accurately weigh up the financial benefits of bundling compared to a standalone strategy.

\subsubsection{Assessing potential survey instruments}

\section{Proposition:}

- $\quad$ By narrowing the scope of monetisation strategies being explored, a wider range of survey instruments are feasible to assess pricing and propensity to pay.

Proposed approach:

- $\quad$ Future studies should utilise survey instruments with multi-step processes, such as: the Gabor-Granger method, the Van Westendorp Price Sensitivity Meter, conjoint analysis and discrete choice models.

- If sufficient resources can be secured, discrete choice modelling provides the most flexible and accurate survey instrument.

- If resources are more limited, the Gabor-Granger method and the Van Westendorp Price Sensitivity Meter are industry-standard survey instruments useful to assess pricing and willingness to pay for product concepts.

To improve the accuracy of survey insights, I would recommend using a multi-step survey instrument to assess pricing. Prominent methods used by market researchers include the Gabor-Granger method, the Van Westendorp Price Sensitivity Meter, as well as discrete choice modelling (Lipovetsky, Magnan, \& Polzi, 2011).

The Gabor-Granger method helps to identify the highest price that each respondent would pay for a product, by getting respondents to articulate their willingness to pay at several randomly selected price-points (Ibid). The Van Westendorp Price Sensitivity Meter helps assess the limits of price elasticity, by asking respondents to indicate the price at which a product is perceived as being: 'cheap,' 'expensive,' 'too cheap,' or 'too expensive' (Ibid). Discrete choice modelling utilises complex scenario-based testing techniques, to assess willingness to pay for a product when it is offered alongside substitutes at different prices (Ibid). 
Lipovetsky, Magnan and Polzi recommend discrete choice modelling as the most flexible and accurate pricing technique (Ibid). However, they also warn that it is one of the most expensive and complex types of survey to administer (Ibid). If resources can be secured for discrete choice modelling, then this is the technique that I would recommend. Alternatively, the Gabor-Granger method and the Van Westendorp Price Sensitivity Meter are both techniques that are widely used to assess pricing for new products. 


\section{CHAPTER 7 CONCLUSION}

The News, Renewed project was established with two core objectives:

1) To identify the most promising business model for funding online journalism, through academic research.

2) To enable implementation of the best monetisation strategy, through the development of a technology enterprise.

This chapter provides a snapshot of conclusions drawn from my entrepreneurial journey with PressPass, based on a synthesis of my literature review, consumer survey and interviews with news organisations.

Although the old business models that once sustained journalism are 'crumbling,' I am confident that collaboration through bundling can enable an even better model to rise from the ashes.

\subsection{News, Renewed: objective 1}

\subsubsection{Evaluating the benefits of global bundling}

The News, Renewed survey revealed a clear consumer preference for monetisation strategies that feature an element of global bundling (Section 4.2). The proportion of respondents willing to 'definitely' pay $\$ 10$ or more per month for a global news package $(5.4 \%, n=23)$, was between $3 x$ and $23 x$ higher than all other news-only alternatives surveyed. Furthermore, the overall estimated conversion rate for a global news package was between $2.3 \mathrm{x}$ and $10.8 \mathrm{x}$ more popular than all news-only alternatives. Meanwhile, a global news and multimedia package was approximately $2 \mathrm{x}$ more popular than a global news package for each of these metrics.

As discussed within Section 6.1 a global news package has been selected as the primary focus of the PressPass platform. From a pragmatic perspective, there are already many hurdles to overcome in the process of trying to create a global news package, without trying to simultaneously negotiate deals for the bundling of other forms of media 
content. Furthermore, additional research is required to assess the economic viability of revenues that would be allocated to news within a scenario of multimedia bundling.

By increasing estimated conversion rates, a global news package has the potential to generate far greater revenues than existing standalone subscription strategies. As outlined within Section 4.6, overall industry revenues could be approximately $5.8 \mathrm{x}$ higher than under a standalone subscription. By enabling economies of scale, scope and aggregation (Section 2.2), bundling creates substantial financial rewards that allow the self-interest of individual news organisations to align more closely with the collective interests of the journalism industry (Section 2.3).

Another advantage of a global news package is that as more publications participate in bundling, there will be an increasingly comprehensive range of unique quality content that cannot be readily duplicated outside the bundle. Consequently, consumers will have a stronger incentive to pay for news under a bundling strategy, potentially lowering the risk of defection to free alternatives. If a majority of news organisations choose to bundle, then the risk of defection could be reduced even further.

Survey findings within Chapter 4 also suggest that the Innovator's Dilemma for bundling will be less challenging than the dilemma posed by archetypal 'disruptive technologies' with lower prospects of consumer success. Specifically, Christensen posits that disruptive technology typically underperforms established products in mainstream markets, offers lower levels of profit, and is initially embraced by consumers on the fringes of a market. Bundling, however, appears to outperform established subscription products in mainstream markets, offers higher levels of profit, and is embraced by far more consumers than standalone subscriptions.

Furthermore, Section 4.7 indicates that the risk of cannibalisation for existing standalone subscription revenue is likely to be low. If the News, Renewed survey findings can be replicated at a larger scale, then the Innovator's Dilemma for global bundling may prove to be a dilemma largely based on psychological fears, rather than tangible reality. 


\subsubsection{Evaluating strategies for future studies}

As discussed within Section 6.8.2, I recommend that future studies to assess willingness to pay should be conducted using discrete choice modelling. Although this is one the most complex and expensive survey instruments available, I am hopeful that funding can be obtained either through philanthropic support, private investment, co-funding from news organisations, or a combination of all three. Section 6.8.1 also outlines a number of proposed survey strategies, such as: limiting survey options to just standalone subscriptions and a global news package, creating a hypothetical news package with named mastheads, and direct surveying of news organisations' readers.

Although market research will be an invaluable tool to comprehensively assess the merits of bundling, I have some concerns that an overemphasis on market quantification could stunt the momentum of the PressPass project. As Christensen warns, it is common for companies to "demand quantification of market sizes and financial returns before they can enter a market," causing them to become "paralysed [...] when faced with disruptive technologies" (p. xxvi). While I believe that further market research should be pursued, it should not come at the expense of conducting a trial launch within test markets. There is sufficient evidence from my preliminary research to identify global bundling as a strategy with very high potential for significant financial rewards, and reasonable steps should be taken to validate this value proposition through a live market launch (Section 6.7.1).

\subsection{News, Renewed: objective 2}

\subsubsection{Evaluating platform features}

Throughout the PressPass project, one of my biggest challenges has been trying to reconcile the multifaceted feedback from news organisations. Instead of having the freedom to simply pursue a platform strategy with the highest prospects of consumer success, I have had to weigh up the complex concerns of potential publishing partners. At the heart of my entrepreneurial dilemma, has been balancing the extent to which industry fears and conservatism should be allowed to shape the features and functionality of PressPass. 
On the one hand, developing platform features that acquiesce to industry conservatism could facilitate the establishment of content partnerships. On the other hand, the resultant platform strategy could undermine the long-term prospects of PressPass. Furthermore, the feedback from news organisations was not monolithic. Consequently, platform functionality developed to allay the fears of one news organisation, could result in features that trigger the fears of another.

The contrast between PressPass 1.0 and 2.0 illustrates this tension clearly. On the one hand, PressPass 1.0 directly integrates with news organisation's websites and provides complete control over editorial decisions. The decentralised nature of the platform helps allay the strong fears that many interviewees have about the loss of control that could arise through aggregation. Another benefit of direct integration is that it increases consumer awareness of global bundling, maximising uptake and subsequent revenues. Direct integration, however, also triggers fears that PressPass 1.0 would directly compete with standalone subscriptions and fuel cannibalisation.

On the other hand, PressPass 2.0 operates as an aggregation platform at an arm's-length from each news organisation's website. This helps allay the strong fears that many interviewees have about the risk of cannibalisation posed by direct integration. Furthermore, aggregation provides a superior reader experience, increasing customer satisfaction. An aggregation platform, however, triggers several concerns, including the risk that readers could flow to competitors, and the fear of losing control over the curatorial experience. Even with the safeguards proposed within Section 6.2.2, some interviewees were reluctant to partner with PressPass. Furthermore, an arm's-length strategy risks pushing bundling to the margins, stunting consumer uptake.

In an ideal scenario, I believe that PressPass 1.0 and 2.0 should be pursued as complementary platform strategies, followed by PressPass 3.0 once logistical hurdles have been overcome (further details, Section 6.2.3). Instead, I am faced with the difficult prospect of choosing a strategy that has the best prospects of getting publishers on board. I am hoping that interviewee fears of cannibalisation might be minimised, through the successful launch of targeted market trials of PressPass 1.0 (see Section 6.7.1). If early market trials are successful, it might be possible to pursue a full market launch of both PressPass 1.0, 2.0 and 3.0 without compromising functionality. Future 96 
negotiations are required to determine the exact scope of features that are both practical and desired by the journalism community.

\subsubsection{Evaluating ownership and governance structures}

In regards to ownership, I am an advocate for PressPass maintaining complete independence from sectional ownership by specific news partners. Ownership by news partners not only raises concerns about operational independence and conflicts of interest, but could result in operational instability and barriers to partnership development with non-owners. Furthermore, co-ownership could result in significant legal scrutiny from regulatory bodies such as the Commerce Commission.

I appreciate, however, that there is a delicate tension that needs to be addressed. On the one hand, I risk losing important partnerships if I do not allow any news organisations to have an ownership stake. Co-ownership provides a strong financial incentive for news partners to align their strategy with PressPass, and could create a key competitive advantage over other platforms. On the other hand, co-ownership by news organisations could have a detrimental impact on the long-term success of PressPass, potentially undermining operational independence and introducing the risk of instability with decision-making.

I am willing to consider co-ownership structures that strive for a balance between individual and collective interests. As discussed within Section 6.3.1, a compromise might be found within the model of the Kirkpatrick cooperative, which enables coownership while also upholding operational independence. Furthermore, as discussed within Section 6.3.2, operational independence could be upheld within a conventional limited liability company through careful crafting of its constitution and articles of association.

I am continuing to explore the best strategies for enabling a successful ownership and governance structure, and am still evaluating which ownership and governance structure will be most beneficial for the journalism community in the long term. In the meantime, the PressPass platform is owned by Ripple Media Limited (company number: 5189621). Once an ideal structure has been identified and agreed upon, I plan to create a new legal entity to which ownership of the PressPass platform can be transferred. 


\subsubsection{Evaluating pricing and revenue distribution models}

I believe that the pricing strategy for PressPass should be focused on identifying the price-point at which maximum overall revenue is generated by the global news package. As discussed within Section 6.4, the fear of cannibalisation has resulted in pressure to price global subscriptions higher than the revenue-maximising price-point. If I acquiesce to such fears, uptake and revenue from global bundling would be significantly hindered. Once again, I am faced with an entrepreneurial dilemma as I evaluate whether I concede to industry fears for the sake of developing partnerships, or continue to challenge conservative conventional wisdom by advocating for a 'bundling first' pricing strategy. I am hopeful that market data generated by further research and a trial launch will provide insights that minimise the fears of potential news partners.

In regards to royalty distribution, Section 6.4 outlines my belief in the merits of a system where subscription revenue is equitably distributed based on readership engagement metrics. From a collective perspective, I think there are strong indicators to suggest that equitable revenue distribution will help facilitate partnerships by establishing trust in the PressPass platform. Individually, however, news organisations have an incentive to push for premium rates that are higher than their competitors. While a 'premium' tier within a consumer news package could be a compromise, it also risks undermining the prospects of success for bundling. I am hoping that careful crafting of equitable royalty metrics will result in a system that provides 'premium' content with greater financial rewards than 'non-premium' content - without resorting to premium rates for specific publishers.

\subsubsection{Evaluating partnership and launch strategies}

As discussed within Section 6.7, conditional contracts and time-sensitive partnership incentives are promising strategies that could help secure partners for the PressPass platform. Conditional contracts are a useful logistical tool for establishing the parameters of a global news package within a low risk environment, since contracts are only activated once a threshold of partnerships has been reached. I am hopeful that such a strategy will be highly conducive to collective action, by spreading the risk as the journalism community transitions from isolated standalone strategies to a bundled ecosystem. 
Time-sensitive partnership incentives are also useful for facilitating collective action, by creating private inducements with a strong first-mover advantage. Specifically, offering discounted commission rates for the first news partners creates additional motivation to embrace bundling as a core strategy from an early stage, rather than pursuing a bundle strategy tentatively on the margins.

Once partnerships are secured, a trial launch will be an invaluable tool to evaluate the value proposition of bundling and establish a pathway of precedent that can then be followed by the wider journalism community. At the heart of PressPass' success, will be partnering with news organisations that are willing to lead the industry forward.

All news organisations interviewed had at least one individual who thought that global bundling was worth pursuing. Consequently, there are some promising foundations upon which partnerships can be built. The key to success will be strengthening relationships with project advocates within each news organisation, and working with them to identify ways to get buy-in from the wider team. 


\section{REFERENCES}

Alexander, A., Owers, J., \& Carveth, R. (2004). An Introduction to Media Economics Theory and Practice. In A. Alexander, J. Owers, R. Carveth, C. A. Hollifield, \& A. N. Greco (Eds.), Media Economics: Theory and Practice (pp. 3-49). Mahwah, NJ: Lawrence Erlbaum Associates, Inc.

APN News and Media. (2014, September 4). Supplemental Disclosure Information.

Babe, R. E. (2011). The Place of Information in Economics. In E. A. Comor (Ed.), Media, Structures, and Power: The Robert E. Babe Collection (pp. 22-43). Toronto, Canada: University of Toronto Press.

Bakos, Y., \& Brynjolfsson, E. (1999). Bundling information goods: Pricing, profits and efficiency. Management Science, 45(12), 1613-1630.

Bakos, Y., \& Brynjolfsson, E. (2007). Bundling and competition on the Internet. In E. Brousseau \& N. Curien (Eds.), Internet and Digital Economics: Principles, Methods and Applications (pp. 313-325). Cambridge, UK: Cambridge University Press.

Carveth, R. (2004). The Economics of Online Media. In A. Alexander, J. Owers, R. Carveth, C. A. Hollifield, \& A. N. Greco (Eds.), Media Economics: Theory and Practice (pp. 265-283). Mahwah, NY: Lawrence Erlbaum Associates, Inc.

Chandon, P. (2005). Do Intentions Really Predict Behaviour? Self-Generated Validity Effects in Survey Research. Journal of Marketing, 69(2), 1-14.

Christensen, C. M. (2003). The Innovator's Dilemma. New York, NY: HarperCollins.

Christensen, C. M., Allworth, J., \& Skok, D. (2012, September 15). Breaking News: Mastering the art of disruptive innovation in journalism. Retrieved from http://niemanreports.org/articles/breaking-news/

Doctor, K. (2012, September 27). The newsonomics of Pricing 201. Retrieved from http://www.niemanlab.org/2012/09/the-newsonomics-of-pricing-201/

Doctor, K. (2015, January 22). Newsonomics: How deep is the newspaper industry's money hole? Retrieved from http://www.niemanlab.org/2015/01/newsonomicshow-deep-is-the-newspaper-industrys-money-hole/

Ellis, J. (2014a, May 7). If my newspaper puts up a metered paywall, how many people will pay? Here's some data. Retrieved from http://www.niemanlab.org/2014/05/if-my-newspaper-puts-up-a-meteredpaywall-how-many-people-will-pay-heres-some-data/

Ellis, J. (2014b, November 25). Why Google is taking another shot at helping readers pay for news. Retrieved from http://www.niemanlab.org/2014/11/why-google- 
is-taking-another-shot-at-helping-readers-pay-for-news/

Facebook Newsroom. (2015, May 12). Company Info. Retrieved from http://newsroom.fb.com/company-info/

Fahy, B. (2014, February 21). Audience up, ad spend down: a depressing graph for Fairfax and APN? Retrieved from http://stoppress.co.nz/blog/2014/02/apnfairfax-online-ad-spend

Fahy, B. (2015, April 17). Nielsen numbers show stuff.co.nz moving up the top ten rankings, as other big sites lose audience :: StopPress. Retrieved from http://stoppress.co.nz/blog/2015/04/nielsen-numbers-show-stuffconz-movingtop-ten-rankings-other-big-sites-lose-audience

GfK, \& IAB. (2014). Original Digital Video Consumer Study (p. 60). GfK Media \& Entertainment and the Interactive Advertising Bureau.

Gray, J. (2015, February 13). Pay wall plan on track, says APN chief. New Zealand Herald. Retrieved from http://www.nzherald.co.nz/business/news/article.cfm?c_id=3\&objectid=114010 63

Grueskin, B., Seave, A., \& Graves, L. (2011). The Story So Far: What We Know About the Business of Digital Journalism. New York, NY: Columbia University Press.

Kaye, J., \& Quinn, S. (2010). Funding journalism in the digital age: business models, strategies, issues and trends. New York, NY: Peter Lang Publishing Inc.

Lapadat, J. C. (2010). Thematic Analysis. In A. J. Mills, G. Durepos, \& E. Wiebe, Encyclopedia of Case Study Research (pp. 926-928). Thousand Oaks, CA: SAGE Publications, Inc. Retrieved from http://dx.doi.org.helicon.vuw.ac.nz/10.4135/9781412957397.n342

Lipovetsky, S., Magnan, S., \& Polzi, A. Z. (2011). Pricing Models in Marketing Research. Intelligent Information Management, 3, 167-174.

Lomas, N. (2014, December 12). Inkl Wants To Be "Spotify For News.” Retrieved from http://social.techcrunch.com/2014/12/12/ink1/

Lumley, T. (2011, December 13). Below the margin of error $\mid$ Stats Chat. Retrieved from http://www.statschat.org.nz/2011/12/13/below-the-margin-of-error/

McChesney, R. W., \& Nichols, J. (2010). The Life and Death of American Journalism: The Media Revolution that Will Begin the World Again. New York, NY: Nation Books.

Media Take. (2014, July 22). Maori Television. 
Ministry of Education. (2013). Participation rates in tertiary education. Retrieved from https://www.educationcounts.govt.nz/indicators/data/student-engagementparticipation/3744

New York Times. (2014, March 24). Innovation. Retrieved from http://www.scribd.com/doc/224608514/The-Full-New-York-Times-InnovationReport

Nielsen. (2014a). Nielsen Online Ratings, October 2014.

Nielsen. (2014b). Today's Top Headlines: 8.9 Million Australians go Online for their Daily News. Retrieved from http://www.nielsen.com/au/en/insights/news/2014/todays-top-headlines-89million-australians-go-online-for-their-daily-news.html

Olson, M. (1971). The Logic of Collective Action: Public Goods and the Theory of Groups. New York, USA.: Schocken Books.

Pew Research Center. (2013). Key Findings, State of the News Media 2013. Retrieved from http:/www.stateofthemedia.org/2013/overview-5/key-findings/

Phelps, A. (2012, July 18). Wielki sukces! Piano Media expands its national paywall model to Poland. Retrieved from http://www.niemanlab.org/2012/07/wielkisukces-piano-media-expands-its-national-paywall-model-to-poland/

Pickard, A. J. (2007). Research methods in information. London: Facet Publishing.

Pullar-Strecker, T. (2014, November 14). No paywall plans for news. Retrieved from http://www.stuff.co.nz/business/industries/63200873/fairfax-nz-has-no-paywallplans-for-news

Ries, E. (2011). The Lean Startup: How Today's Entrepreneurs Use Continuous Innovation to Create Radically Successful Businesses. New York, NY: Crown Publishing Group.

Risen, E., \& Risen, L. (2008). The Use of Intent Scale Translations to Predict Purchase Interest (White Paper). BioTrak Research Inc.

Sandler, T. (1995). Collective Action: Theory and Applications (4th ed.). Ann Arbor, MI.: University of Michigan Press.

SimilarWeb. (2015, May 5). Website Ranking - Top 50 Sites By Category \& Country. Retrieved from http://www.similarweb.com/global

Statistics New Zealand. (2013, December 3). 2013 Census QuickStats about national highlights: Age and Sex. Retrieved from http://www.stats.govt.nz/Census/2013census/profile-and-summary-reports/quickstats-about-national-highlights/ageand-sex.aspx 
Statistics New Zealand. (2014a, August 14). National Population Estimates: At 30 June 2014. Retrieved from

http://www.stats.govt.nz/browse_for_stats/population/estimates_and_projections /NationalPopulationEstimates_HOTPATH3Jun14.aspx

Statistics New Zealand. (2014b, October 3). New Zealand Income Survey: June 2014 quarter. Retrieved from http://www.stats.govt.nz/browse_for_stats/income-andwork/Income/NZIncomeSurvey_HOTPJun14qtr.aspx

Sweney, M. (2014a, February 7). Spotify Premium membership offer for Times subscribers. Retrieved from

http://www.theguardian.com/media/2014/feb/07/spotify-premium-membershiptimes-subscribers

Sweney, M. (2014b, October 21). The Guardian overtakes New York Times in comScore traffic figures | Media | The Guardian. Retrieved from http://www.theguardian.com/media/2014/oct/21/the-guardian-overtakes-newyork-times-in-comscore-traffic-figures 


\title{
Appendix A: $\quad$ News, Renewed: \\ Survey Questions
}

\author{
BY
}

\section{ALEXANDER COLIN CLARK}

Submitted to the Victoria University of Wellington

In partial fulfilment of the requirements for the degree of

Master of Advanced Technology Enterprise

Victoria University of Wellington

2015 
Personal information

\section{Online news survey}

This survey asks for information about your news reading habits, and also explores your opinions about paying for access to news. The survey takes about 10 minutes to complete, and answers will be kept anonymous.

\section{Background:}

Our team is researching the future of online news, searching for ways to improve the way that journalism is funded, created and shared. We are undertaking this research as students within Victoria University's Master of Advanced Technology Enterprise programme. If you would like more information about our research then feel free to contact our team leader, Alex Clark (alex.clark@vuw.ac.nz).

Defining news and journalism:

This survey uses a very broad definition of news and journalism. Our definition includes established news outlets, as well as blogs and other forms of social commentary about current events.

\section{Section 1) Background information}

Please provide some background information about yourself.

1) What is your age?
Under 18
(18-24
25-30
$31-40$
41-50
( $51-60$
O $61+$

2) Are you a student?

0 Yes

No

3) What is your annual income?
Under $\$ 15,000$
- $\$ 15,000-\$ 40,000$
$\$ 40,001-\$ 80,000$
O $\$ 80,000+$

Prefer not to disclose 
4) If you are happy to be contacted with follow-up questions, please provide your details below:

$\begin{array}{ll}\text { First name: } & \square \\ \text { Email address: } & \end{array}$

\section{Section 2) Your news reading habits}

1) How often do you visit news websites?
Never
Hardly ever (once per week, or less)
Occasionally (several times a week)
Often (several times per day)

2) Approximately how many news websites do you visit each week?
None
( 1
2-3
4-10
$10+$

3) If you visit more than one news website, what are the main reasons?

Please tick all that apply

I like to access a diverse range of perspectives and opinions from multiple news sources.

$\square$ I like to visit a variety of news websites that specialise in different topics.

$\square$ I visit several sites via links posted on social media (i.e. Facebook, Twitter etc.)

$\square$ Other (please specify)

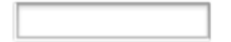

$\square$ I only visit one news website

4) Do you spend more time on New Zealand news sites, or overseas?
Mostly New Zealand news sites
Mostly overseas news sites
About the same amount of time 


\section{5) What are the main reasons that you read news?}

Please tick all that apply.
D Personal interest.
$\square$ It's important for my job.
It's important for my studies.
Other

6) What types of news do you read most often?

Please tick all that apply.

\begin{tabular}{|c|c|c|c|}
\hline$\square$ Local news & Politics & $\square$ Technology/Science & $\square$ Events \\
\hline$\square$ National news & $\square$ sport & $\square$ Entertainment/ Gossip & $\square$ Travel \\
\hline$\square$ International news & Finance/ Business & $\square$ Arts/ culture & $\square$ Other \\
\hline
\end{tabular}

7) Do you ever access news using the following platforms?

Please tick all that apply.
$\square$ Social networks (e.g. Facebook, Twitter, Linkedln, Quora, etc.)
$\square$ Mobile apps (e.g. Flipboard, Feedly, Pulse, News360, etc.)
$\square$ RSS readers (e.g. FeedDemon, Newsblur, Newsgator, etc.)
$\square$ None of the above

\section{8) Do you pay for any of the following types of media content?}

Please tick all that apply
$\square$ Print subscription (newspapers or magazines)
$\square$ Online news subscription
Pay TV (e.g. Sky Television)
$\checkmark$ Online video streaming subscription (e.g. Netflix)
$\square$ Online music streaming subscription (e.g. Spotify)
Digital media content from online stores (e.g. iTunes or Kindle)
$\triangle$ Other

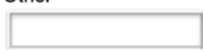
None of the above

9) Do you ever make credit card purchases online?

Yes 
10) Do you own a smartphone (for example, an iPhone, Android or Windows Phone).

Yes

No

\section{Section 3 - Your thoughts about funding journalism}

This section asks for your opinions about different approaches to funding journalism.

\section{Background information:}

News organisations are losing a lot of money by putting their news online for free. For every $\$ 1$ they gain in online advertising, they currently experience a $\$ 16$ decrease in print advertising. As a result, news teams have become much smaller throughout the world and many publications are struggling to survive.

News organisations are currently looking for new revenue models to support the creation of high quality journalism. Over the next 12 months, most news websites in New Zealand and around the world are planning to charge readers for full access to their content.

Note: Statistics sourced from "The State of the News Media 2013," by the Pew Research Center's Project for Excellence in Journalism.

\section{Imagine a scenario where all of your favourite news sites started charging for full online access:}

1) How likely are you to pay for each of the following options?

\begin{tabular}{|c|c|c|c|c|c|c|c|c|}
\hline & \multicolumn{2}{|c|}{ Definitely not } & Unlikely & \multicolumn{2}{|c|}{ Maybe } & Probably & \multicolumn{2}{|c|}{ Definitely } \\
\hline $\begin{array}{l}\text { A small fee to access each } \\
\text { article. }\end{array}$ & \multicolumn{2}{|l|}{$\mathrm{O}$} & $\mathrm{O}$ & \multicolumn{2}{|c|}{0} & $\mathrm{O}$ & \multicolumn{2}{|r|}{$\mathrm{O}$} \\
\hline $\begin{array}{l}\text { A monthly fee to access one } \\
\text { news website in New Zealand. }\end{array}$ & \multicolumn{2}{|l|}{0} & 0 & \multicolumn{2}{|c|}{0} & 0 & \multicolumn{2}{|r|}{0} \\
\hline $\begin{array}{l}\text { A monthly fee to access all news } \\
\text { websites in New Zealand }\end{array}$ & \multicolumn{2}{|l|}{0} & O & \multicolumn{2}{|c|}{0} & 0 & \multicolumn{2}{|r|}{0} \\
\hline $\begin{array}{l}\text { A monthly fee to access all news } \\
\text { websites in the world. }\end{array}$ & \multicolumn{2}{|l|}{$\mathrm{O}$} & 0 & \multicolumn{2}{|c|}{0} & 0 & \multicolumn{2}{|r|}{ O } \\
\hline $\begin{array}{l}\text { A monthly fee to access all news } \\
\text { websites, as well as TV shows, } \\
\text { movies, music and other media. }\end{array}$ & \multicolumn{2}{|l|}{0} & O & \multicolumn{2}{|c|}{0} & 0 & \multicolumn{2}{|r|}{0} \\
\hline \multicolumn{9}{|c|}{ 2) How much would you be prepared to pay? } \\
\hline & $\$ 0$ & $\$ 1-3$ & $\$ 4-6$ & $\$ 7-9$ & $\$ 10-12$ & \multicolumn{3}{|c|}{ More than } \\
\hline $\begin{array}{l}\text { A monthly fee to access one } \\
\text { news website in New Zealand. }\end{array}$ & 0 & 0 & $\mathrm{O}$ & O & 0 & $\mathrm{O}$ & $\mathrm{O}$ & 0 \\
\hline $\begin{array}{l}\text { A monthly fee to access all news } \\
\text { websites in New Zealand }\end{array}$ & 0 & 0 & 0 & 0 & 0 & 0 & 0 & 0 \\
\hline $\begin{array}{l}\text { A monthly fee to access all news } \\
\text { websites in the world. }\end{array}$ & 0 & O & O & O & O & 0 & 0 & ○ \\
\hline $\begin{array}{l}\text { A monthly fee to access all news } \\
\text { websites, as well as TV shows, } \\
\text { movies, music and other media. }\end{array}$ & 0 & 0 & 0 & 0 & 0 & 0 & 0 & 0 \\
\hline
\end{tabular}


3) Have you ever encountered a paywall on a news website?

Note: A paywall blocks news articles that you want to read, and asks you to pay for access

Yes

No

4) Have you ever paid money for access to a news website?

Yes

No

5) What do you think are the biggest barriers to paying for online news?

Please tick all that apply.

$\square$ There are free alternatives that I can easily switch to

$\square$ I think that online news should be free

$\square$ I can't afford to pay for online news

$\square$ I don't like making payments online

$\square$ I access news from many sites and it is unrealistic to pay for each individually

$\square$ other

Please feel free to share your thoughts about the payment options above, and to explain the reasons for your answers within this section.

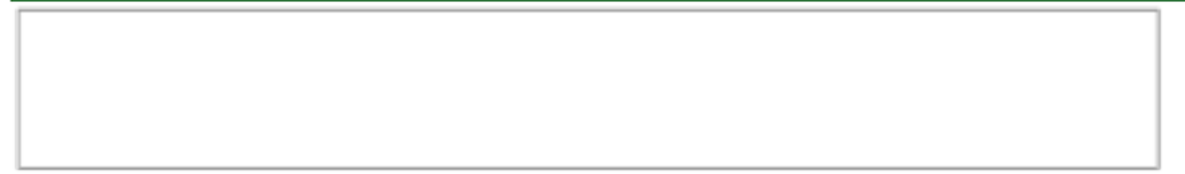

In the previous section of this survey, you said that you would consider paying for news if you could gain access to more than one website. What do you think are the biggest benefits of this approach?

Please tick all that apply

It is cheaper than paying for multiple subscriptions.

$\square$ It is more convenient than creating multiple subscriber accounts.

$\square$ It provides access to a diverse range of opinions and perspectives from multiple sources.

It provide access to a variety of news websites that specialise in different topics.

$\square$ Other 
Please feel free to explain your preference for this option in more depth.

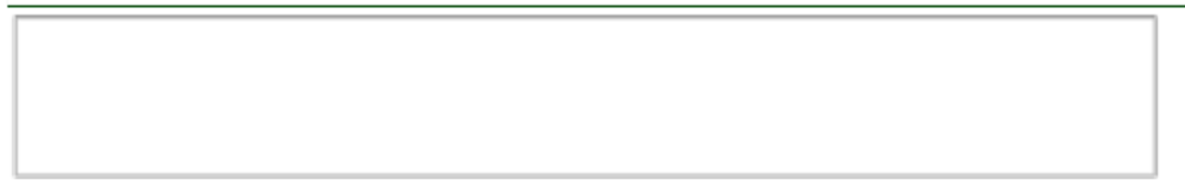

Imagine a scenario where general news stories remained free, but you had the option to pay for extras:

1) How likely are you to pay for each of the following options?

\begin{tabular}{|c|c|c|c|c|c|}
\hline & Definitely not & Unlikely & Maybe & Probably & Definitely \\
\hline $\begin{array}{l}\text { A monthly fee to remove } \\
\text { advertising. }\end{array}$ & 0 & 0 & 0 & 0 & 0 \\
\hline $\begin{array}{l}\text { A monthly fee for a news app on } \\
\text { your mobile or tablet. }\end{array}$ & 0 & 0 & 0 & 0 & 0 \\
\hline $\begin{array}{l}\text { A monthly fee to access premium } \\
\text { news content, such as } \\
\text { investigative reporting, extended } \\
\text { articles and interactive } \\
\text { multimedia. }\end{array}$ & 0 & O & $\mathrm{O}$ & 0 & 0 \\
\hline $\begin{array}{l}\text { A monthly donation to support } \\
\text { your favourite news website or } \\
\text { blogger. }\end{array}$ & 0 & 0 & 0 & 0 & 0 \\
\hline $\begin{array}{l}\text { A donation to support the creation } \\
\text { of specific stories that you are } \\
\text { interested in. In this scenario, } \\
\text { journalists would pitch story ideas } \\
\text { about important topics or issues } \\
\text { and news readers would fund } \\
\text { them. }\end{array}$ & 0 & 0 & 0 & 0 & 0 \\
\hline
\end{tabular}

2) Still thinking about the scenario described above, how much would you be prepared to pay for each of the following options?

\begin{tabular}{|c|c|c|c|c|c|c|c|c|}
\hline & \$o & $\$ 1-3$ & $\$ 4-6$ & $\$ 7-9$ & $\$ 10-12$ & $\$ 13-15$ & $\begin{array}{l}\text { More than } \\
\$ 15\end{array}$ & Unsure \\
\hline $\begin{array}{l}\text { A monthly fee to remove } \\
\text { advertising. }\end{array}$ & 0 & 0 & 0 & 0 & 0 & 0 & 0 & 0 \\
\hline $\begin{array}{l}\text { A monthly fee for a news app on } \\
\text { your mobile phone or tablet. }\end{array}$ & 0 & 0 & 0 & 0 & 0 & 0 & 0 & 0 \\
\hline $\begin{array}{l}\text { A monthly fee to access } \\
\text { premium news content. }\end{array}$ & 0 & 0 & O & 0 & 0 & O & 0 & 0 \\
\hline $\begin{array}{l}\text { A monthly donation to support } \\
\text { your favourite news website or } \\
\text { blogger. }\end{array}$ & 0 & 0 & 0 & 0 & 0 & 0 & 0 & 0 \\
\hline $\begin{array}{l}\text { A donation to support the } \\
\text { creation of specific stories that } \\
\text { you are interested in. (Please } \\
\text { estimate a monthly amount). }\end{array}$ & 0 & 0 & 0 & 0 & 0 & 0 & 0 & 0 \\
\hline
\end{tabular}

Please feel free to share your thoughts about the payment options above, and to explain the reasons for your answers within this section. 


$+2$

Imagine a scenario where all news remained free, but new advertising techniques were used to earn more money:

1) How would you feel about the following options?

\begin{tabular}{|c|c|c|c|c|c|}
\hline & Stongly dislike & Dislike & No strong feelings & Like & Like very much \\
\hline $\begin{array}{l}\text { An increase in articles that are } \\
\text { paid for by advertisers, and } \\
\text { promote their products or } \\
\text { services. }\end{array}$ & 0 & 0 & 0 & 0 & 0 \\
\hline $\begin{array}{l}\text { An increase in the number of } \\
\text { advertisements. }\end{array}$ & 0 & 0 & 0 & 0 & 0 \\
\hline $\begin{array}{l}\text { An increase in the prominence } \\
\text { of advertisements. (For } \\
\text { example, ads that cover the } \\
\text { entire page or videos that play } \\
\text { automatically). }\end{array}$ & 0 & 0 & 0 & 0 & O \\
\hline
\end{tabular}

If you had to choose, would you rather pay for news, or experience an increase in advertising?
Pay for news
Increase in advertising
Unsure

Please feel free to share your thoughts about the advertising techniques described above, and to explain the reasons for your answers within this section.

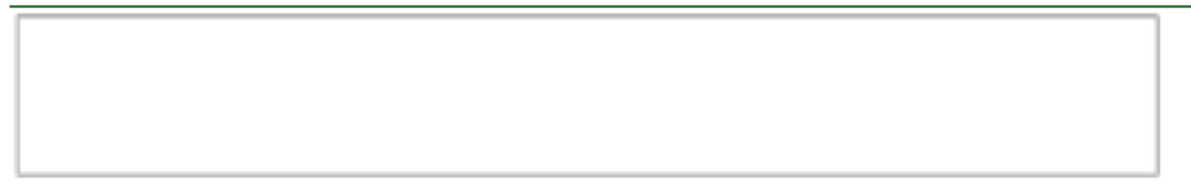

Please feel free to share your thoughts about funding online news.

Do you think it is reasonable to pay?

Do you think there are better alternative forms of funding?

Are there features or services that would increase your likelihood to pay?

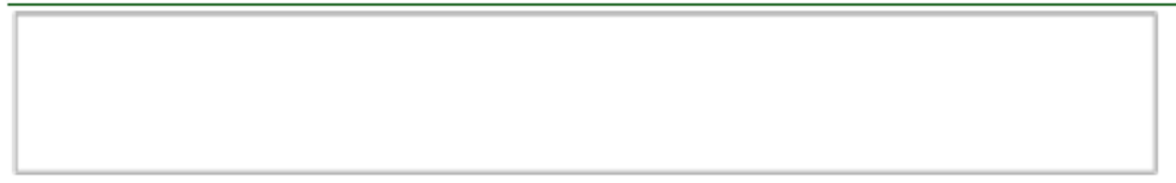

Please feel free to share your thoughts about online news journalism.

What do you like most about online news?

What do you think could be improved? 
Appendix B: Enterprise Case Study 

APPENDIX B

ENTERPRISE CASE STUDY:

PRESSPASS

BY

\title{
PUNEETH ANANDARAJ AND ALEXANDER CLARK
}

\author{
Submitted to the Victoria University of Wellington \\ In partial fulfilment of the requirements for the degree of \\ Master of Advanced Technology Enterprise
}

Victoria University of Wellington

2015 


\section{TABLE OF CONTENTS}

TABLE OF CONTENTS.......................................................................................... 2

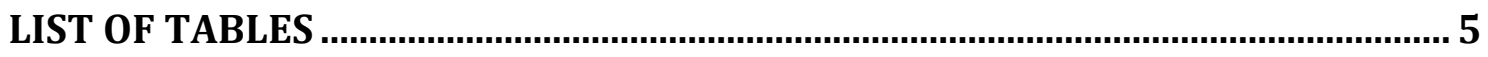

LIST OF FIGURES

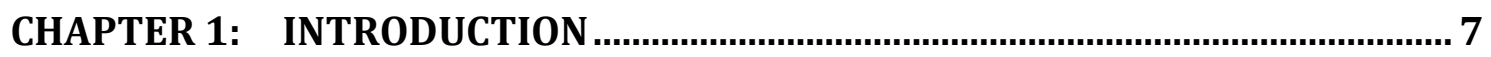

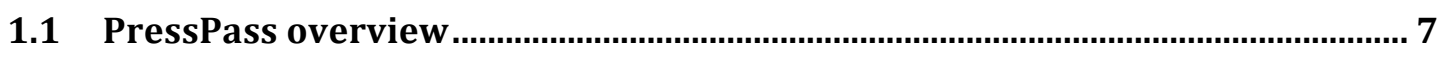

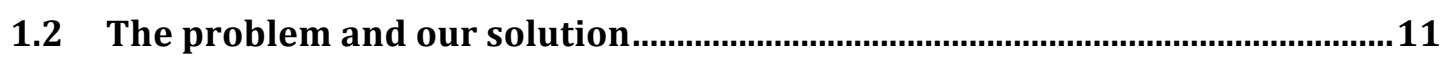

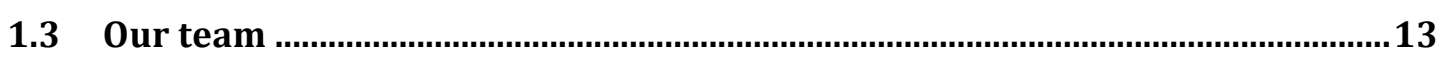

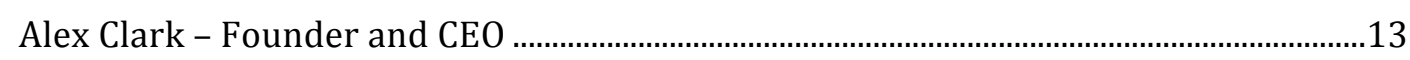

Puneeth Anandaraj - Founding Developer............................................................................14

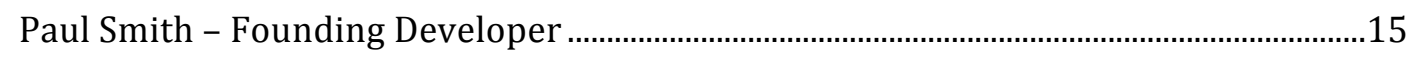

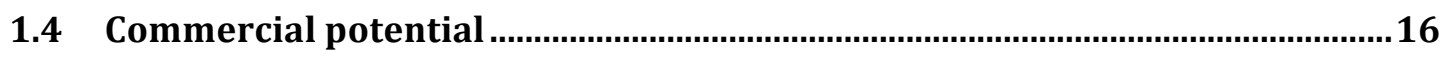

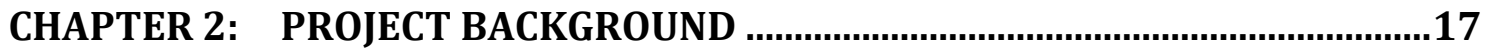

2.1 Project seed: 'Digital Commons or Digital Enclosures' ……...............................17

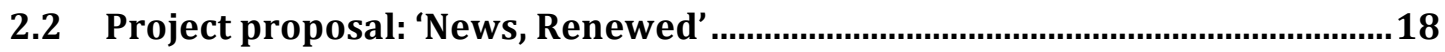

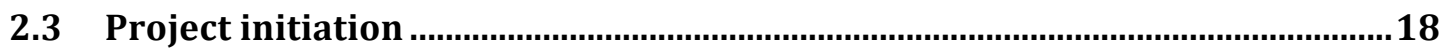

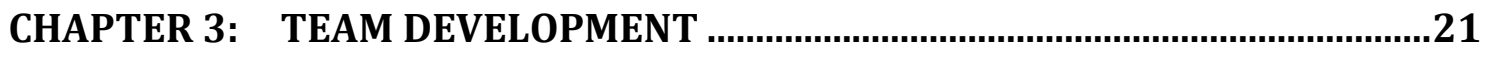

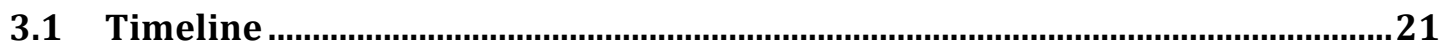

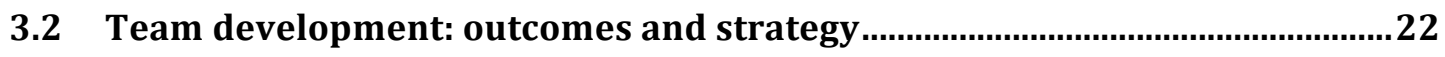

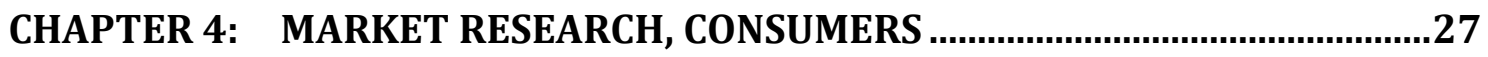

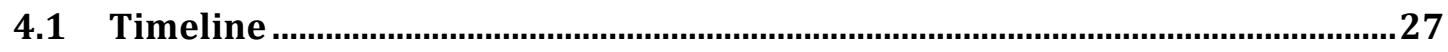

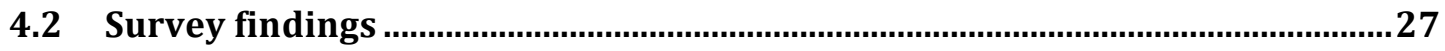

4.3 Identifying the best funding strategy for PressPass .............................................32

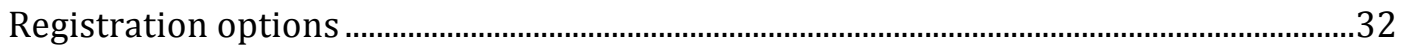

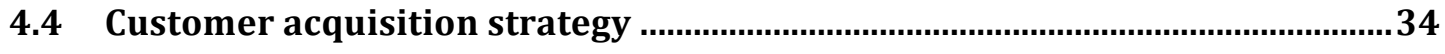

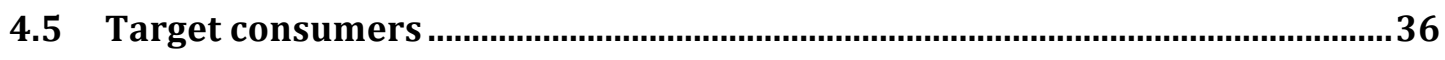

Age

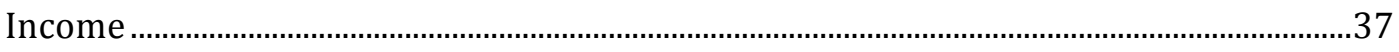

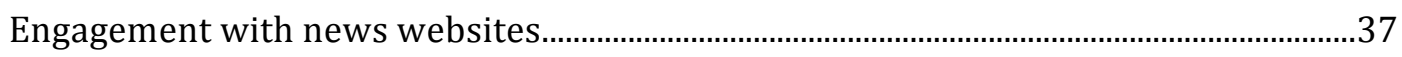

Media purchasing habits................................................................................................ 
CHAPTER 5: MARKET RESEARCH AND PARTNERSHIP DEVELOPMENT,

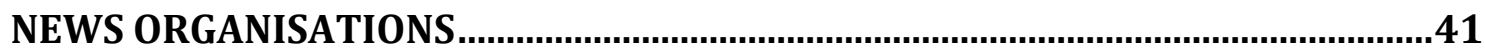

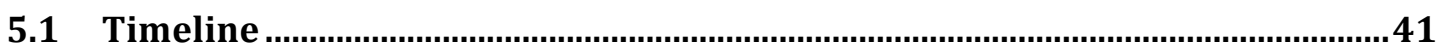

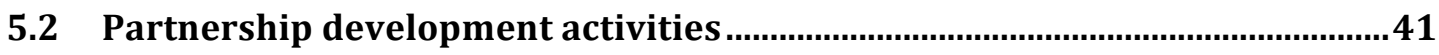

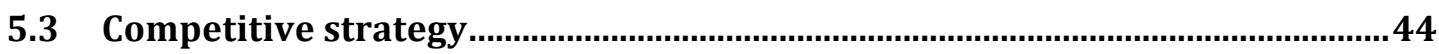

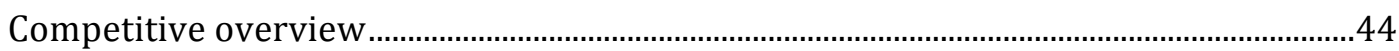

Competitive advantage ......................................................................................................... 45

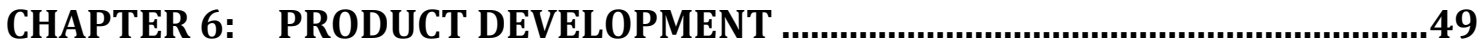

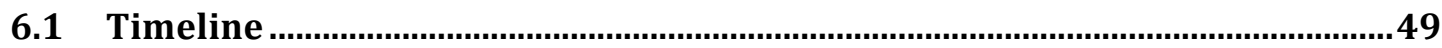

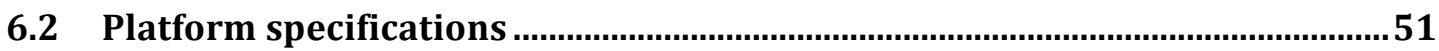

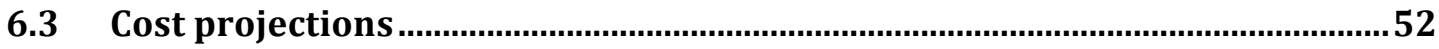

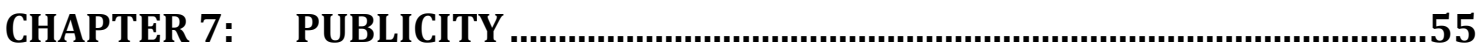

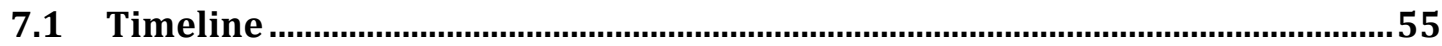

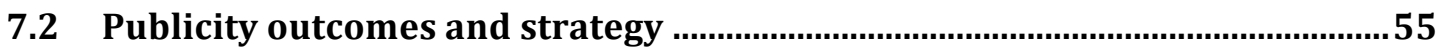

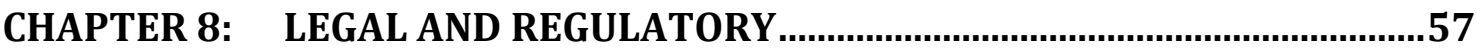

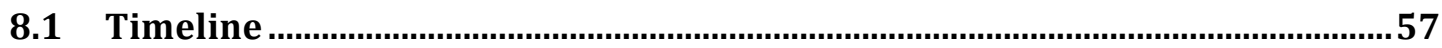

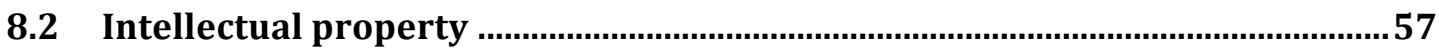

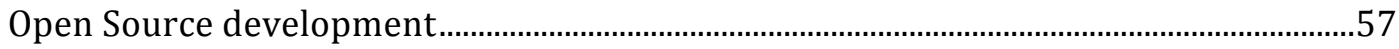

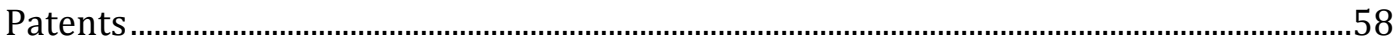

Trademark application.........................................................................................................

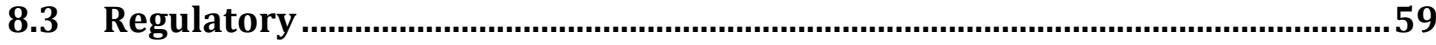

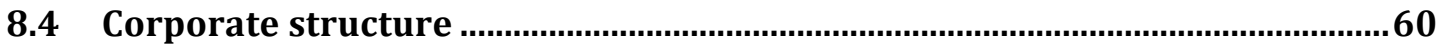

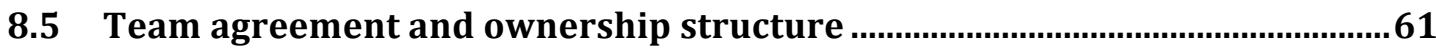

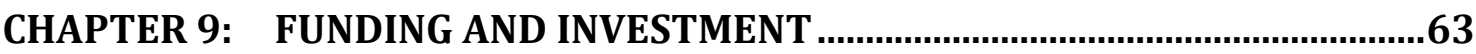

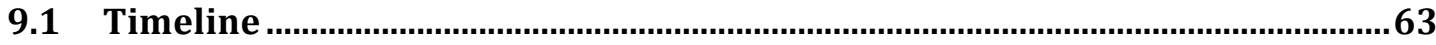

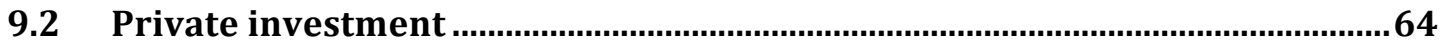

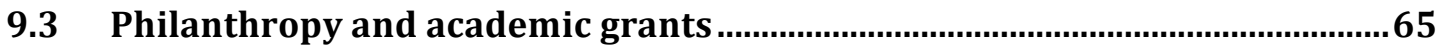

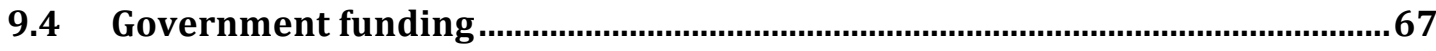

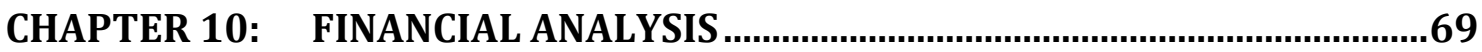

10.1 Pricing, commission structure and royalty distribution ................................69

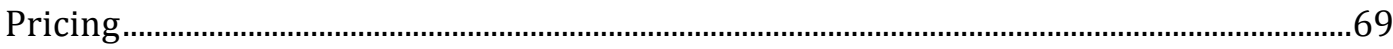

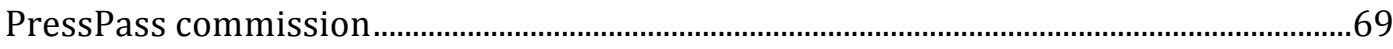

Conversion commission........................................................................................................... 
Royalty distribution. .70

Revenue flow: hypothetical breakdown 70

10.2 Financial model comparing a standalone strategy with global bundling ..71

10.3 PressPass revenue model.................................................................................. 73

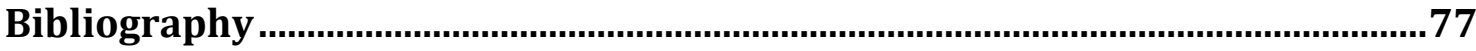




\section{LIST OF TABLES}

Table 1. Team development: Timeline of key milestones and activities..........................................................21

Table 2. Market research, consumers: Timeline of key milestones and activities........................................27

Table 3. Monetisation strategies explored within survey .................................................................................28

Table 4. Market research, news organisations: Timeline of key milestones and activities.........................41

Table 5. Roles of interviewees within news organisations...............................................................................42

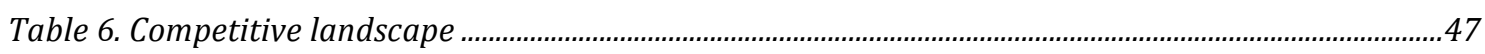

Table 7. Product development: Timeline of key milestones and activities.....................................................49

Table 8. Existing functionality of the PressPass platform …..................................................................51

Table 9. Current development tasks for the PressPass platform ..................................................................52

Table 10. Future plans for adding extra functionality to the PressPass platform........................................52

Table 11. Cost of Virtual Private Server (VPS) at different scales of usage, for current specifications...53

Table 12. Publicity: Timeline of key milestones and activities .....................................................................55

Table 13. Legal and regulatory: Timeline of key milestones and activities....................................................57

Table 14. Funding and investment: Timeline of key milestones and activities ...........................................63

Table 15. Estimated revenue under standalone package, all news organisations......................................72

Table 16. Estimated revenue under a standalone package, New Zealand Herald ........................................73

Table 17. Total revenue under a global bundling strategy, all publishing partners...................................73

Table 18. Estimated revenue under a global bundling strategy, New Zealand Herald...............................73

Table 19. Revenue model for New Zealand, high conversion rate estimate ....................................................74

Table 20. Revenue model for New Zealand, medium conversion rate estimate ............................................75

Table 21. Revenue model for New Zealand, low conversion rate estimate.....................................................75

Table 22. Revenue model for Australian expansion, low conversion rate estimate.......................................75

Table 23. Revenue model for USA expansion, low conversion rate estimate ..................................................76 


\section{LIST OF FIGURES}

Figure 1. Step 1 of the PressPass user experience 8

Figure 2. Step 2 of the PressPass user experience

Figure 3. Step 3 of the PressPass user experience

Figure 4. Step 4 of the PressPass user experience ___ 10

Figure 5. Step 5 of the PressPass user experience ___ 11

Figure 6. Willingness to pay for news at different levels of packaging ___ 29

Figure 7. Willingness to pay, 18-30 year olds___ 30

Figure 8. Willingness to pay for news under alternative funding strategies_____ 31

Figure 9. Willingness to pay for a global news package (age)___ 36

Figure 10. Willingness to pay for a global news package (income) ___ 37

Figure 11. Willingness to pay for a global news package (number of news sites visited each week)___38

Figure 12. Willingness to pay for a global news package (frequency of visits) ___ 38

Figure 13. Willingness to pay for a global news package (proportion of time spent reading New Zealand sites versus international) ___ 38

Figure 14. Willingness to pay for a global news package (type of news read most often) ___ 39

Figure 15. Willingness to pay for a global news package (current media purchases) ___ 39

Figure 16. Diagram of data flow required for the PressPass platform___ 54 


\section{CHAPTER 1: INTRODUCTION}

\subsection{PressPass overview}

PressPass provides bundled access to the world's best news websites, for one monthly subscription fee. Once registered, paying subscribers receive a universal login account that can be used to unlock premium news articles within any partner website. The platform integrates seamlessly with existing news websites, providing news organisations with full control over the editorial experience, including story selection and layout.

The codebase has been written using the JQuery programming language, allowing news organisations to integrate it into their existing websites by adding a line of JavaScript code. Once integrated, the platform provides paywall infrastructure, reader analytics, user authentication and payment collection. ${ }^{1}$

A brief summary of the PressPass user experience is provided below. Please note that this functionality is based on the core features of our prototype, and additional features are being planned.

Step 1: A user visits their chosen news website, by entering its URL into their browser. The PressPass platform appears as a thin blue ribbon along the top of the screen, and a counter lets users know the number of free articles they have (Figure 1).

\footnotetext{
${ }^{1}$ A full overview of the platform's features can be viewed within Section 6.2.
} 


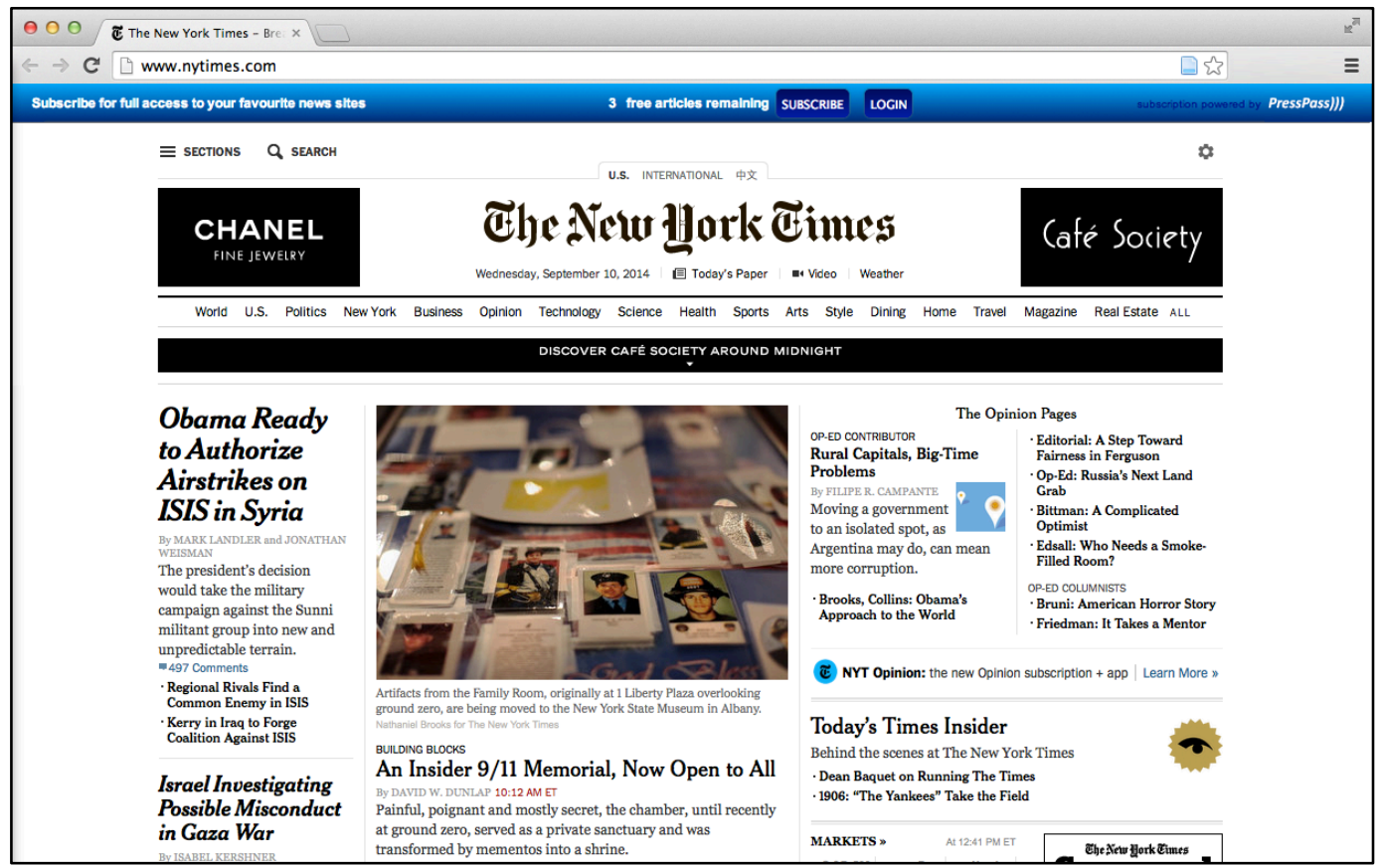

Figure 1. Step 1 of the PressPass user experience

Step 2: Once a user reaches their limit of free articles, the PressPass paywall appears and they are prompted to create an account. Readers can register their details by using an existing social media login, such as Facebook, or can create an account from scratch using an email address (Figure 2).

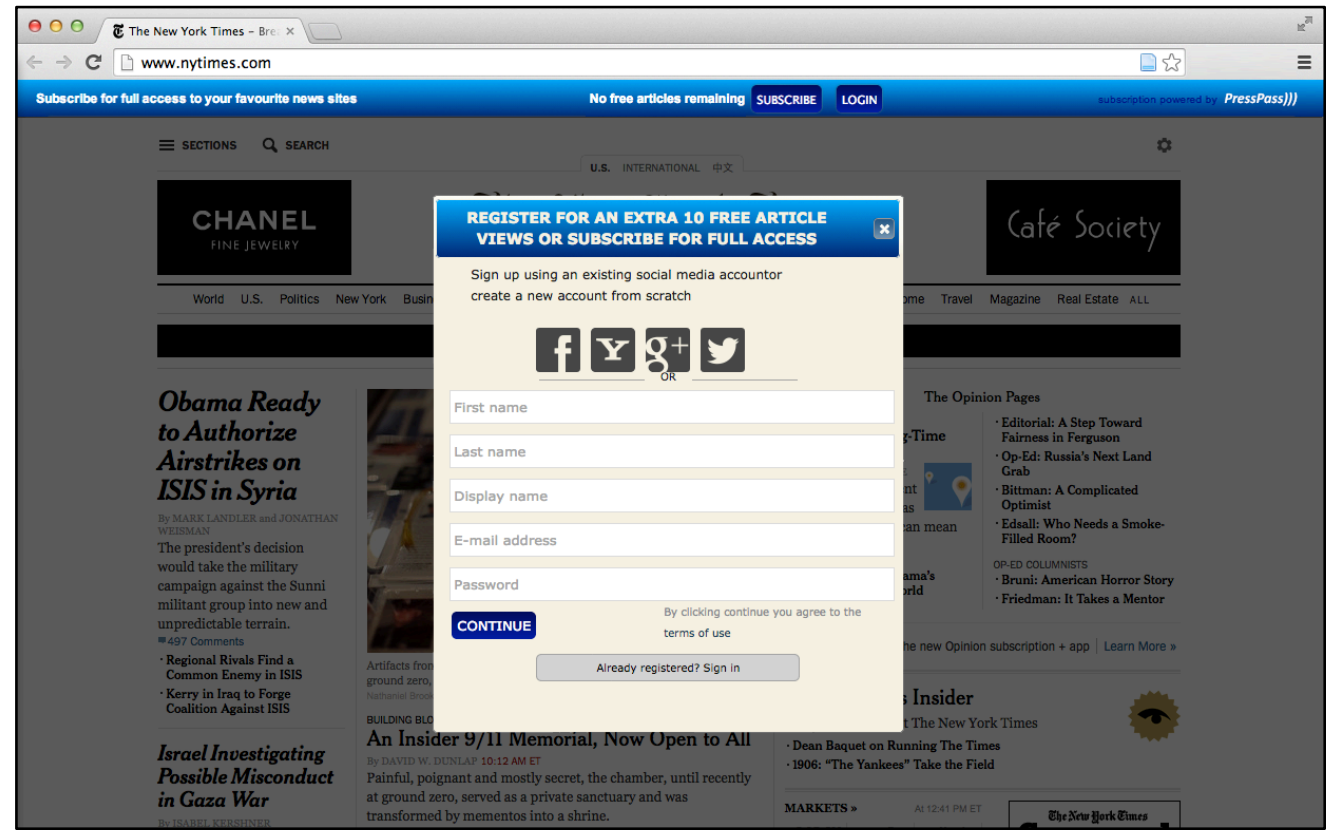

Figure 2. Step 2 of the PressPass user experience 
Step 3: After registering their details, readers choose from the following options (Figure $3)$.

- Free account: Readers register to receive additional free page views.

- Standalone subscription: Payment for full access to a single news website.

- National package: Payment for full access to all news partners within New Zealand.

- Global package: Payment for full access to all news partners in the world.

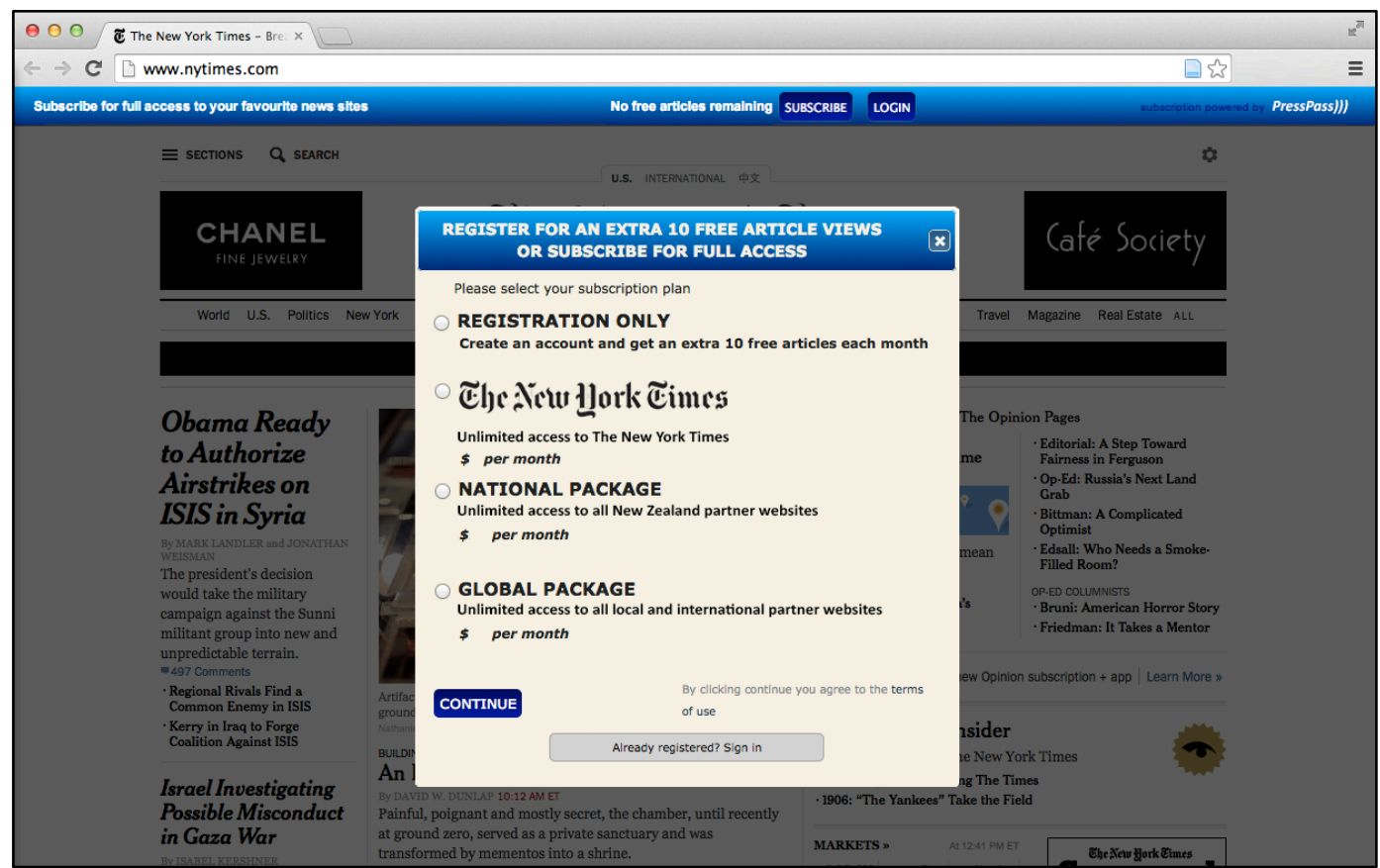

Figure 3. Step 3 of the PressPass user experience 
Step 4: The user then selects their payment method. They can use their credit card, PayPal account, internet banking account, or a subscription token ${ }^{2}$ (Figure 4).

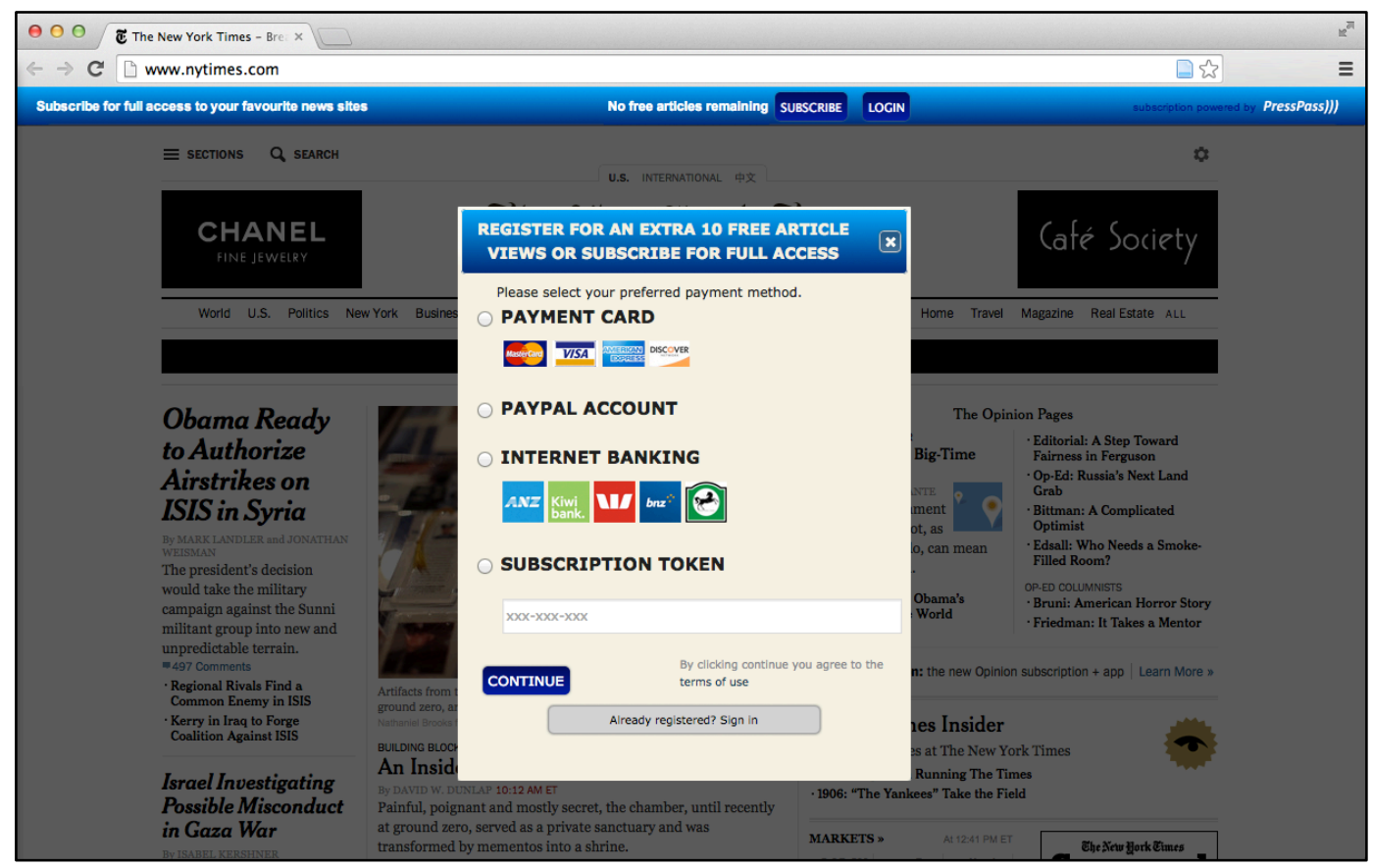

Figure 4. Step 4 of the PressPass user experience

Step 5: Once payment has been made, the user is logged in. If they have subscribed to the global package, they can use their universal login account to access premium content within any partner website (Figure 5).

\footnotetext{
${ }^{2}$ Subscription tokens can be purchased from selected retailers, or can be used by news organisations to provide their print subscribers with online access to their site.
} 


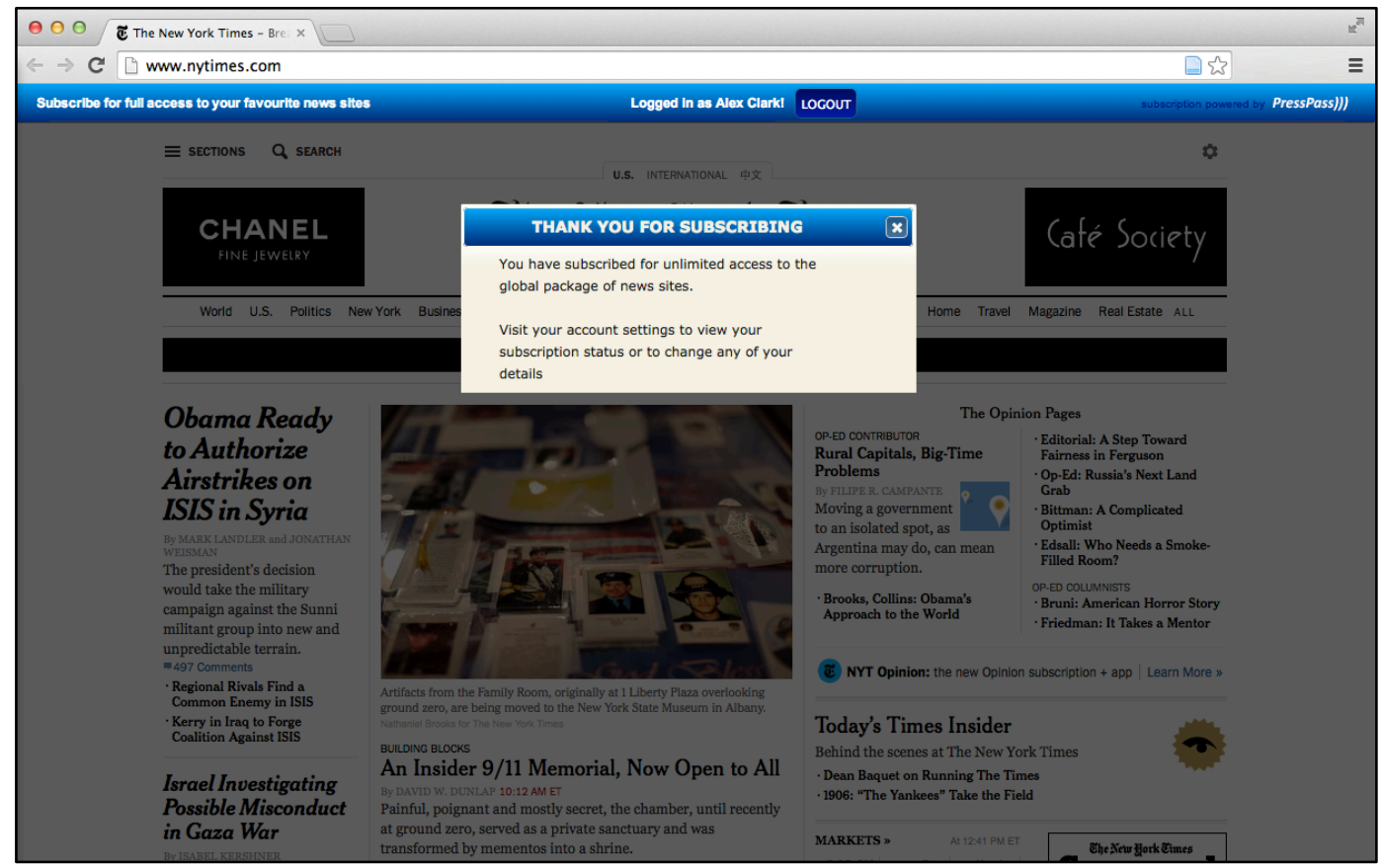

Figure 5. Step 5 of the PressPass user experience

\subsection{The problem and our solution}

The journalism community needs better monetisation strategies to fund the creation of news in an online environment. As audiences have shifted from print to online, print revenues have collapsed causing extensive disruption to the traditional business model of news organisations (Grueskin, Seave, \& Graves, 2011).

The primary business model pursued online has been to offer audiences free access, with revenue generated by online advertising (Siapera \& Veglis, 2012). When news organisations first launched websites, print revenue heavily subsidised the production costs of journalism disseminated online (Ibid). However, print revenues have since plummeted and online advertising revenues have not grown fast enough to fill the deficit (Ibid).

In the USA, it has been estimated that for every $\$ 1$ gained in online advertising revenue, $\$ 16$ in print advertising revenue is lost (The Pew Research Center, 2013). Ongoing revenue losses have resulted in American newsrooms being cut by 30\% since 2000 (The Pew Research Center, 2013). 
In New Zealand, it has been estimated that between \$18-19 in print advertising is lost for every \$1 gained in online advertising (Fahy, 2014). Falling revenues have resulted in thousands of New Zealand journalists losing their jobs over the past decade, making it difficult to sustain quality journalism (Myllylahti, 2013).

In response to the shortfalls of online advertising, news organisations throughout the world have begun adopting an online subscription model. Across the USA, more than $50 \%$ of daily news websites now charge for full access (Doctor, 2012). In New Zealand, the country's two largest news websites are currently assessing plans to charge for full access to their news content (Gray, 2015; Pullar-Strecker, 2014).

NZME, who owns nzherald.co.nz, is currently planning a metered paywall ${ }^{3}$ across their New Zealand digital brands (APN News and Media, 2014). Fairfax, who owns stuff.co.nz, is considering subscriptions for specialist news content, such as business articles (Pullar-Strecker, 2014).

Internationally, online subscriptions have had mixed success. While paywalls can provide a much needed revenue boost in the short term, they often fail to compensate for continued losses from print. Only a small proportion of readers ever pay for digital subscriptions, and growth rates quickly plateau after initial uptake.

The USA's largest provider of paywall technology, Press + , states that the average paywall converts 0.5 percent of unique visitors into subscribers, while high performing sites convert between one and two percent (Ellis, 2014). The New York Times has one of the world's most successful paywalls, yet converts just 1.5 percent of its online readers into digital subscribers and uptake is plateauing (The New York Times, 2014).

Our market research has revealed that consumers are far more likely to pay for an online subscription if access to several news websites is bundled into national and global packages. Not only does bundling increase the number of paying subscribers, it also

\footnotetext{
${ }^{3}$ A metered paywall allows readers to view a certain number of free articles each month, before access is restricted and the user is prompted to pay for a subscription.
} 
increases the amount that subscribers are willing to pay for news. For a detailed overview of our market research findings, please view Section 4.2.

The PressPass platform was created to enable national and global packages of news. By providing the technical infrastructure required for bundled packages, we hope to empower news organisations to generate new revenue streams that are not possible under a standalone subscription strategy.

\subsection{Our team}

Below is a brief overview of team members working on the PressPass platform. For a more in-depth overview of team activities and strategy, see Chapter 3.

\section{Alex Clark - Founder and CEO}

From 2007-9, Alex was the editor of Tearaway Magazine, a youth publication distributed throughout New Zealand to an audience of 155,000 readers. His employment coincided with the 2008 Financial Crisis, and he experienced first-hand the subsequent decline in print advertising that impacted the journalism industry.

Following his work at Tearaway, Alex completed a Bachelor of Arts in Media Studies and International Relations at Victoria University. His final year was spent on exchange at the University of Texas at Austin and the University of California, Berkeley. While on exchange he studied journalism, internet and communications law, entrepreneurship and media management.

Upon his return to New Zealand Alex worked as a research assistant within Victoria University's School of Information Management, exploring the future of digital media. He also worked as a research assistant within Victoria Business School, looking at innovation within Wellington's ICT industry, in a joint initiative with Grow Wellington and the Wellington City Council.

Alex enrolled in the Master of Advanced Technology Enterprise so that he could explore ways to improve funding for online journalism, within a unique context that combined academic research with the development of a practical solution. 
Core roles and responsibilities:

- Project coordination: Create wireframes and specification documents, to inform the development work undertaken by Paul and Puneeth.

- Market research: Develop survey questions, distribute survey to online respondents and conduct face-to-face interviews with consumers and publishers.

- Partnership development: Establish relationships with the journalism community, by meeting with news organisations and independent journalists.

- Media engagement: Share the PressPass project with the wider journalism community via media outlets.

- Financial modelling: Develop models and projections to assess the financial viability of specific monetisation strategies.

- Miscellaneous: Company incorporation, registration of trademarks, purchase of web domains, and other administrative tasks.

\section{Puneeth Anandaraj - Founding Developer}

Puneeth is a developer with experience using several programming languages and frameworks, including: ASP.NET, HTML5, CSS, JavaScript, jQuery, Xamarin, Phonegap, C\#, C++, MySQL, and Oracle.

Puneeth has a Bachelor of Technology from the Amrita School of Engineering in India. After graduation, he worked for Infosys Limited for 2 years in the Education and Research department, specialising in .NET technologies. His core work was to provide entry-level training to recent graduates, as well as training for professional developers who needed to improve their technical skills.

Puneeth moved to New Zealand in 2011, and completed a Post-graduate Diploma in Computer Science at Victoria University. Upon graduation he started working as a .NET developer for NorthSouth GIS, and worked with mobile technologies, JavaScript development, and security.

Puneeth enrolled in the Master of Advanced Technology Enterprise so that he could apply his technical skills within an entrepreneurial context. After assessing the seed 
projects presented to students, he chose the PressPass project as the best way to achieve his goals.

Core roles and responsibilities:

- Development of the PressPass ribbon using JQuery.

- Design of the code structure and skeleton, enabling easy integration with other systems and easy implementation of new features.

- Implementation of social sign-on, using third-party authentication through providers such as Facebook.

- Design of the UI layout.

\section{Paul Smith - Founding Developer}

Paul is an open source developer with experience using several programming languages and frameworks, including: JavaScript, jQuery, Meteor, MongoDB, HTML, CSS, MySQL, and Zend.

Paul has been working as a freelance developer since 2006, working on a variety of projects ranging from website development and network maintenance, through to the project management of a design and manufacturing platform for kitchen bench-tops.

In 2012 he was an early contributor to Loomio, an open source platform that assists groups and organisations with collaborative decision-making. He has a passion for community-based projects, and has been a core organiser of the Taranaki TimeBank initiative.

Prior to joining PressPass, Paul was working on an open source web platform for collecting, assessing, discussing and categorising news from multiple sources. He is passionate about improving the news ecosystem through digital technology, and joined the PressPass team to help further this goal.

Core roles and responsibilities:

- Design and implementation of the CSS (style and design aesthetics).

- Implementation of the user interface for registration and subscription. 
- Implementation of the cross-domain-storage feature, using Meteor and MongoDB.

- Management of the server-side code.

\subsection{Commercial potential}

The PressPass platform empowers news organisations to implement a global bundling strategy, which has the potential to significantly increase their revenues. Financial modelling shows that the New Zealand journalism industry could earn an estimated $\$ 28$ million by participating in a global subscription package. This is nearly four times as much as the revenue that could be generated under a standalone subscription strategy (see Section 10.2).

PressPass itself has the potential to be a highly successful commercial enterprise. Within the New Zealand market, financial modelling shows that the platform could earn between $\$ 3.2$ and $\$ 12.9$ million through its commission earned on subscription sales. If the platform expands within the Australian market, a low estimate suggests that around $\$ 16.6$ million could be generated in commission revenue. For the USA, a low estimate indicates that commission revenue could be approximately $\$ 255$ million each year (see Section 10.3).

Due to the lightweight nature of the PressPass platform, infrastructure costs are projected to be low. An estimate calculated by Puneeth indicates that hosting could cost less than \$2,000 per month, even at extremely high levels of uptake. A lightweight platform also means that employment costs will likely be low for development and maintenance, especially during the early stages of the project.

The large profit margin between potential revenue and costs, puts PressPass in a healthy position to seek investment. However, as outlined in Section 9.1, it is important for the team to develop firmer commitments from potential publishing partners to maximise the platform's chance of success. 


\section{CHAPTER 2: PROJECT BACKGROUND}

PressPass was developed within the Master of Advanced Technology Enterprise (MATE) at Victoria University. MATE is an interdisciplinary programme that explores the relationship between academic research and commercial product development. At the start of the programme, students are presented with a selection of seed projects that focus on commercialising academic research. During a four-week introductory course, students select a project and establish teams that utilise their disciplinary expertise. Students then undertake activities essential to the success of their enterprise, such as market validation, product development and building customer relationships. Below is a summary of the formative stages that led to development of the PressPass platform.

\subsection{Project seed: 'Digital Commons or Digital Enclosures'}

Prior to the MATE programme, Alex Clark was a research assistant within the School of Information Management working on a project entitled, Digital Commons or Digital Enclosures: The Future of Online Content Distribution. Initiated in August 2013, the project involved interviews with journalists, musicians, authors and publishers, and explored the ways that creators chose to share their content online. The key focus was to better understand the factors that influence whether content is made freely available, or put behind restrictive barriers.

The research revealed a delicate tension within the creative industries: creators expressed a strong desire for their work to be openly accessible to as many people as possible, yet the process of creation has a range of associated costs that need to be funded. Within the creative industries there is widespread concern that online funding strategies are overly restrictive, impacting the ability to connect with audiences. Conversely, many funding strategies predicated on free online access are unable to fund creation.

Many interviewees expressed a strong interest in finding a middle ground between free open access and overly restrictive monetisation strategies. Repeatedly, interviewees pointed to the model of 'pay-once-access-all' bundling as a promising solution, citing 
the success of prominent industry examples such as Spotify and Netflix. Under these models, users pay one monthly fee for unlimited access to all content within the media ecosystem. Creators are then rewarded with royalty payments, allocated according to levels of audience engagement.

Interviewees also discussed a wide range of alternative funding strategies for online content. Despite the variety of ideas, there was widespread confusion as to which strategies were best suited for each type of content. This was compounded by a lack of qualitative data, particularly from comprehensive studies that assessed multiple strategies side-by-side. Furthermore, the technical infrastructure to enable these strategies was often limited or non-existent. The Digital Commons project highlighted the need for further research, so that better strategies could be identified and a solution built.

\subsection{Project proposal: 'News, Renewed'}

In December 2013, Alex Clark applied for the Master of Advanced Technology Enterprise, and submitted a proposal to expand upon the Digital Commons project. The proposal was entitled News, Renewed, and focused on improving the way that journalism is funded online. The journalism industry was chosen as a focus, due to the significant financial struggles being experienced by news organisations throughout the world (see Section 1.2).

The proposal was centred around two key objectives: to conduct a comparative analysis of multiple online funding strategies, and to build an online platform that enables the best funding strategy to be easily implemented by the journalism community. Puneeth Anandaraj was also applying for the MATE programme, and met with Alex several times during December to discuss the potential of the News, Renewed project.

\subsection{Project initiation}

On the $27^{\text {th }}$ of January 2014, Puneeth and Alex began the 4-week introductory programme for the Master of Advanced Technology Enterprise. During this period, they formally established a team around the News, Renewed project. After developing an 
enterprise plan outlining key activities and milestones, they began development of their enterprise in March 2014.

The following chapters summarise the enterprise activities undertaken during the first 12 months of development, as well as the resulting outcomes and strategies. Each chapter focuses on a particular aspect of enterprise development, as outlined below:

- Chapter 3: Team Development

- Chapter 4: Market Research, Consumers

- Chapter 5: Market Research, News Organisations

- Chapter 6: Product Development

- Chapter 7: Publicity

- Chapter 8: Legal and Regulatory

- Chapter 9: Funding and investment

- Chapter 10: Financial analysis 


\section{CHAPTER 3: TEAM DEVELOPMENT}

\subsection{Timeline}

Table 1. Team development: Timeline of key milestones and activities

\begin{tabular}{|c|c|}
\hline DATE & ACTIVITIES \\
\hline November 2013 & $\begin{array}{l}\text { Alex advertises the News, Renewed project to computer science } \\
\text { students at Victoria University and to the wider start-up community. }\end{array}$ \\
\hline December 2013 & $\begin{array}{l}\text { Puneeth Anandaraj and Alex Clark meet during the MATE application } \\
\text { process, and discuss the potential of the News, Renewed project. }\end{array}$ \\
\hline 17 January 2014 & $\begin{array}{l}\text { Alex meets with a web solutions delivery manager at 3Months } \\
\text { (development company), to discuss components of PressPass that } \\
\text { could be outsourced. }\end{array}$ \\
\hline February 2014 & $\begin{array}{l}\text { Puneeth Anandaraj and Alex Clark form an official team within the } \\
\text { MATE programme during ATEN501. }\end{array}$ \\
\hline 6 March 2014 & $\begin{array}{l}\text { Weekly team mentoring sessions begin with Michael Elwood-Smith, a } \\
\text { business strategist with close ties to Wellington's start-up } \\
\text { community. }\end{array}$ \\
\hline 7 March 2014 & $\begin{array}{l}\text { Alex meets with two lecturers within the computer science } \\
\text { department, to discuss the possibility of aligning PressPass } \\
\text { development work with course outcomes. }\end{array}$ \\
\hline 2014 & $\begin{array}{l}\text { Puneeth visits India, and during his trip meets with acquaintances } \\
\text { within the IT community to discuss the possibility of outsourcing } \\
\text { some components of PressPass development. }\end{array}$ \\
\hline 6 April 2014 & $\begin{array}{l}\text { Paul Smith, a developer from New Plymouth, reaches out to Alex } \\
\text { Clark via email after completing the consumer survey. He expresses } \\
\text { an interest in contributing to the PressPass project. }\end{array}$ \\
\hline April to May 2014 & Paul, Alex and Puneeth discuss the PressPass project via Skype. \\
\hline 20 June 2014 & $\begin{array}{l}\text { Paul Smith begins working with Puneeth on the source code, } \\
\text { contributing approximately } 10-20 \text { hours per week from this date } \\
\text { onwards. }\end{array}$ \\
\hline 4 July 2014 & $\begin{array}{l}\text { Alex Clark and Puneeth Anandaraj sign the PressPass team } \\
\text { agreement. }\end{array}$ \\
\hline 16 July 2014 & $\begin{array}{l}\text { Alex meets with a business development manager at Catalyst IT (open } \\
\text { source development company), to discuss components of PressPass } \\
\text { that could be outsourced. }\end{array}$ \\
\hline 15 August 2014 & Paul Smith signs the PressPass team agreement. \\
\hline 16 January 2014 & Puneeth renews the PressPass team agreement. \\
\hline 15 February 2014 & Paul Smith renews the PressPass team agreement. \\
\hline
\end{tabular}




\subsection{Team development: outcomes and strategy}

High-level summary:

- PressPass' team strategy is focused on building its internal capacity for core development tasks.

- All team members have signed a team agreement, which is reviewed every 6 months.

- Some outsourcing of development work may be considered, but only in situations where there is a clear advantage over internal capacity building.

- JavaScript has been chosen as the core development language, and future team members will need to be proficient in its usage.

- Our next major addition to the team will be a User Experience design to refine and enhance platform functionality and design (aim: by June 2015).

- Once news partnerships are established, we will start hiring our customer support team for readers and news organisations.

Alex first began the search for team members in November 2013, when he sent out requests to a database of computer science students at Victoria University. While he did receive some interest from several students, whom he met with on several occasions, it was difficult to find individuals with suitable skillsets and with an academic focus that aligned with the project. Alex also advertised in different forums associated with the Lightning Lab accelerator in Wellington and The Icehouse incubator in Auckland, and had conversations with several developers. While several individuals showed an interest in the concept, they were not willing to work without income.

Alex and Puneeth met in December 2014, to discuss the PressPass project. They also met with some of the computer science students and individuals from the start-up community who showed an initial interest in the project. Early meetings were focused on choosing a development language, and sketching up initial wireframes and specifications. Each potential team member had a slightly different development background, working with either open source or proprietary frameworks, as well as a variety of programming languages. 
Initial considerations explored the possibility of each team member programming a platform module in their own preferred language, with APIs (application programming interfaces) to form interconnections between each component. Module based development was soon dismissed as impractical, and instead it was decided to programme using JavaScript. While it JavaScript was not the core strength of every potential developer, it was a language that everyone had at least some proficiency in. It was also decided that Wellington's JavaScript community was stronger than for proprietary frameworks such as Microsoft's .NET, which would make it easier to build upon the team in future.

Within a few weeks most Victoria students indicated that it would not be possible to continue work on the project, largely due to academic commitments and the lack of a direct link to their own research. Puneeth, however, maintained a strong interest in the project and formally joined the team in February as part of the Master of Advanced Technology. Once the introductory coursework requirements for the MATE programme had been completed, Alex and Puneeth began work on the PressPass project in March. They also began weekly mentoring sessions with Michael Elwood-Smith, who worked with the PressPass team throughout the year to help refine their enterprise plan and development strategy.

Outside of the MATE programme, Alex explored ways to expand the development capacity of the project. In January he visited the development company, 3Months, to discuss the possibility of outsourcing some development tasks. In July, he met with the open source development company, Catalyst IT, to explore the same proposition. At this stage, Alex was hoping that the companies would be interested in doing some development work in return for equity or convertible notes. Each company, however, was not prepared to undertake such work due to the early stage of the project and their lack of available resources. Puneeth also explored the possibility of outsourcing, during a trip to India in May 2014, discussing the possibility with acquaintances within the IT community.

The advantages and disadvantages of outsourcing were discussed at length with our team mentor, Michael Elwood-Smith, as well as other members of Wellington's start-up community. It was advised that our focus should be on building the internal capacity of 
our team, and to only consider outsourcing in situations where it would provide a clear advantage. For example, if there was a one-off technical solution that required extremely specialised expertise, or if the team needed to meet an urgent deadline that would be impossible to meet internally. Furthermore, it was recommended that any outsourcing should be limited to New Zealand companies with direct accountability.

Each advisor emphasised the importance of having any outsourced developers strongly invested in the success of the project. Some recommended using equity as a motivating factor. Others advised against equity, saying it was better to maintain ownership and control, while achieving dedication to the project through other structural approaches. For example, contractual agreements could be created to include a buy-out clause, where the external team could eventually be integrated internally. Alternatively, a proportion of payment could be reserved for the ongoing success and maintenance of the features developed.

Alex and Puneeth are still open to the possibility of outsourcing for some tasks, however, their core focus is to develop the internal capacity of their team. Any outsourcing undertaken will be carefully considered, only in situations where it provides us with a clear advantage over internal capacity building, and with a development team who is invested in the success of our project.

Another activity that Alex undertook to expand the team, was to meet with two lecturers within the computer science department at Victoria University. Alex hoped to identify a way to align PressPass development with academic outcomes for undergraduate and graduate students. While there was some interest in the idea, the lecturers highlighted that it would be difficult to align development with course outcomes due to the specific goals of each course and research project.

In April, a developer named Paul Smith reached out to Alex via email. Paul had completed Alex's consumer survey online, and was interested in learning more about the News, Renewed project. An open source developer from New Plymouth, Paul had been working on his own news platform for several months. He was passionate about improving online journalism, and wanted to explore ways in which he could contribute to the PressPass platform. Throughout April and May, Puneeth and Alex had regular 
discussions with Paul. During these calls they learnt more about each other's background, shared information about existing code and specifications, and discussed Paul's availability.

On the $20^{\text {th }}$ of June 2014, Paul joined the team and began contributing approximately 10-20 hours each week. Over the following months, Puneeth and Paul worked together to develop the PressPass prototype (see Chapter 6 for further details about the development process). Between them, they found that their complementary skillsets allowed them to develop all of the core features of the PressPass prototype.

As development of the PressPass platform progressed, it became increasingly important to have a team agreement that outlined roles and mutual expectations about the project. The team agreement was signed by each team member over July and August, and formed a foundation upon which the team could explore the potential of the PressPass project. Further details about the team agreement can be found within our legal section, in Chapter 8.

For the next stages of development, the team has identified that a user experience designer will be useful to further refine the design and functionality of the PressPass platform during preparation for launch. Aside from product development, other roles relevant to launch will be need to be filled. Once firm partnerships have been established with news organisations, the team will begin looking at ways to expand its capability, particularly in regards to customer support for readers and publishers. Some positions will need to be part of our core team, such as customer support for publishers, particularly as we expand the number of news partners. Other roles could potentially be outsourced, such as call centre support for readers, ideally within New Zealand.

Other core roles that advisors have recommended, include: Chief Operating Officer, Chief Financial Officer, Chief Marketing Officer, and Chief Sales Officer. The team has been advised to only expand as each role becomes necessary, and only when suitable resources are available. As such, the need for team expansion will be assessed on an ongoing basis. 


\section{CHAPTER 4: MARKET RESEARCH, CONSUMERS}

\subsection{Timeline}

Table 2. Market research, consumers: Timeline of key milestones and activities

\begin{tabular}{|l|l|}
\hline DATE & ACTIVITIES \\
\hline 3-7 March 2014 & $\begin{array}{l}\text { Alex completes first draft of consumer survey, with feedback } \\
\text { and input from Puneeth and Michael Elwood-Smith. }\end{array}$ \\
\hline 10-21 March 2014 & $\begin{array}{l}\text { Alex conducts initial testing of consumer survey, with students, } \\
\text { academics, and people from within Wellington's start-up } \\
\text { community. }\end{array}$ \\
\hline 24 March to 13 April & $\begin{array}{l}\text { Alex launches the online survey, and distributes with the } \\
\text { assistance of Puneeth. Alex conducts face-to-face interviews. }\end{array}$ \\
\hline 14-18 April 2014 & Alex undertakes preliminary data analysis. \\
\hline 19-30 May 2014 & Alex completes full data analysis. \\
\hline
\end{tabular}

\subsection{Survey findings}

High-level summary:

- Bundling emerged as the most popular monetisation strategy amongst consumers.

○ Overall, only $0.5 \%$ of consumers said that they would definitely purchase a subscription to a single New Zealand news website.

$\circ$ For a national package of all news sites, $1.4 \%$ (2.8x increase).

○ For a global package of all news sites, $6.6 \%$ (13x increase).

○ For a global news package bundled with music and video, $12.5 \%(25 \mathrm{x}$ increase).

- 18-30 year olds are the least likely age group to purchase a single New Zealand news website, however they are the most likely to purchase a global package of news.

- Nobody between the ages of 18-30 said that they would definitely purchase a subscription to a single New Zealand news website. 
○ $11.9 \%$ said that they would definitely purchase a global package of news websites (1.8x overall average).

- The perceived quality of journalism is one of the most important factors when consumers choose whether or not to pay for news.

The team's survey of 457 newsreaders was undertaken from March-April 2014, and assessed people's willingness to pay for ten online monetisation strategies, as detailed in Table 3.

Table 3. Monetisation strategies explored within survey

\begin{tabular}{|c|c|}
\hline STRATEGY & DESCRIPTION \\
\hline Pay-per-article & A small fee to access each article. \\
\hline Standalone subscription & $\begin{array}{l}\text { A monthly subscription for unlimited access to one New } \\
\text { Zealand news website. }\end{array}$ \\
\hline National package & $\begin{array}{l}\text { A monthly subscription for access to all news websites in New } \\
\text { Zealand. }\end{array}$ \\
\hline Global package & $\begin{array}{l}\text { A monthly subscription for access to all news websites in the } \\
\text { world. }\end{array}$ \\
\hline $\begin{array}{l}\text { News }+ \text { multimedia } \\
\text { package }\end{array}$ & $\begin{array}{l}\text { A monthly subscription for access to all news websites in the } \\
\text { world, as well as music, television and movies. }\end{array}$ \\
\hline Crowdfunding & $\begin{array}{l}\text { Journalists pitch story ideas, and readers donate funds } \\
\text { towards the creation of a specific story. }\end{array}$ \\
\hline Donations & $\begin{array}{l}\text { Readers donate funds to a particular journalist or news } \\
\text { organisation to support their operations. }\end{array}$ \\
\hline Mobile application & $\begin{array}{l}\text { A monthly subscription for access to a mobile news } \\
\text { application, available on phones or tablets. }\end{array}$ \\
\hline Fee to remove advertising & $\begin{array}{l}\text { A monthly subscription to remove advertising from news } \\
\text { websites. }\end{array}$ \\
\hline Premium content & $\begin{array}{l}\text { A 'freemium' model, where general news articles remain free } \\
\text { but readers pay a monthly fee for access to premium stories. }\end{array}$ \\
\hline
\end{tabular}

The survey findings revealed that consumers' willingness to pay for news increases considerably when readers can subscribe to a package of content from multiple providers (Figure 6). If news organisations around the world participate in subscription packages, they will significantly increase the number of paying subscribers. 


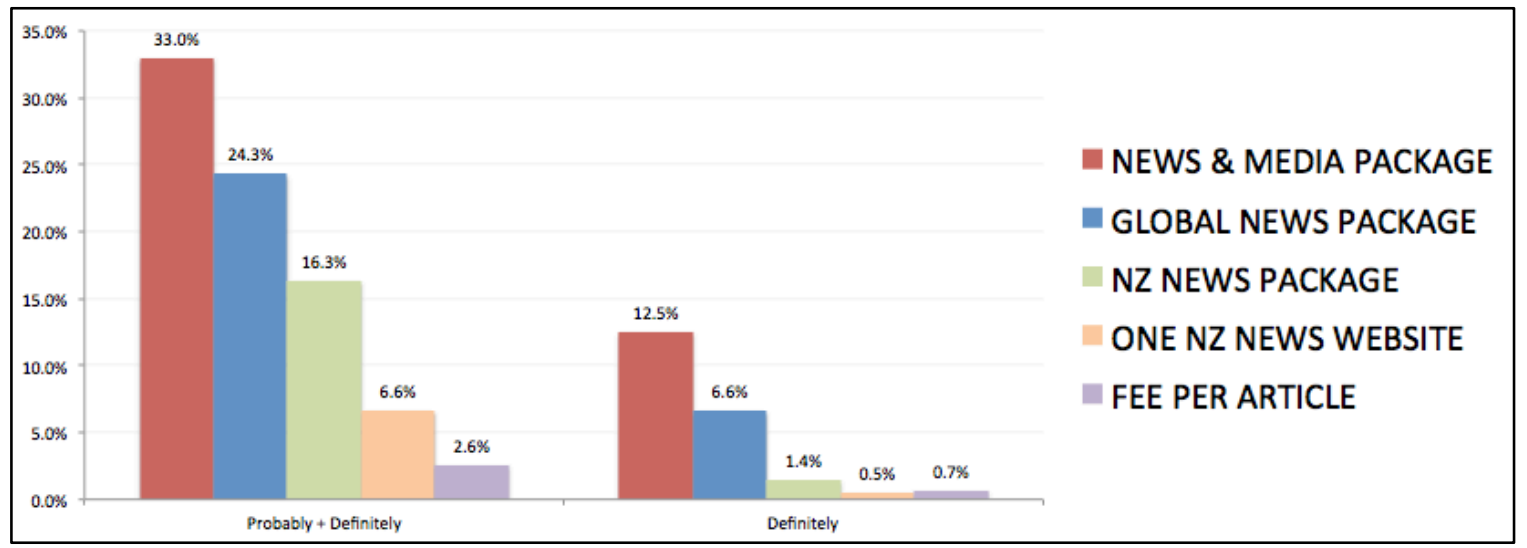

Figure 6. Willingness to pay for news at different levels of packaging

Overall, the least popular payment option was paying a fee to access each article. An aggregate of $2.6 \%$ of respondents said that they would probably or definitely pay for news under this model, while only $0.7 \%$ said that they would definitely pay.

Slightly ahead of payment-per-article was the option of a standalone subscription, for unlimited access to one New Zealand news website by itself. An aggregate of $6.6 \%$ of respondents said that they would probably or definitely pay for this option, while only $0.5 \%$ said definitely.

The popularity of a national news package, containing all journalism websites in New Zealand was substantially more popular than a standalone subscription. An aggregate of $16.3 \%$ of respondents said that they would probably or definitely pay for this option, while $1.4 \%$ said definitely.

A global news package was the most popular of all news-only options presented to respondents. An aggregate of $24.3 \%$ of respondents said that they would probably or definitely pay for this option, while $6.6 \%$ said definitely.

Respondents were most willing to pay for a global multimedia package, containing news, music, television and movies. An aggregate of 33\% of respondents said that they would probably or definitely pay for this option, while $12.5 \%$ said definitely. 
Our survey also revealed that bundling significantly increases the propensity to pay within 18-30 year olds (see Figure 7). Under a standalone subscription strategy, 18-30 year olds are the least likely demographic to purchase news. Out of 134 respondents, nobody said that they would definitely purchase one New Zealand news website by itself.

Under a bundled subscription strategy, however, 18-30 year olds become the most likely age group to purchase news. For a global news package, $11.9 \%$ said that they would definitely pay. For a news and multimedia package, $23 \%$ said that they would definitely pay. For each of these packages, 18-30 years are nearly twice as willing to definitely pay than the overall average.

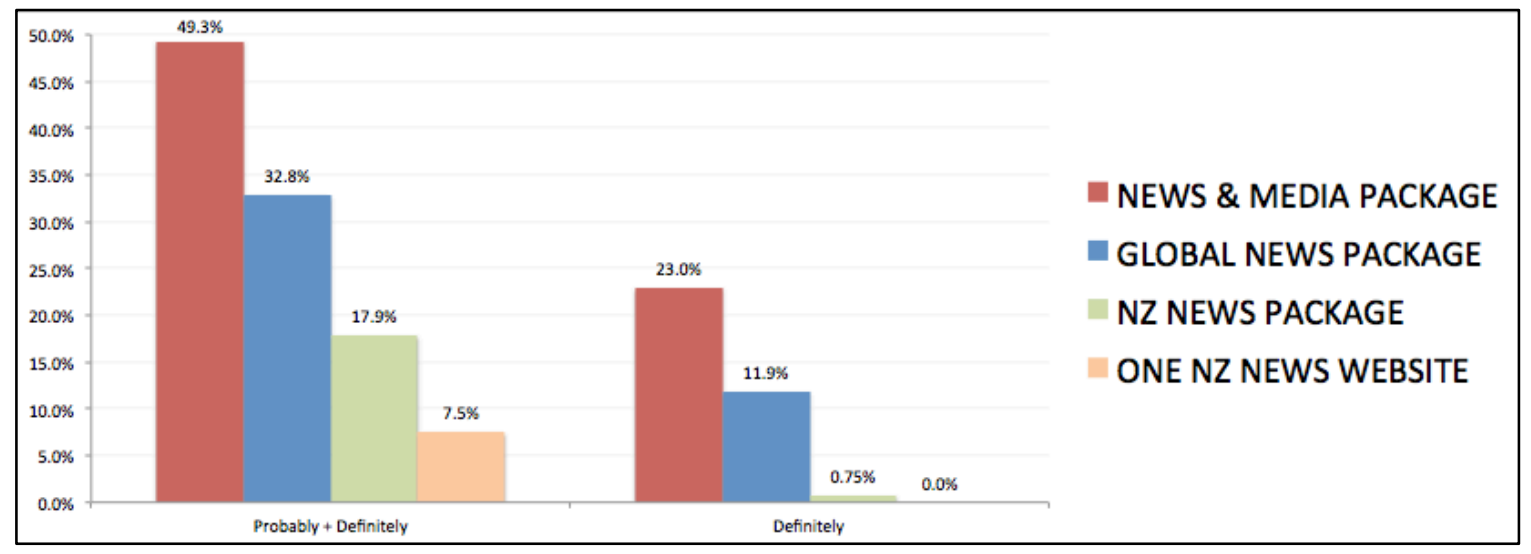

Figure 7. Willingness to pay, 18-30 year olds

We also looked at consumer's willingness to pay for news under alternative monetisation models. Multimedia bundling was more popular than all other strategies explored within the survey, and emerged as a clear winner, closely followed by global news bundling (see Figure 8). 


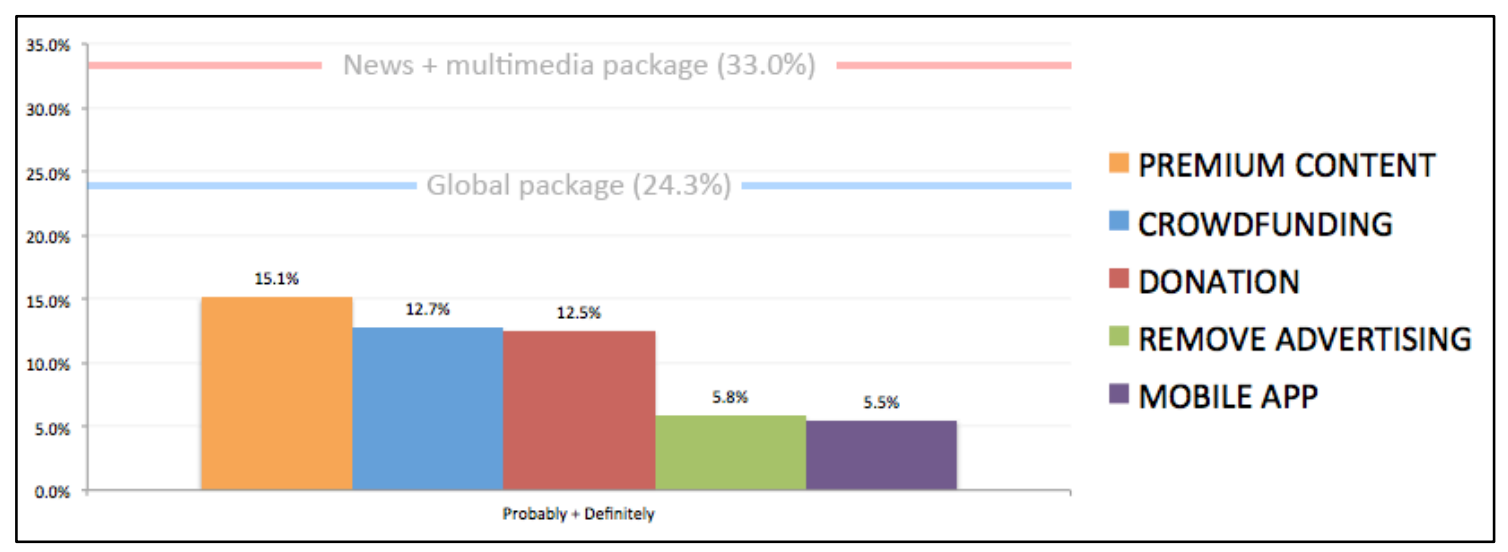

Figure 8. Willingness to pay for news under alternative funding strategies

Out of the alternative strategies explored, a premium content strategy was most popular, with $15.1 \%$ of respondents indicating that they would probably or definitely purchase. Qualitatively, many respondents expressed that they would not pay for journalism unless the content was of high quality. This finding highlights the importance of producing premium journalism, regardless of the funding strategy pursued.

Donations (12.7\%) and crowdfunding (12.5\%) were also popular among respondents, and should be considered as strong alternatives for raising additional revenue. Qualitatively, there was widespread enthusiasm for the direct support of journalism through voluntary donations. Some respondents, however, expressed concerns that having writers beholden to donations could undermine the independence of journalism.

A subscription fee to remove advertising (5.8\%) was one of the least popular funding methods. While it may appeal to a niche category of readers, it is unlikely to provide substantial revenue. Furthermore, some respondents indicated that they enjoy advertisements when they promote products or services they are interested in. Others highlighted that they simply use products such as AdBlock ${ }^{4}$ to achieve the same outcome for free.

${ }^{4}$ AdBlock is a free web browser plugin that allows users to block advertising within websites. 
A subscription to a mobile news app (5.5\%) was the least popular alternative strategy. In hindsight, this survey question was inadequate to properly explore this strategy. The phrasing only explored respondents' general willingness to pay, without specific reference to features and functionality. There are a wide variety of mobile news applications, each with their own unique functionality, and further research is needed to assess willingness to pay within this category.

\subsection{Identifying the best funding strategy for PressPass}

The survey findings directly influenced the registration options selected for the PressPass platform. Below is a brief overview of each option, as well as its role within PressPass' overall funding strategy. Note that registration options could be dropped or added prior to launch, depending on negotiations with publishers. Furthermore, some options could be added after launch. In particular, a global multimedia package could be added if negotiations are successful with online subscription services such as Netflix and Spotify (see Section 4.4 for further details).

\section{Registration options}

When registering, users can choose to either have a free account, or pay for a subscription to one publication, a national package, or a global package. Each of these options has strategic importance to news organisations and the success of PressPass.

1) Free account: A free account brings readers into the sales pipeline, providing an opportunity to nurture a direct relationship while promoting the benefits of a subscription. Registration details also provide valuable demographic insights, allowing websites to earn more revenue from display advertising.

2) Standalone subscription: The option to subscribe to a single news site allows publishers to maintain a standalone strategy, while experimenting with a bundled ecosystem. Furthermore, some readers would prefer a standalone subscription. Within our survey, $14 \%$ of respondents preferred a single site over a global package, mostly readers from older demographics. 
3) National PressPass: Our survey revealed that $15 \%$ of respondents would prefer a national package over a global package. By providing a national package as an option, we will be able to more effectively cater to consumer preferences and maximise the number of successful conversions.

4) Global PressPass: The global package was by far the most popular news option within our survey, and has the highest potential for success. The number of respondents willing to definitely pay for a global package was 13 times greater than a standalone subscription, and nearly five times greater than a national package. 


\subsection{Customer acquisition strategy}

High-level summary:

- Integration with existing news websites provides PressPass with a direct marketing channel to connect with large marketplaces of loyal news consumers.

- PressPass' free registration option is an important lead generator for connecting with news consumers, who can be upsold to a national or global package through targeted marketing campaigns.

- News partners have a direct financial incentive to promote the PressPass platform, due to a conversion commission where they receive $20 \%$ of revenue from each customer who subscribes to a package via their website.

- $\quad$ PressPass will pursue mutually beneficial partnerships with ISPs and media streaming services, with cross-promotional deals to bundle PressPass with their offerings.

- PressPass will promote its service via traditional outlets such as print, radio and television, as well as online via Google AdWords, Facebook Ads, and using techniques such as SEO and content marketing.

- PressPass aims to convert a minimum of $2.5 \%$ of readers within 6 months, $5 \%$ within 12 months, and $10 \%$ within 24 months.

By integrating with existing news websites, PressPass gains a direct marketing channel to connect with large audiences of loyal readers. Whenever a reader visits a partner news website, the PressPass platform will be prominently visible along the top of the webpage. Furthermore, as soon as a reader reaches their monthly limit of free articles, they will be prompted to create a subscription account using the PressPass platform.

At this stage, readers may choose to create a free account for additional page views. A free account brings readers into the sales pipeline, providing PressPass with a valuable opportunity to implement a targeted marketing campaign based on each user's unique demographic traits. This is likely to be one of the platform's most prominent customer acquisition strategies.

News partners will also have financial incentives to convert their readers into paying subscribers. The most direct incentive is a $20 \%$ conversion commission, paid to each news partner whenever they convert a reader to the national or global package. News 
partners also receive royalty payments whenever a subscriber visits their website, creating further inventive to maximise the number of conversions. (See Section 10.1 for further details).

Once partnerships have been established with news organisations, PressPass will seek to develop mutually beneficial partnerships with other online media providers such as Spotify, Pandora, Netflix, Lightbox and Neon. By bundling with music and video content, PressPass will be able to further increase the number of readers willing to pay for news, particularly amongst the 18-30 year old demographic. For music and video providers, PressPass will be able to provide a direct channel to older demographics that are difficult to reach with online streaming services.

PressPass is also considering partnerships with Internet Service Providers (ISP) such as Spark, Slingshot and Orcon. There are a number of ways that these partnerships could function. One, is to have ISP customers receive a free PressPass account when paying for a particular internet plan. This approach is similar to Spark's partnership with Spotify, where some mobile plans include a free Spotify subscription. Other possibilities include a free trial, or a promotional discount code offered to ISP customers.

In addition to the customer acquisition strategies outlined above, PressPass plans to run a promotional campaign across print, radio, television and online. Online strategies include a the use of Google AdWords, Facebook Ads, and mobile display advertising, as well as SEO optimisation and content marketing.

Customer acquisition targets:

$-2.5 \%$ of readers within 6 months

$-5 \%$ of readers within 12 months

$-10 \%$ of readers within 24 months 


\subsection{Target consumers}

High-level summary:

- $\quad$ PressPass' target consumers include

○ $\quad 18-30$ year-olds

$\circ \quad$ Readers with an income above $\$ 80,000$

○ Readers who visit more than four news websites each week

○ Readers who visit news websites several times per day

○ Readers who mostly visit international news websites

- Readers with an interest in finance, business and politics

Survey data revealed that there are a number of demographic traits that correlate with an increased propensity to pay for a global package. By identifying these traits, PressPass will be able to better target consumers with tailored promotional campaigns that maximise their rate of conversion.

\section{Age}

Readers between the ages of 18 and 30 are most likely to pay for a global news package, and will provide the highest rate on return when targeted with marketing campaigns (Figure 9).

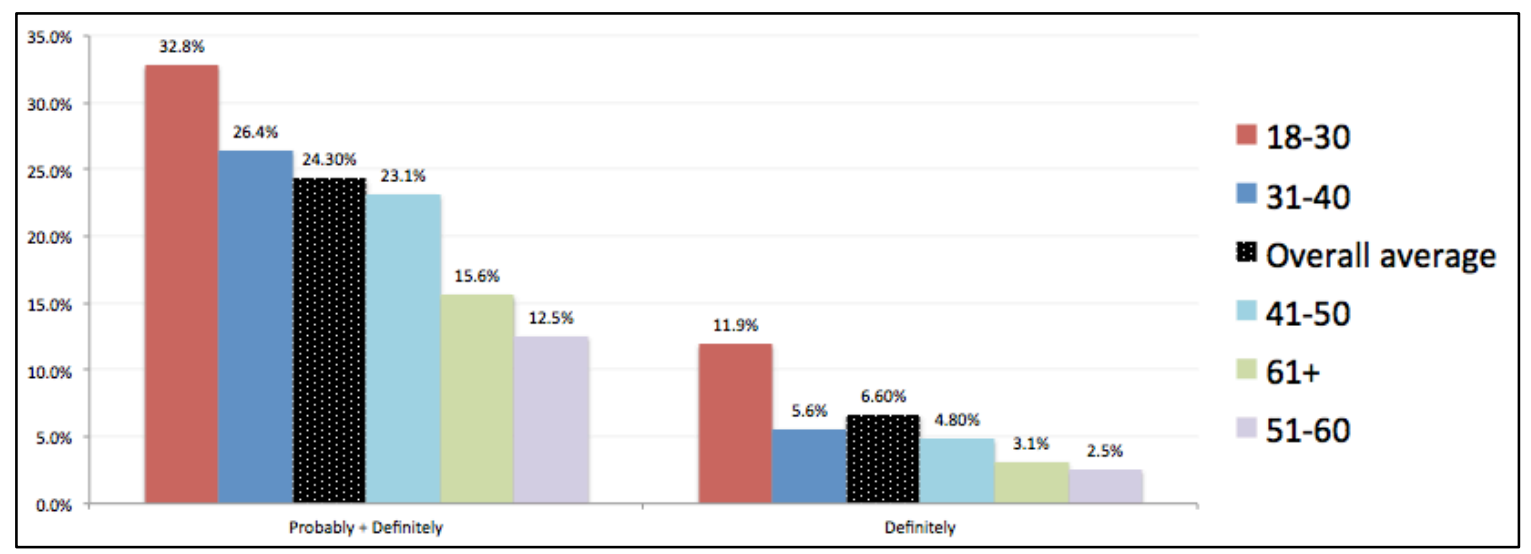

Figure 9. Willingness to pay for a global news package (age) 


\section{Income}

Those with an income over $\$ 80,000$ are most likely to probably or definitely purchase a global package. This is presumably due to their higher disposable income. Interestingly, those with an income between $\$ 15-40,000$ are the most likely to definitely purchase a global package. This may be due to this income group containing a higher proportion of respondents within the 18-30 year old demographic (Figure 10).

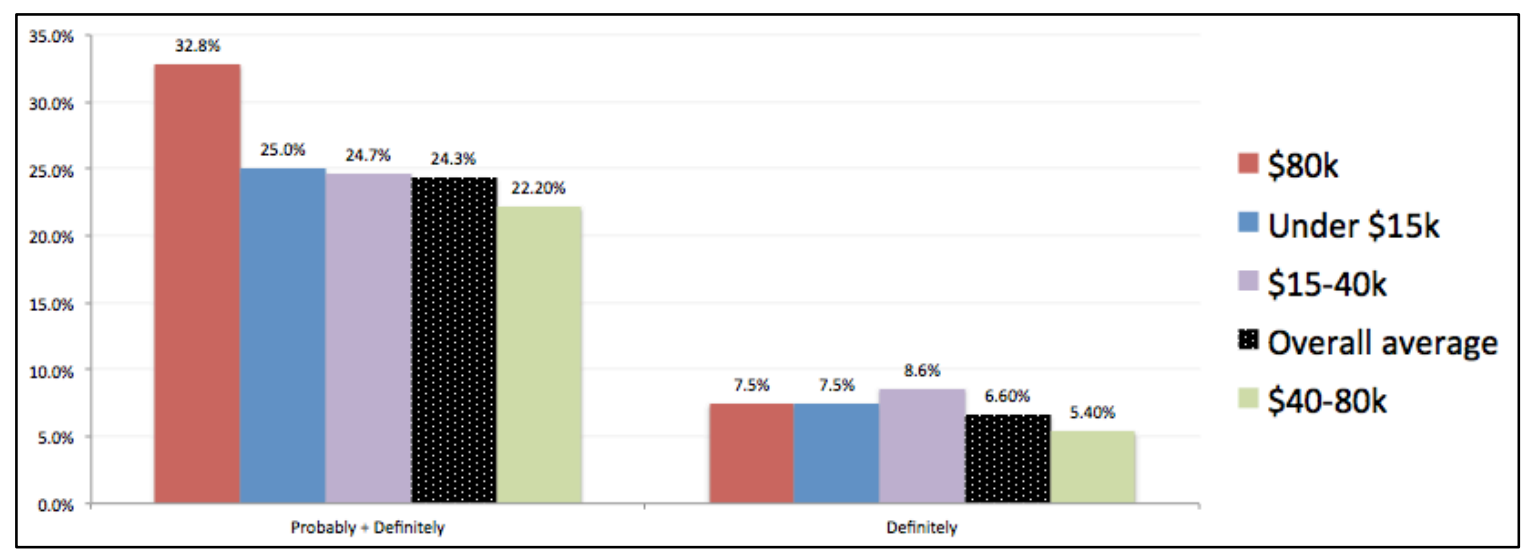

Figure 10. Willingness to pay for a global news package (income)

\section{Engagement with news websites}

Consumers who visit more than 10 news websites each week are more than twice as likely to say that they'd definitely purchase a global package, very closely followed those who visit 4-10 websites per month (Figure 11). Consumer's propensity to pay is also highest if they visit news sites several times per day (Figure 12), and if they spend most of their time reading international news websites (Figure 13). Those consumers who are most interested in business and politics, also have a substantially higher propensity to pay than those who prefer other topics (Figure 14). 


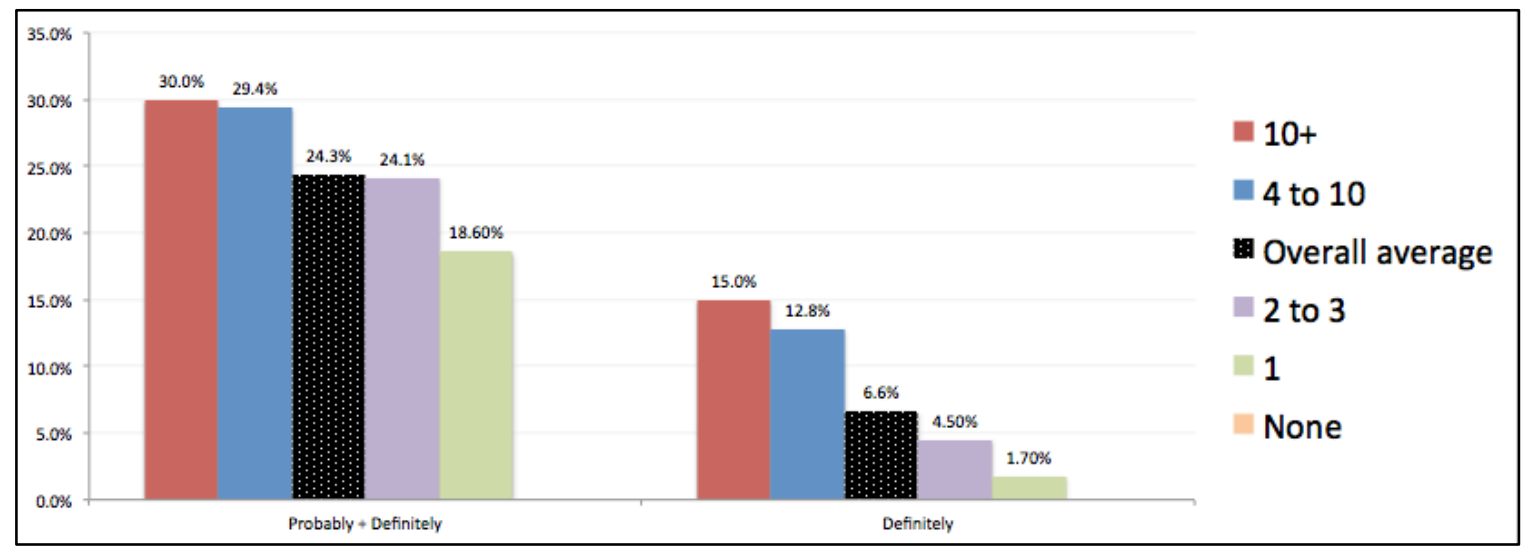

Figure 11. Willingness to pay for a global news package (number of news sites visited each week)

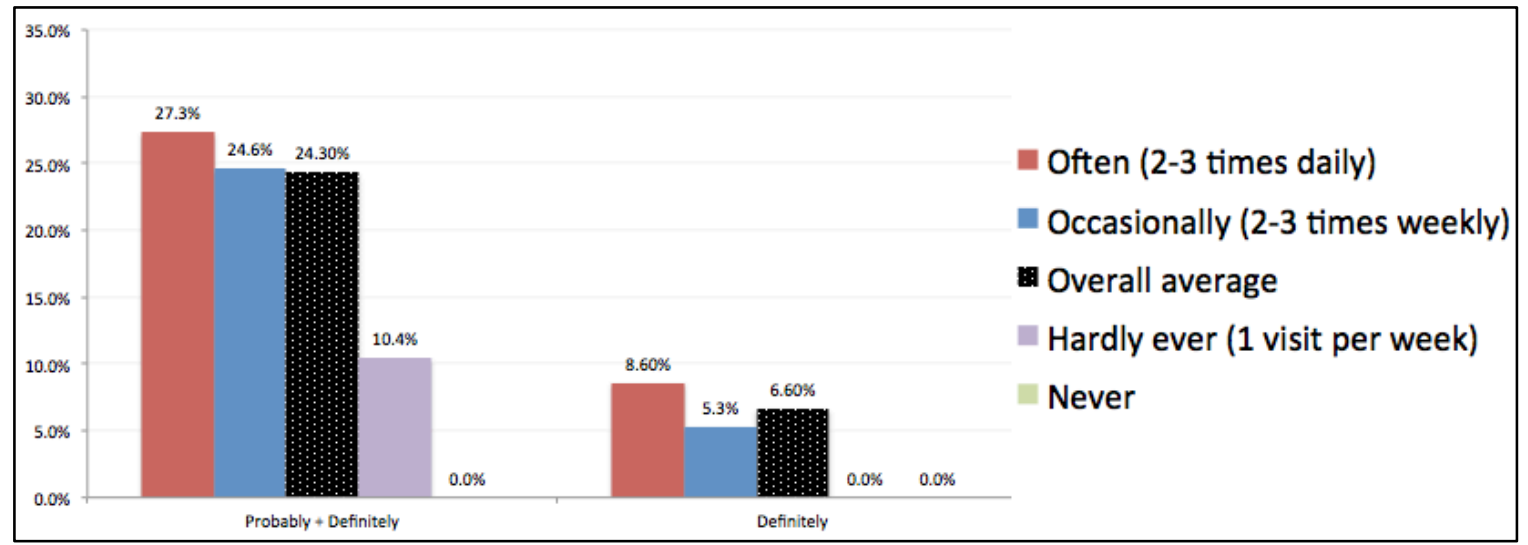

Figure 12. Willingness to pay for a global news package (frequency of visits)

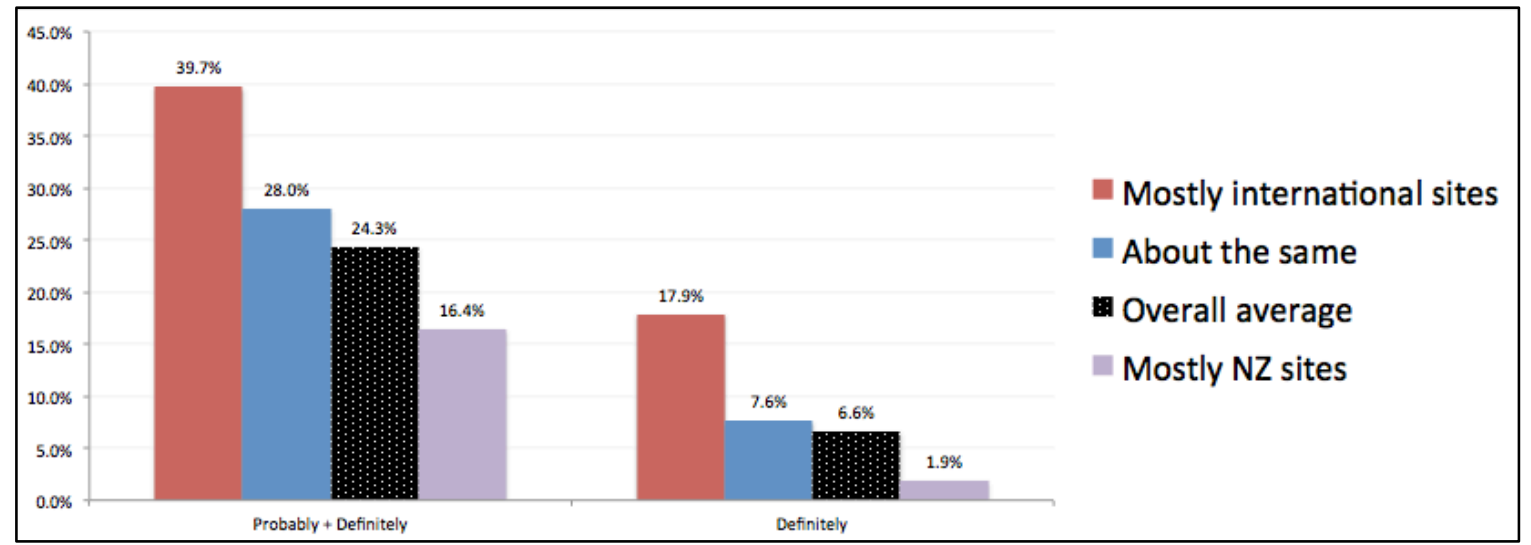

Figure 13. Willingness to pay for a global news package (proportion of time spent reading New Zealand sites versus international) 


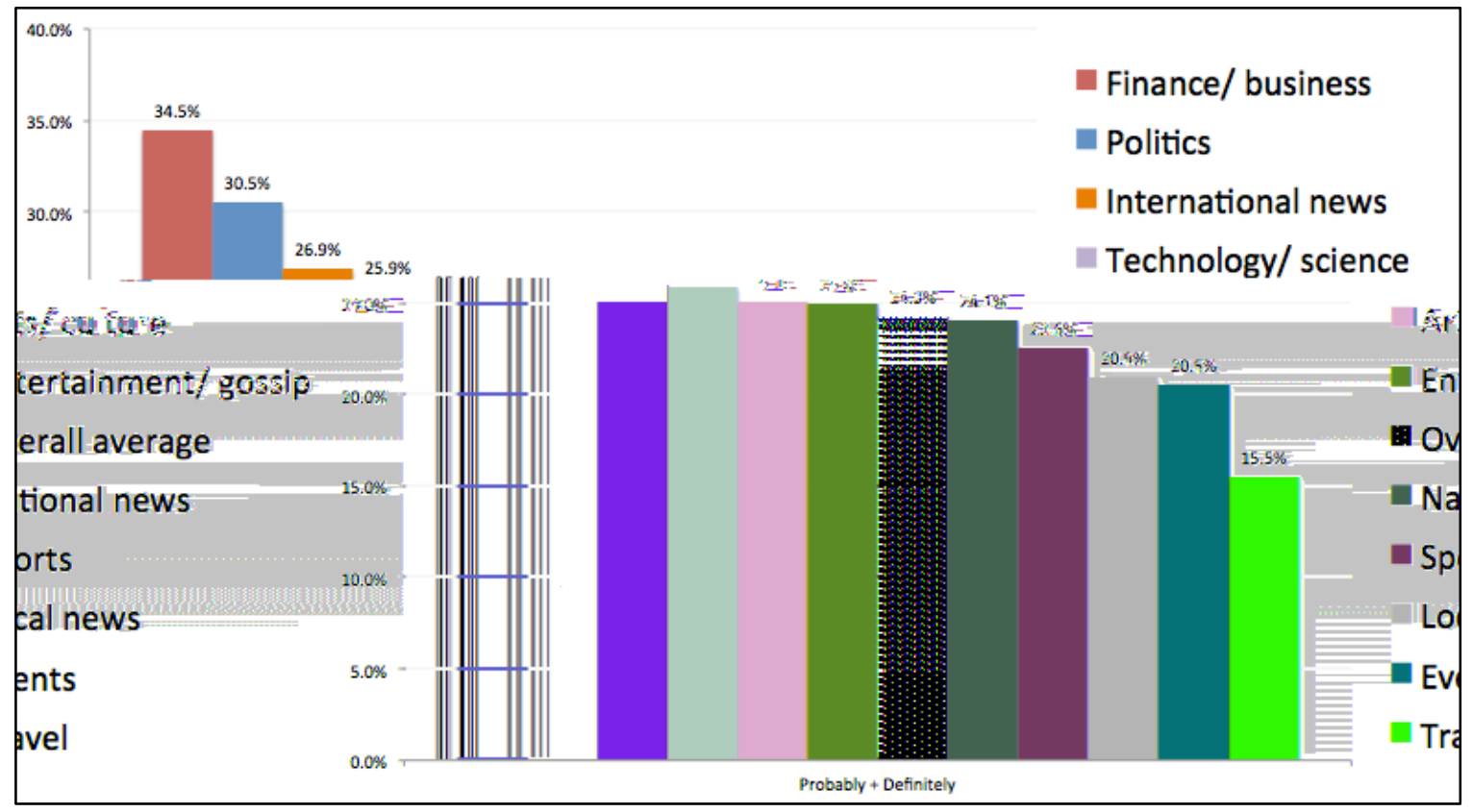

Figure 14. Willingness to pay for a global news package (type of news read most often)

\section{Media purchasing habits}

Those who already have an online video subscription are nearly three times as likely to to definitely purchase a global subscription, while those with an online music subscription are nearly twice as likely (Figure 15). It is likely that this increased propensity to pay aligns with the younger demographic that typically purchases online subscriptions. Furthermore, those with online subscriptions are familiar with the 'payonce-access-all' model of bundling. This particular finding strongly supports the strategy of partnering with services such as Spotify and Netflix, as outlined in Section 4.4 .

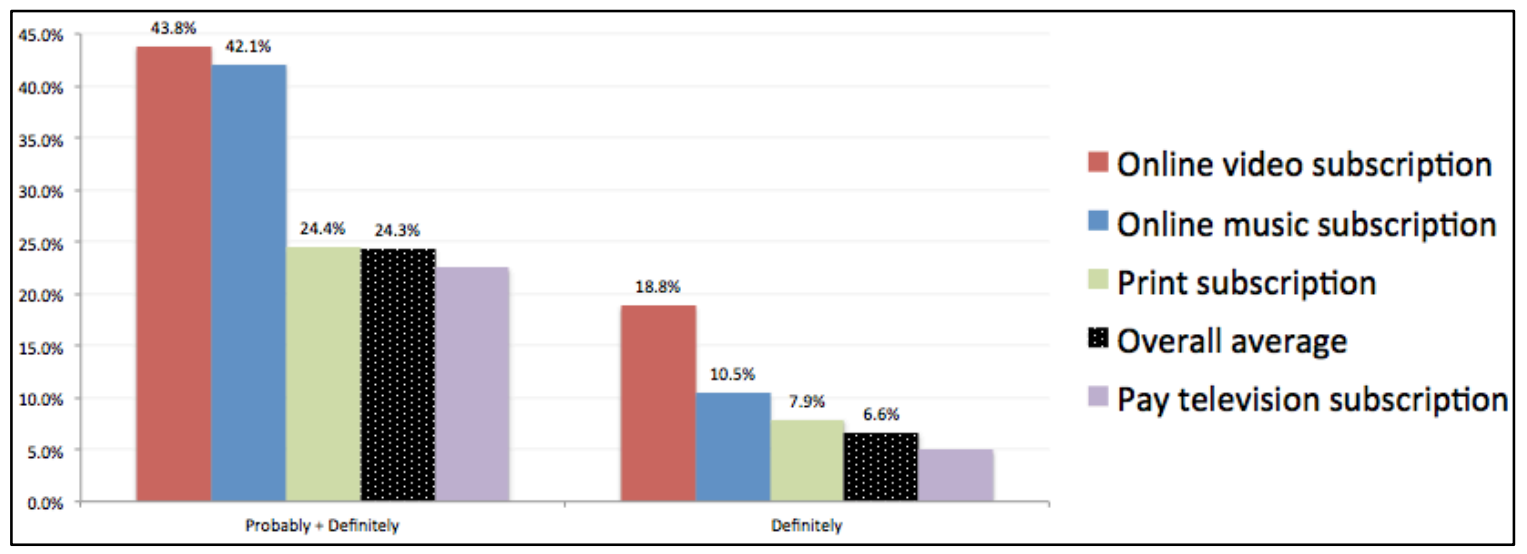

Figure 15. Willingness to pay for a global news package (current media purchases) 


\section{CHAPTER 5: MARKET RESEARCH AND PARTNERSHIP DEVELOPMENT, NEWS ORGANISATIONS}

\subsection{Timeline}

Table 4. Market research, news organisations: Timeline of key milestones and activities

\begin{tabular}{|l|l|}
\hline DATE & ACTIVITIES \\
\hline 2 June 2014 & $\begin{array}{l}\text { Alex has a phone interview with an executive at Radio New } \\
\text { Zealand. }\end{array}$ \\
\hline 6-10 August 2014 & Auckland trip: Alex has 3x meetings with NZME. \\
\hline 20-21 August 2014 & $\begin{array}{l}\text { Auckland trip: Alex has 1x meeting with TVNZ, 1x meeting with } \\
\text { MediaWorks. }\end{array}$ \\
\hline 24 August to & $\begin{array}{l}\text { USA trip: Alex has 3x meetings with the New York Times, 4x } \\
\text { meetings with the Economist, 1x meeting with National } \\
\text { Geographic. }\end{array}$ \\
\hline 8-10 October 2014 & $\begin{array}{l}\text { Auckland trip: Alex has 1x meeting with TVNZ, 1x meeting with } \\
\text { MediaWorks. }\end{array}$ \\
\hline 2014 & $\begin{array}{l}\text { Auckland trip: Alex has 2x meetings with NZME, 1x meeting with } \\
\text { MediaWorks. }\end{array}$ \\
\hline 2014 November & $\begin{array}{l}\text { Auckland trip: Alex has 1x meeting with TVNZ } \\
\text { 2010 }\end{array}$ \\
\hline
\end{tabular}

\subsection{Partnership development activities}

High-level summary:

- In New Zealand, Alex conducted several meetings with senior management within NZME, TVNZ and MediaWorks.

- In the USA, Alex met with senior management within the New York Times, the Economist, and National Geographic. 
- Feedback about the prototype was positive, particularly regarding the way it provides news organisations with full control over editorial decisions, layout and advertising.

- News organisations desired an intermediary platform that was fair, equitable and transparent. This feedback helped shape the principles that guide the PressPass platform.

- Some key aspects of the platform that require further negotiation include: pricing, commission structure and royalty distribution.

- For US news websites, a launch of PressPass in NZ provides a low-risk opportunity to assess the benefits of bundling.

- For NZ news websites, partnering with PressPass provides an opportunity to launch their paywalls with a world-leading strategy.

Between June and November 2014, Alex met with NZME, TVNZ, MediaWorks, the New York Times, the Economist, and National Geographic. He met with a total of 26 employees in senior management positions, who had input into each news organisation's monetisation strategy. Within each organisation, Alex met with senior managers who had responsibility for strategy, marketing, revenue, consumer research, digital content, new products and technology. Table 5 provides a full overview of each employee's role, seniority and primary responsibility within the organisation.

Table 5. Roles of interviewees within news organisations

\begin{tabular}{|l|l|l|}
\hline ROLE & SENIORITY & $\begin{array}{l}\text { PRIMARY RESPONSIBILITY } \\
\text { (number of people) }\end{array}$ \\
\hline $\begin{array}{l}\text { Research and Insights; } \\
\text { Strategy and Analytics; } \\
\text { Research and Analytics; }\end{array}$ & Head; Director; & $\begin{array}{l}\text { Conducting consumer research, } \\
\text { and using insights to inform } \\
\text { strategy. } \\
\text { (four people) }\end{array}$ \\
\hline $\begin{array}{l}\text { Digital Content; Digital Media; } \\
\text { Digital; Online Content }\end{array}$ & $\begin{array}{l}\text { Head; Group Director; } \\
\text { General Manager; } \\
\text { Executive Producer; } \\
\text { Group Editor }\end{array}$ & $\begin{array}{l}\text { Coordinating and maintaining } \\
\text { digital content. } \\
\text { (five people) }\end{array}$ \\
\hline $\begin{array}{l}\text { Marketing; Digital Marketing; } \\
\text { Circulation Innovation }\end{array}$ & Head; Director & $\begin{array}{l}\text { Promoting the uptake of } \\
\text { content offerings. } \\
\text { (four people) }\end{array}$ \\
\hline News and Current Affairs & $\begin{array}{l}\text { Head; Editor of Content; } \\
\text { Director; Deputy } \\
\text { Director; }\end{array}$ & $\begin{array}{l}\text { Coordinating the creation of } \\
\text { editorial content. } \\
\text { (four people) }\end{array}$ \\
\hline
\end{tabular}




\begin{tabular}{|c|c|c|}
\hline $\begin{array}{l}\text { Technology; Product; Product } \\
\text { Management, Digital } \\
\text { Solutions; New Initiatives; } \\
\text { Business Development and } \\
\text { Innovation }\end{array}$ & $\begin{array}{l}\text { CTO; Executive Director; } \\
\text { Vice President; Assistant } \\
\text { Managing Editor; }\end{array}$ & $\begin{array}{l}\text { The creation and } \\
\text { implementation of new } \\
\text { products and innovations. } \\
\text { (five people) }\end{array}$ \\
\hline $\begin{array}{l}\text { Revenue; Finance and } \\
\text { Operations }\end{array}$ & $\begin{array}{l}\text { Group Head; Vice } \\
\text { President }\end{array}$ & $\begin{array}{l}\text { Oversight of organisational } \\
\text { revenue strategy. (two people) }\end{array}$ \\
\hline Chief Executive Officer & CEO & $\begin{array}{l}\text { Decision-making responsibility } \\
\text { for organisation. (two people) }\end{array}$ \\
\hline
\end{tabular}

The individuals that Alex met within these organisations agreed that global bundling is a promising strategy for the industry to consider. When shown the prototype, they provided positive feedback about the way it easily integrates with existing websites and provides full control over editorial and advertising. Furthermore, they liked the ability to maintain direct relationships with their readers, rather than being side-lined by a central aggregator. One of the biggest fears of news organisations was losing control to a third-party intermediary, and the decentralised nature of the PressPass platform allayed many of these fears.

News organisations also expressed a desire for robust reassurances that the intermediary would be fair, equitable and transparent. This helped shape the core principles guiding the project, which include: platform independence, non-exclusivity, open source development, and a commission structure that includes rebates for news partners. These principles are explained in greater depth within Section 5.3, and form part of our competitive strategy.

Aspects of the platform that require further negotiation include: determining the method used to set pricing for the national and global packages, negotiating the commission structure, and determining the exact method used for royalty distribution. Our current strategy for finding a suitable solution is outlined within Section 10.2.

While discussions are still at an early-stage, there has been significant interest in trialing the PressPass platform within the NZ market. American publishers were particularly interested in having the opportunity to assess the benefits of bundling, without risking the cannibalisation of their existing strategy within the USA. For New Zealand 
publishers, many were enthusiastic about the prospect of leading the journalism industry by adopting the best monetisation strategy available.

PressPass' current focus is on converting initial interest in the PressPass platform into formalised commitments. Since New Zealand news organisations are continuing to delay their premium-content strategy, it has been difficult to develop firmer commitments.

\subsection{Competitive strategy}

There are a handful of companies attempting to improve the way that news is monetized online. Each company has developed a platform that has its own strengths and weaknesses. However, none have yet implemented a monetization strategy that sufficiently offsets the ongoing losses from print revenue. A competitive analysis of our strongest competitors has been provided within Table 6 (page 46), with a brief summary below.

\section{Competitive overview}

Piano Media: Provides national paywalls within Slovenia, Slovakia and Poland. Integrates with existing news sites, providing a universal login account that unlocks all partner sites for one monthly fee.

Press+: Provides standalone paywall infrastructure to over 600 news websites, mostly within Europe and the USA. Integrates with existing news sites, and charges separately for access to each site.

Blendle: Provides a web browser and tablet application with pay-per-view access to articles from nearly all publishers in the Netherlands, as well as some international partners.

Inkl: Provides a mobile website that allows subscribers to pay one fee to access news from all publishing partners. 
TinyPass: A monetisation platform that integrates with existing websites, allowing news organisations to either establish a standalone paywall or to charge pay-per-view access to individual articles.

\section{Competitive advantage}

The key competitive strengths of our platform are summarized below. Our publisher interviews revealed a strong mistrust of intermediaries, and a fear they will gain excessive dominance over the journalism ecosystem. PressPass strengthens its trustworthiness by being independent, open source, low cost and non-exclusive. These principles help provide PressPass with a competitive advantage over the alternative monetisation platforms available to news organisations.

Low commission: We will charge zero commission for subscriptions to a single website, which is lower than any of our competitors. We will charge only $20 \%$ for subscriptions to our global package, and will further cut our commission as profit margins increase. Our competitors' rates: Press $+20 \%$ (standalone), Piano 30\% (national bundle), Blendle 30\% (pay-per-article), TinyPass (tiered structure, see Table 6), Inkl (data unavailable).

Open Source: When the PressPass platform is launched, it will be released under an open source license. Existing platforms are proprietary, resulting in a power imbalance between the journalism community and intermediaries. By adopting open source, the journalism community will be able to see how the PressPass code works, verify its security, and expand upon its core functionality. Our platform will also be interoperable with other platforms and services.

Independence: Most existing platforms have links with particular news organisations, while some publishers have direct ownership stakes. Feedback from news organisations suggests that competitive rivalries will hinder efforts to create an all-inclusive universal package, if direct publisher ownership exists. Furthermore, many publishers fear that conflicts of interest could arise as a result of direct ownership. PressPass' independence allows the platform to work across competitive boundaries, in the interests of the entire journalism community 
Non-exclusive: All publishing partners are welcome to use alternative platforms that complement or compete with PressPass. By avoiding exclusivity, PressPass is committed to facilitating a highly competitive journalism ecosystem. While competitors have not yet imposed exclusivity on their partners, some news organisations expressed a fear that exclusivity could be adopted as market power grows.

Multiplatform focus: Monetization strategies need to focus on web, mobile and tablet platforms to reach their full potential. Currently, only Blendle has a multiplatform strategy. PressPass plans to develop mobile applications that complement its web offering.

Best strategy: A universal bundle has emerged as the best strategy within the PressPass team's survey, with $6.6 \%$ of consumers saying they would definitely pay for a global package. Standalone subscriptions (Press + , TinyPass) were the least popular option at 0.5\%. Paying-per-article (Blendle, Tiny Pass) was 0.7\%. National packages (Piano Media) was $1.4 \%$. 
Table 6. Competitive landscape

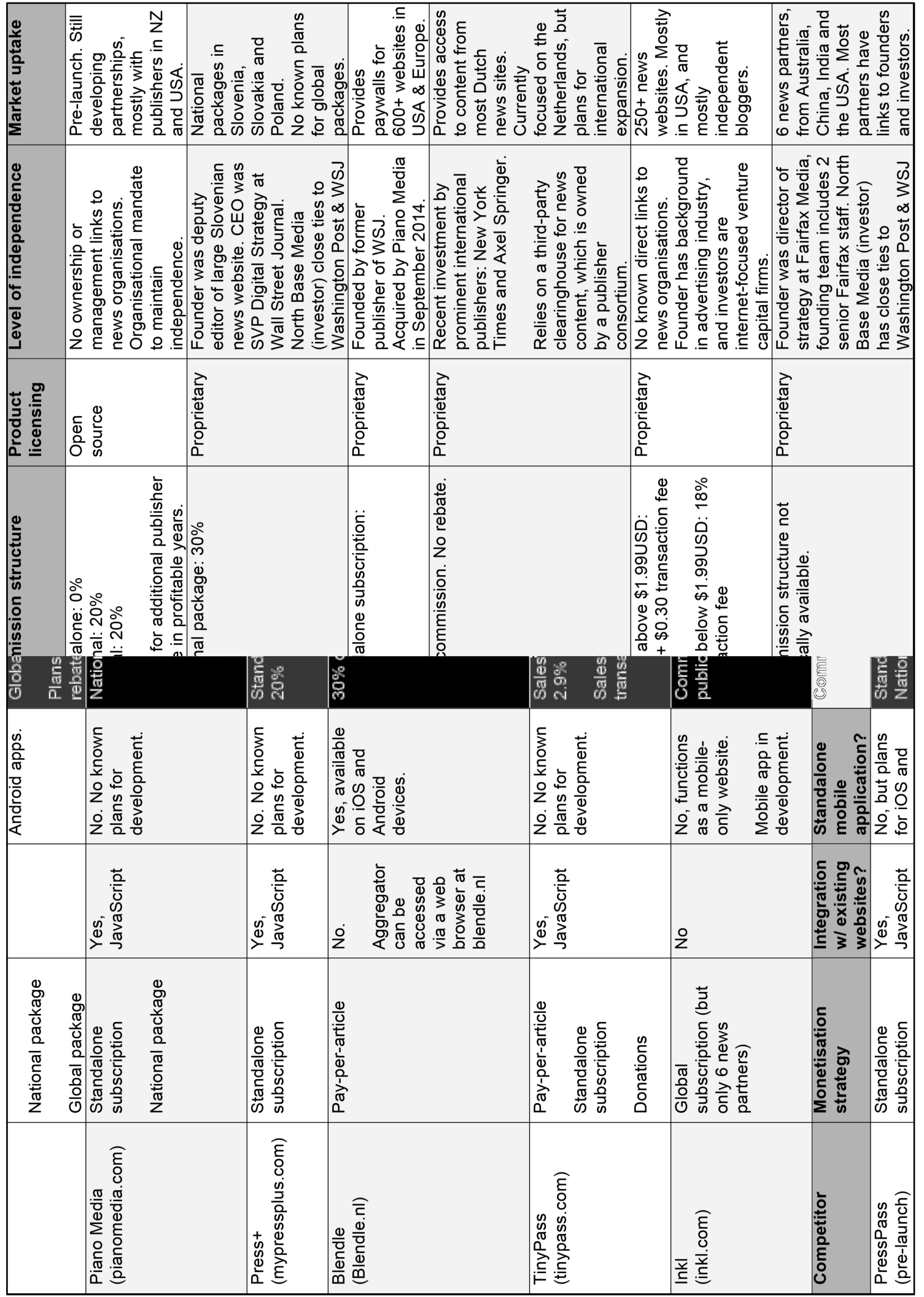




\section{CHAPTER 6: PRODUCT DEVELOPMENT}

\subsection{Timeline}

Table 7. Product development: Timeline of key milestones and activities

\begin{tabular}{|c|c|}
\hline DATE & ACTIVITIES \\
\hline March & $\begin{array}{l}\text { Specifications: Initial specifications document written by Alex and sent to } \\
\text { Puneeth on March } 18^{\text {th }} \text {. Puneeth's development work was initially limited to } \\
\text { basic mock-ups that could be used for demonstrative purposes, but had } \\
\text { minimal functionality. This was so that market research could be used to } \\
\text { validate key assumptions, before investing team resources into full } \\
\text { development. } \\
\text { Demo website: Puneeth creates an early demonstration website, using } \\
\text { 'iframes' to illustrate proposed functionality of the PressPass ribbon. }\end{array}$ \\
\hline April to May & $\begin{array}{l}\text { Prototype development: Puneeth begins early development work on } \\
\text { PressPass ribbon and styles, using the Jquery framework. Prototype is } \\
\text { integrated with a WordPress website for demonstration purposes. }\end{array}$ \\
\hline June & $\begin{array}{l}\text { Login: Login functionality implemented by Puneeth, using Facebook's social } \\
\text { sign-on API. The code was refracted to accommodate integration with } \\
\text { multiple social media sign-on providers. Skeleton design pattern was } \\
\text { updated to implement this functionality. } \\
\text { Analytics: Puneeth and Alex meet with the founder of Piwik, as well as its } \\
\text { lead developer. Piwik is an open source analytics platform that is integrated } \\
\text { with PressPass. The meeting provided an opportunity to discuss ways to } \\
\text { adapt the code to meet PressPass' requirements. } \\
\text { Version control: Puneeth moved the source code to Github Source Control } \\
\text { in mid-June. This was done in preparation for Paul Smith joining PressPass, } \\
\text { and allowed the development team to better manage the source code. }\end{array}$ \\
\hline July & $\begin{array}{l}\text { Specifications: Updated specifications document written by Alex, and sent } \\
\text { to Puneeth and Paul on July } 3 \text {. New specifications were based on the full } \\
\text { analysis of customer interviews, as well as early feedback from the } \\
\text { journalism community. Updated specifications outlined product } \\
\text { functionality in more depth, and provided a timeline with clear milestones. } \\
\text { Analytics: Puneeth installs the PIWIK web analytics software on the server, } \\
\text { allowing it to be enabled on the demonstration sites. In addition to the } \\
\text { standard installation, the code needed to be modified to allow for easier } \\
\text { integration with the websites of future news partners. } \\
\text { Payment: Puneeth integrates a sandboxed version of PayPal with the } \\
\text { registration process. } \\
\text { Design and layout: Paul refined the style sheet for the ribbon to improve } \\
\text { consistency across different browsers. }\end{array}$ \\
\hline
\end{tabular}




\begin{tabular}{|c|c|}
\hline DATE & ACTIVITIES \\
\hline August & $\begin{array}{l}\text { Specifications: Updated specifications were provided to Puneeth and Paul } \\
\text { on July } 20^{\text {th }} \text {, with a focus on improving the code ready for Alex's meetings } \\
\text { with news organisations in Auckland and the USA. Specifications were } \\
\text { largely focused on refinements to design and user interface. } \\
\text { Demo websites: Puneeth made more sample WordPress sites live on the } \\
\text { server. These sample websites were integrated with the PressPass ribbon for } \\
\text { testing and demonstration purposes. } \\
\text { Privacy: Alex has meetings with the Lead Privacy Engineer at Mozilla, as well } \\
\text { as the Technology Projects Director and Technology Operations Director at } \\
\text { the Electronic Frontier Foundation. Discuss technical solutions that will } \\
\text { enable data collection while respecting user privacy. PressPass team decides } \\
\text { that hash encryption of data will be best approach when this functionality is } \\
\text { first implemented, with more complex solutions considered at a later stage. } \\
\text { Code refinement: Puneeth and Paul continued work to refine the code, } \\
\text { improve design elements, remove glitches, minimise loading time, and other } \\
\text { miscellaneous tasks that arose during the development process. }\end{array}$ \\
\hline September & $\begin{array}{l}\text { Cross-domain storage: Two features from the specifications document were } \\
\text { particularly difficult to implement, and required the novel solution of cross- } \\
\text { domain storage. These features were: } \\
\text { 1) To recognise the number of free articles read by anonymous users, } \\
\text { cumulatively across all of the partner news websites. Once the quota of free } \\
\text { articles was reached, the paywall would be triggered. } \\
\text { 2) To enable persistent login across all partner websites. Once signed in, a } \\
\text { user would be automatically logged into any partner website that they } \\
\text { visited. } \\
\text { As a solution, Paul and Puneeth implemented cross-domain storage, which } \\
\text { uses 'iframes' and an HTML5 client storage feature to enable this } \\
\text { functionality. This solution is similar to the method followed by Google, } \\
\text { Facebook and Microsoft. } \\
\text { Server: Meteor and MongoDb were used to develop the server side of the } \\
\text { PressPass platform, storing and sharing data through an API. }\end{array}$ \\
\hline $\begin{array}{l}\text { October to } \\
\text { present }\end{array}$ & $\begin{array}{l}\text { Continued development work to improve the prototype, focusing on tasks } \\
\text { outlined in Table } 9 .\end{array}$ \\
\hline
\end{tabular}




\subsection{Platform specifications}

The features of the PressPass platform, outlined within the tables below, have been based on market research conducted with consumers and news organisations. Table 8 provides an overview of existing functionality with the PressPass prototype. Table 9 outlines current development tasks, as well as expected times for completion. Table 10 provides a summary of additional features that are being considered for future development.

Table 8. Existing functionality of the PressPass platform

\begin{tabular}{|l|l|}
\hline FEATURE & DESCRIPTION \\
\hline Article meter & $\begin{array}{l}\text { The article meter limits the number of free articles that each reader can } \\
\text { view. This feature can be adjusted by publishing partners, allowing them } \\
\text { to determine the exact number of free articles available within their site. } \\
\text { This allows news partners to calculate the ideal threshold for their } \\
\text { website, so that they can maximise conversion rates. This flexibility is } \\
\text { critical for any website with a paywall, as it enables publishers to target } \\
\text { specific readers according to levels of engagement and likelihood of } \\
\text { conversion (Doctor 2013; Doctor 2012) }\end{array}$ \\
\hline Paywall & $\begin{array}{l}\text { Once readers hit their threshold of free articles, our paywall appears and } \\
\text { restricts further reading. Each news partner will have full control over the } \\
\text { news articles they choose to put behind the PressPass paywall. Some } \\
\text { partners will want to put their entire site behind the meter, while others } \\
\text { will prefer to experiment with premium sections of their website. }\end{array}$ \\
\hline Analytics & $\begin{array}{l}\text { Our customised version of the Piwik analytics platform records page } \\
\text { views and time spent reading. }\end{array}$ \\
\hline Social login & $\begin{array}{l}\text { Readers can create an account by signing in with an existing social media } \\
\text { account. We have integrated Facebook, and will have others login } \\
\text { services integrated within the next 4 weeks. }\end{array}$ \\
\hline Payment gateway & $\begin{array}{l}\text { We have integrated PayPal for payment, and will integrate credit card } \\
\text { and online banking once we have selected payment providers. }\end{array}$ \\
\hline
\end{tabular}


Table 9. Current development tasks for the PressPass platform

\begin{tabular}{|l|l|l|}
\hline FEATURE & DESCRIPTION & TIMELINE \\
\hline Reader dashboard & $\begin{array}{l}\text { Allows readers to easily manage their accounts, and } \\
\text { view a list of partner publications }\end{array}$ & By June 2015 \\
\hline $\begin{array}{l}\text { Publisher } \\
\text { dashboard }\end{array}$ & $\begin{array}{l}\text { Allows publishers to gain demographic insights into } \\
\text { reading habits and conversion rates. Also provides a } \\
\text { breakdown of incoming payments from PressPass } \\
\text { royalties and commission (see 10.1). }\end{array}$ & By June 2015 \\
\hline Master dashboard & $\begin{array}{l}\text { Allows PressPass administrators to manage publisher } \\
\text { and reader accounts, and monitor key success metrics. }\end{array}$ & By June 2015 \\
\hline $\begin{array}{l}\text { Customer } \\
\text { database API }\end{array}$ & $\begin{array}{l}\text { Allows users to authenticate with PressPass using their } \\
\text { existing publisher accounts. }\end{array}$ & $\begin{array}{l}\text { Develop once } \\
\text { partnerships } \\
\text { established }\end{array}$ \\
\hline $\begin{array}{l}\text { Cross-platform } \\
\text { API }\end{array}$ & $\begin{array}{l}\text { Allows PressPass login credentials to be used for signing } \\
\text { into the mobile applications of news partners. }\end{array}$ & $\begin{array}{l}\text { Develop once } \\
\text { partnerships } \\
\text { established }\end{array}$ \\
\hline Analytics API & $\begin{array}{l}\text { Allows publishers to easily export all of their PressPass } \\
\text { analytics to other platforms for in-depth analysis. }\end{array}$ & $\begin{array}{l}\text { Develop once } \\
\text { partnerships } \\
\text { established }\end{array}$ \\
\hline
\end{tabular}

Table 10. Future plans for adding extra functionality to the PressPass platform

\begin{tabular}{|l|l|l|}
\hline FEATURE & DESCRIPTION & TIMELINE \\
\hline $\begin{array}{l}\text { Recommended } \\
\text { articles }\end{array}$ & $\begin{array}{l}\text { Provide readers with recommended articles, based on } \\
\text { their reading habits and preferences. }\end{array}$ & $\begin{array}{l}<6 \text { months } \\
\text { after launch }\end{array}$ \\
\hline $\begin{array}{l}\text { Aggregator within } \\
\text { ribbon }\end{array}$ & $\begin{array}{l}\text { Allows readers to easily browse articles by category, } \\
\text { from all news partners. }\end{array}$ & $\begin{array}{l}<12 \text { months } \\
\text { after launch }\end{array}$ \\
\hline $\begin{array}{l}\text { Search bar within } \\
\text { ribbon }\end{array}$ & $\begin{array}{l}\text { Allows readers to search articles across all news } \\
\text { partners. }\end{array}$ & $\begin{array}{l}<6 \text { months } \\
\text { after launch }\end{array}$ \\
\hline $\begin{array}{l}\text { Mobile and } \\
\text { desktop apps }\end{array}$ & $\begin{array}{l}\text { Enable readers to easily browse news from all publishing } \\
\text { partners, within one streamlined app. }\end{array}$ & $\begin{array}{l}<12 \text { months } \\
\text { after launch }\end{array}$ \\
\hline
\end{tabular}

\subsection{Cost projections}

Presspass will have its dynamic data hosted on a dedicated Virtual Private Server (VPS). VPS services are offered by many different cloud service providers, and will be used for running the PIWIK analytics platform, as well as data related to user accounts. As consumer usage of the platform increases, so too will the requirements for our cloud hosting.

Table 11 illustrates the hosting requirements for the PressPass platform at different levels of consumer uptake. The table includes a cost estimate for hosting the dynamic data of PressPass, comparing two cloud-hosting companies that provide Virtual Private 
Servers (VPS). To increase latency and performance, it is best to have a hosting service within New Zealand. With this in mind, the current preference is for VPS City, even though its cost is higher.

Table 11. Cost of Virtual Private Server (VPS) at different scales of usage, for current specifications

\begin{tabular}{|l|l|l|l|l|l|}
\hline Provider & $\begin{array}{l}\text { Hosting } \\
\text { location }\end{array}$ & $\begin{array}{l}\text { Monthly page } \\
\text { impressions }\end{array}$ & $\begin{array}{l}\text { Number of } \\
\text { registered } \\
\text { users }\end{array}$ & $\begin{array}{l}\text { Memory/ number of } \\
\text { processor cores }\end{array}$ & $\begin{array}{l}\text { Cost per } \\
\text { month }\end{array}$ \\
\hline $\begin{array}{l}\text { Digital } \\
\text { Ocean }\end{array}$ & \multirow{2}{*}{ USA/ UK } & 100 million & $250 k-500 k$ & $32 \mathrm{~GB} / 12$ & $\$ 320$ USD \\
\cline { 3 - 6 } & & 150 million & $0.5-1$ million & $48 \mathrm{~GB} / 16$ & $\$ 480$ USD \\
\cline { 3 - 6 } & 200 million & $1-1.5$ million & $64 \mathrm{~GB} / 20$ & $\$ 640$ USD \\
\hline VPS City & \multirow{2}{*}{ NZ } & 100 million & $250 k-500 k$ & $20 \mathrm{~GB} / 5 / 100 \mathrm{~GB}$ SSD & $\$ 644$ NZD \\
\cline { 3 - 6 } & & 150 million & $0.5-1$ million & $32 \mathrm{~GB} / 6 / 250 \mathrm{~GB}$ SSD & $\$ 1,110$ NZD \\
\cline { 3 - 6 } & & 200 million & $1-1.5$ million & $32 \mathrm{~GB} / 6 / 500 \mathrm{~GB}$ SSD & $\$ 1,742$ NZD \\
\hline
\end{tabular}

The PressPass platform also contains many static components, such as JavaScript, CSS and Images, which can be hosted for free within a Content Delivery Network (CDN). The development team is currently planning to use the $\mathrm{CDN}$ service offered by cloudfare.com, which provides high bandwidth speed and unlimited bandwidth data.

The overall cost of the PressPass system is kept quite low, due to the lightweight nature of the platform. The PressPass ribbon does not require a large amount of data to be transferred for its functionality, and user accounts have minimal data storage requirements. The most data-intensive hosting tasks are instead managed by the servers of news organisations, who host the article content accessed by users. A simplified diagram of data flow is outlined in Figure 16. 


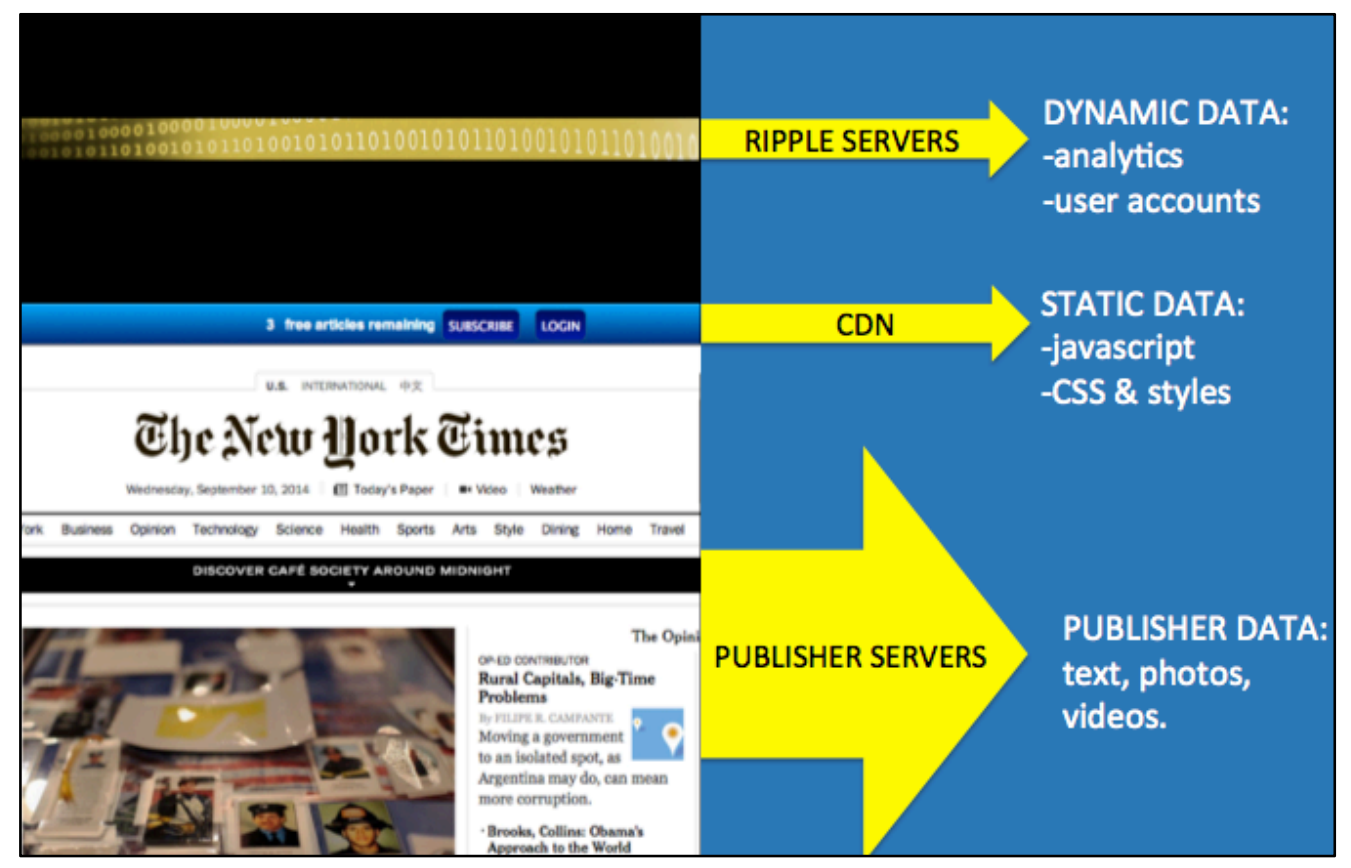

Figure 16. Diagram of data flow required for the PressPass platform 


\section{CHAPTER 7: $\quad$ PUBLICITY}

\subsection{Timeline}

Table 12. Publicity: Timeline of key milestones and activities

\begin{tabular}{|c|l|}
\hline \multicolumn{1}{|c|}{ DATE } & \multicolumn{1}{c|}{ ACTIVITIES } \\
\hline 14 June 2014 & $\begin{array}{l}\text { Alex sends emails to Radio New Zealand's MediaWatch producer, to } \\
\text { discuss the possibility of sharing the PressPass project with listeners. }\end{array}$ \\
\hline 1 July 2014 & $\begin{array}{l}\text { Alex meets with the hosts of MediaWatch (Colin Peacock and Jeremy } \\
\text { Rose). }\end{array}$ \\
\hline 17 July 2014 & Alex is interviewed for the MediaWatch programme. \\
\hline 23 July 2014 & $\begin{array}{l}\text { Alex creates a website to share the PressPass project with the public } \\
\text { (www.fundingnews.co.nz). He provides the URL to MediaWatch, for } \\
\text { promotion within their radio broadcast and online article. }\end{array}$ \\
\hline 3 August 2014 2014 & $\begin{array}{l}\text { Alex has an interview with Victoria University's communication's team. } \\
\text { posted on the Radio New Zealand website. }\end{array}$ \\
\hline 4 August 2014 & The Victoria University press release is distributed. \\
\hline 4-8 August 2014 & $\begin{array}{l}\text { Alex sends out emails to media outlets, with a one-pager describing the } \\
\text { PressPass project. }\end{array}$ \\
\hline 7 August 2014 & $\begin{array}{l}\text { Alex has a face-to-face interview with the New Zealand Listener's media } \\
\text { columnist. }\end{array}$ \\
\hline 12 August 2014 & $\begin{array}{l}\text { Alex has a phone interview with the National Business Review's media } \\
\text { columnist. }\end{array}$ \\
\hline 13 August 2014 & $\begin{array}{l}\text { Alex has a phone interview with the New Zealand Herald's media } \\
\text { columnist. }\end{array}$ \\
\hline 15 August 2014 & Article is published within the New Zealand Herald. \\
\hline 26 August 2014 & Article is published within the National Business Review. \\
\hline 30 October 2014 & Article is published within the New Zealand Listener. \\
\hline & \\
\hline
\end{tabular}

\subsection{Publicity outcomes and strategy}

Media coverage about PressPass can be viewed via the following link: http://www.fundingnews.co.nz/media-coverage

Direct access to each item of media coverage can be viewed via the links below:

Radio New Zealand Interview: https://soundcloud.com/kiwialexnz/news-renewedradio-new-zealand-mediawatch-interview

Victoria University press release: http://www.victoria.ac.nz/sim/about/news/2014news/study-shows-consumers-willing-to-pay-for-online-news 
National Business Review article:

https://www.dropbox.com/s/1k21whhuo9lt24i/National\%20Business\%20Review\%20$\% 20 \mathrm{Ad} \% 20$ Hoc.pdf?dl $=0$

New Zealand Herald article:

https://www.dropbox.com/s/rtt4xyz2xb4c4st/NZ\%20Herald.pdf?dl=0

Media publicity was pursued as a strategy to increase early awareness of the PressPass project. The coverage was particularly useful to provide some external validation of the project during the early stages of development, and helped facilitate relationships with individuals within the journalism community.

Several team advisors have recommended taking a hiatus from further publicity until further progress has been made with publisher partnerships. Once the platform has a clear timeline for launch, the next round of media publicity will be focused on raising product awareness among consumers.

To coincide with the New Zealand launch, Alex may also write articles for journals that are popular amongst the international journalism community, such as Walkey's in Australia (www.walkleys.com). This will help raise awareness of the platform, and could facilitate the development of partnerships within international markets. 


\section{CHAPTER 8: LEGAL AND REGULATORY}

\subsection{Timeline}

Table 13. Legal and regulatory: Timeline of key milestones and activities

\begin{tabular}{|c|c|}
\hline DATE & ACTIVITIES \\
\hline 5 May 2014 & $\begin{array}{l}\text { Alex incorporates Ripple Media Limited, the parent company of } \\
\text { PressPass. }\end{array}$ \\
\hline 14 May 2014 & $\begin{array}{l}\text { Alex meets with Ramsey Margolis, head of Huia Co-op, a consulting } \\
\text { company that provides advice regarding the establishment of } \\
\text { cooperative businesses. }\end{array}$ \\
\hline 10 June 2014 & $\begin{array}{l}\text { Alex has a phone call with the Commerce Act Chief Investigator, at the } \\
\text { Commerce Commission. }\end{array}$ \\
\hline 4 July 2014 & Alex Clark and Puneeth Anandaraj sign the PressPass team agreement. \\
\hline 21 July 2014 & $\begin{array}{l}\text { Alex meets with Julie Chrisford from VicLink, to discuss the intellectual } \\
\text { property strategy for the PressPass platform. }\end{array}$ \\
\hline 30 July 2014 & $\begin{array}{l}\text { Alex has a call with Sacha Judd, lawyer at Buddle Finlay, to discuss the } \\
\text { best corporate structure to balance commercial and altruistic goals of } \\
\text { PressPass. }\end{array}$ \\
\hline 7 August 2014 & $\begin{array}{l}\text { Alex meets with Gavin Ellis, author of Trust Ownership and the Future of } \\
\text { News. Discuss possible governance structures to balance commercial } \\
\text { and altruistic goals of PressPass. }\end{array}$ \\
\hline 15 August 2014 & Paul Smith signs the PressPass team agreement. \\
\hline 18 August 2014 & Phone call with Gavin Ellis, continued discussions regarding governance. \\
\hline 19 Nov 2014 & Meeting with Gavin Ellis, continued discussions regarding governance. \\
\hline 19 Nov 2014 & Submit trademark application to IPONZ for the PressPass brand. \\
\hline
\end{tabular}

\subsection{Intellectual property}

The following sections were informed by discussions with Julie Chrisford from VicLink, as well as informal discussions with mentors and advisors within Wellington's start-up community.

\section{Open Source development}

The PressPass team has adopted an open source development strategy, which is a particularly important for creating a relationship of trust and collaboration with the journalism community. Counter-intuitively, an open source strategy requires the establishment of clear ownership and copyright over the source code. This is because 
open source licensing is dependent on the licensor having intellectual property rights over the code.

To ensure clear ownership, each team member has signed a clause within the team agreement that allocates ownership to Ripple Media Limited, under the understanding that the source code will be made available under open source licensing at launch. The team has not yet chosen a specific open source license, and has been advised to apply a license at a later stage once the project has matured. There are many different options available, and the team will need to assess the best possible license that maximises the project's goals. This will be assessed on an ongoing basis, particularly as relationships with news partners and the wider development community are further developed.

\section{Patents}

Early on, it was decided that patents were not a practical solution for PressPass, even when proprietary development was being considered. Not only is it difficult to patent software in New Zealand, but the process also requires a large investment of time and energy. The approval timeframe can extend over a period of 12 months or more, and the level protection is low. Furthermore, competitors within the IT industry can often copy the functionality of a platform without breaking patent laws. Rather than seeking IP protection, the team's main focus with patent law is to conduct a comprehensive 'freedom to operate' search to ensure that no elements of the platform infringe on existing patents. An initial search has not revealed any existing patents that overlap with our functionality, however, a more in-depth search will need to be conducted once the team has the financial resources to do so.

\section{Trademark application}

In November, Alex applied for a trademark to protect the PressPass brand. The process was relatively straightforward, but did involve some external advice to assess the best product/service categories to seek protection within. The application has been accepted, with no objections raised. Once PressPass has further financial resources, trademark applications will be sought in other relevant markets such as Australia and the USA. 


\subsection{Regulatory}

The New Zealand journalism market is one of the most concentrated in the western world, consisting of a near-duopoly between NZME and Fairfax Media. Any initiative that seeks to create collaboration between the two entities is therefore going to be subject to a high level of regulatory scrutiny from the Commerce Commission. With this in mind, Alex reached out to the Commerce Commission early during the development stages to discuss plans, and to ensure that all possible efforts were taken to maintain regulatory compliance. In June, Alex discussed PressPass with the Commerce Act Chief Investigator at the Commerce Commision.

The Chief Investigator was unable to provide specific legal advice due to statutory limitations, and also due to the fact that comprehensive assessments can't be made of hypothetical business models. He did, however, point out the three key sections of the Commerce Act that would apply to the project. Section 27, Agreements that substantially lessen competition, applies if a business undertakes actions that lower the level of competition in the market. Section 36, Taking advantage of market power, applies if a business has a substantial degree of market power and takes advantage of that power. Section 30, Certain provisions of contracts with respect to prices deemed to substantially lessen competition, is focused on addressing issues that arise when companies attempt to fix, maintain or control pricing through unfair practices.

His preliminary view was that Section 27 did not apply, pointing out that the proposed platform was unlikely to lessen competition as there are dozens of providers of online news and information, as well as several platforms through which news is shared. Furthermore, Section 36 is unlikely to apply due to the low market power of PressPass. Section 30 is unlikely to be an issue, since each competitor is negotiating with PressPass independently, resulting in a normal supplier and purchaser agreement.

Specific actions that he said would trigger a high level of regulatory scrutiny, included direct negotiation between publishers about prices within the platform. Furthermore, direct ownership or investment from publishers would trigger a very high level of scrutiny from the Commerce Commission. 
He did point out that Section 31 provides limited exceptions within the Commerce Act, that allow for companies to pursue joint ventures in exceptional circumstances for the purposes of additional services. Even under these circumstances, PressPass would face a very high level of scrutiny, and may not meet the criteria for a joint venture if there was direct investment from publishers.

Since independence is already a prominent principle guiding the PressPass platform, it is expected that our current strategy of avoiding direct media ownership will be beneficial both legally, commercially and altruistically.

\subsection{Corporate structure}

During the early stages of PressPass, the team had discussed the possibility of cooperative ownership to increase adoption by the journalism community and maximise equitability. Alex had discussions with several individuals who had understanding of cooperative structures, and asked for their advice. A common theme that emerged was that cooperatives are extremely delicate organisations to maintain, and are most successful when there is very strong alignment between members. In the case of PressPass, the highly competitive nature of the journalism industry creates the risk of inherent instability if structured as a cooperative business.

Many contacts within the journalism industry emphasised the recent failure of NZPA, a cooperative newswire agency that ultimately collapsed. From a collective perspective, it made logical sense for the service to be maintained, and the dissolution had a detrimental impact on the wider New Zealand journalism industry. However, competitive rivalries had lead some members to believe that it was in their own selfinterest to abandon the initiative, and thought it would have a greater negative impact on their competitors than themselves. Industry contacts expressed a belief that PressPass would be more stable as an independent entity, with a strong mandate to operate in the collective interest of the journalism community, rather than operating as a collective of members focused on maximising their own self-interest.

Other limitations of a cooperative structure were the added complexity of regulatory requirements related to incorporation and membership obligations. It was recommended 
that the pursuit of collective goals could be achieved through a more simple corporate structure, with a carefully crafted constitution and articles of association. Furthermore, the underlying business model of PressPass can be used to enshrine altruistic goals within the day-to-day operations of the platform, as demonstrated with our proposed commission structure.

As the platform is further developed, the corporate structure will continue to be refined. It has been advised that the team should avoid committing itself to a particular corporate structure while the PressPass team is small and without investors, to provide maximum flexibility to the changing needs of the business. With this advice in mind, PressPass was incorporated under the parent company of Ripple Media Limited in May 2014, as a limited liability company with the default corporate structure. The structure will be assessed on an ongoing business at pivotal stages, such as discussions about potential investment or the development of news partnerships.

\subsection{Team agreement and ownership structure}

The team agreement for PressPass has been a pivotal document that outlines team member's expectations and obligations regarding ongoing development of the platform. Key provisions include the transfer of intellectual property to the parent company, Ripple Media Limited, as well as outlines regarding the future allocation of equity and remuneration.

The team's mentor, Michael Elwood-Smith has been particularly influential during the formation of this agreement, emphasising the need for fluid provisions that meet the flexible requirements of start-up businesses. In particular, he highlighted the importance of outlining clear principles so that the project could move forward with mutual alignment of expectations.

In regards to equity, he recommended avoiding an exact distribution until a significant event of market validation, such as imminent investment or partnership contracts. At this stage, it will become easier to assess the value of the enterprise, as well as the past contributions and intended future contributions of each team member. 
Factors that will be considered to allocate ownership include the proportion of hours contributed, the amount of personal finances invested in the company, and overall contribution to the success of the enterprise. An outside mediator will be consulted if any team members wish to get a second opinion during the process of equity allocation, and the team agreement will be renewed on a regular basis to ensure all team members continue to agree with its provisions. 


\section{CHAPTER 9: FUNDING AND INVESTMENT}

\subsection{Timeline}

Table 14. Funding and investment: Timeline of key milestones and activities

\begin{tabular}{|c|c|}
\hline DATE & ACTIVITIES \\
\hline 13 March 2014 & $\begin{array}{l}\text { Alex has a meeting with Dave Allison, Manager of the Angel HQ } \\
\text { investment network. }\end{array}$ \\
\hline 17 June 2014 & Alex has meeting with an investor met through the Angel HQ network. \\
\hline 6 August 2014 & $\begin{array}{l}\text { Alex has a Skype call with Dan Sinker, head of the Knight Mozilla } \\
\text { OpenNews project, which funds online journalism projects. }\end{array}$ \\
\hline 20 August 2014 & $\begin{array}{l}\text { Alex has a Skype call with Marie Gilot, programme officer at the } \\
\text { Knight Foundation, which funds online journalism projects. }\end{array}$ \\
\hline 22 August 2014 & $\begin{array}{l}\text { Alex has a meeting with Jordan Carter, CEO of Internet New Zealand. } \\
\text { Discussion about funding that could be available through INZ grants. }\end{array}$ \\
\hline 8 September 2014 & $\begin{array}{l}\text { Alex visits Harvard's Nieman Journalism Lab. Meets with Nieman Lab } \\
\text { journalists, as well as the director of their fellowship programme. }\end{array}$ \\
\hline 23 September 2014 & $\begin{array}{l}\text { Alex meets with Dawn Garcia, Managing Director of John S. Knight } \\
\text { Journalism Fellowships at Stanford. }\end{array}$ \\
\hline 29 September 2014 & $\begin{array}{l}\text { Alex has meeting with New Zealand Trade and Enterprise's Business } \\
\text { Development Manager for the San Francisco Bay Area. }\end{array}$ \\
\hline 11 Nov 2014 & Alex has meeting with Alan Hucks, head of incubation at Creative HQ. \\
\hline 13 Nov 2014 & $\begin{array}{l}\text { Alex has meeting with the coordinators of Lightning Lab 2015: Connor } \\
\text { Archbold (programme manager) and Mark MacLeod-Smith } \\
\text { (programme director). }\end{array}$ \\
\hline 17 Nov 2014 & $\begin{array}{l}\text { Alex has phone call with John Holt, director of the Kiwi Landing Pad in } \\
\text { San Francisco. }\end{array}$ \\
\hline 1 December 2014 & $\begin{array}{l}\text { Submission of applications for Stanford's JSK journalism innovation } \\
\text { fellowship, and Harvard's Nieman-Berkman fellowship in journalism } \\
\text { innovation. }\end{array}$ \\
\hline 8 December 2014 & $\begin{array}{l}\text { Alex is invited to attend a Lightning Lab Bootcamp in Auckland, and } \\
\text { continues discussions with coordinators. }\end{array}$ \\
\hline 11 December 2014 & $\begin{array}{l}\text { Alex has a meeting with Geoff Todd, managing director of VicLink, to } \\
\text { discuss potential support as well as investment strategies. }\end{array}$ \\
\hline 12 December 2014 & $\begin{array}{l}\text { Alex has a meeting with R\&D investment managers at Grow } \\
\text { Wellington, to discuss Callaghan Innovation funding. }\end{array}$ \\
\hline 16 December 2014 & $\begin{array}{l}\text { Alex meets with Sean Wilson, CEO of Syl Semantics. Discuss } \\
\text { preparation of an investment proposal. }\end{array}$ \\
\hline 17 December 2014 & Alex, Puneeth and Paul complete their Lightning Lab application. \\
\hline 7 January 2014 & $\begin{array}{l}\text { Alex has meeting with Dave Allison, manager of Angel HQ. Discuss } \\
\text { preparation of an investment proposal }\end{array}$ \\
\hline 7 January 2014 & $\begin{array}{l}\text { Alex has meeting with a Business Growth Manager at Grow } \\
\text { Wellington, after being referred by R\&D investment managers. }\end{array}$ \\
\hline 15 January 2014 & $\begin{array}{l}\text { Alex, Puneeth and Paul have interview with the Lightning Lab } \\
\text { selection panel, after being shortlisted among the top } 20 \text { teams. }\end{array}$ \\
\hline 20 January 2014 & $\begin{array}{l}\text { Alex has a meeting with an Angel HQ investor to discuss development } \\
\text { of an investment proposal. }\end{array}$ \\
\hline
\end{tabular}




\subsection{Private investment}

Dave Allison, the manager of Angel HQ, has provided an advisory role to PressPass, for many aspects of private investment. Other important advisors have been Sean Wilson, the CEO of Syl Semantics, as well as a range of individuals within Wellington's startup community. Key feedback throughout the year has emphasised the importance of establishing firm contractual partnerships with news organisations. While investment may be possible based on current publisher relationships, a greater the level of commitment will increase the value of PressPass, allowing larger amounts of capital to be raised in return for less equity.

A delicate cost-benefit assessment is required before raising money, finding the ideal balance between pursuing money to fund growth, and pursuing growth to maximise the amount that can be raised. In terms of investors, it has been advised to seek individuals with domain expertise within the journalism industry, so that an investor can be found with a strong understanding of the problem space and can fully grasp the potential of PressPass' solution. Some advisors recommended direct investment from publishers, to maximise their commitment to the platform's success. This, however, would hinder the platform's independence and result in additional requirements to meet Commerce Commission legislation.

One private investment pathway pursued by the PressPass team, was the Lightning Lab accelerator programme. The programme coordinators were quite enthusiastic about the potential of PressPass. The PressPass team was eventually shortlisted within the top twenty applicants, and travelled to Auckland for an interview. Although impressed with the team's progress, the selection panel was ultimately concerned that it might be too early for PressPass to undergo acceleration. In particular, they were apprehensive to accelerate before contractual partnerships had been finalised with news organisations.

The interview panel also expressed concerns at the number of delays that both NZME and Fairfax have had with their paid-content strategy, and pointed out that this implies a lack of coherent strategy. While this does provide an opportunity for a company such as PressPass to help shape the decision-making process and become part of the solution, 
they were concerned that it left the company vulnerable to factors outside of the team's control.

One potential strategy to increase commitment from publishers includes special introductory commission rates for those who first sign agreements, creating a first mover advantage that incentivises commitment. Another possible strategy recommended by advisors, has been the use of partnership agreements that are activated when a certain threshold of partners have joined the platform. This would de-risk the perceived risk of launching a paywall. However, such a policy would need to be pursued only after consultation with the Commerce Commission to ensure alignment with relevant legislation.

\subsection{Philanthropy and academic grants}

Throughout the year, Alex has explored potential funding opportunities available from universities and other philanthropic bodies. Most of these opportunities have been available within the USA. Several individuals recommended applying for Harvard's Nieman-Berkman fellowship in journalism innovation, as well as Stanford's JSK journalism fellowship. Each fellowship offered an opportunity to develop a journalism innovation project focused on both academic research and product development, providing funding and institutional support. Alex applied for both opportunities, however, was ultimately unsuccessful. Alex had met with the directors of each fellowship programme while visiting the USA, and they were impressed with the project and encouraged him to apply. They had warned, however, that competition would be high (400-500+ applicants) and that priority would be given to mid-career journalists currently employed within news organisations.

Another potential source of funding explored was the Knight Foundation, which funds journalism innovation projects. Alex reached out to head of the Knight OpenNews initiative, Dan Sinker, who coordinates funds for open source news projects and fellowships. The conversation revealed that the core of their funding is predominantly focused on development projects embedded within newsrooms, without specific funding available for independent initiatives. Dan did, however, show an interest in the 
project, and recommended a discussion with Marie Gilot within the Knight Foundation. He also said that having an open source focus would be a strong advantage when applying for grant funding.

Alex asked Marie for further details about the Knight Prototype grant, a $\$ 50,000$ contribution towards the development of a functional prototype. While she said that PressPass would be an ideal candidate, the funding is limited to projects based within the USA. Alex explored whether it would be possible to channel funding through a US partner, however this had not been done in the past and was considered to be an unlikely scenario. Funding that is available to international projects includes the Knight News Challenge, which funds news-focused start-up companies. However, funding is usually focused on non-profits, and each year the initiative is themed to focus on a particular category of news project. Another option available to international projects is the Knight Foundation's venture capital investment programme, which the PressPass team may consider once they are ready to seek investment.

In New Zealand, Alex has met with the CEO of Internet New Zealand to discuss potential grant funding that PressPass could apply for. A particularly promising initiative is an upcoming Internet Project Funding Round, being launch in June 2015. There is the potential that PressPass could be eligible, however, the project will need to align closely with the goals of the funding and have a clear community benefit. The team will be meeting with the coordinator of this initiative to discuss whether the project has a strong chance of success and alignment with INZ goals, before committing resources to an application.

Alex also had meetings with VicLink to discuss potential support from Victoria University. Although VicLink have previously invested in start-up companies emerging from Victoria, they no longer have budget allocation available for such investment activities. Grant Todd mentioned that he is working to establish funding for sustaining university enterprise projects following course completion, and thought that PressPass would be an ideal candidate for such funding. Unfortunately, however, this initiative is not likely to be ready in the near future. Geoff emphasised that VicLink's current core mandate is to fund intellectual property owned by the university, and since PressPass is an independent company with full ownership over IP, they do not have a mandate to 
invest and assist with growth. He did, however, offer the option of limited funding to provide office space and mentorship to assist with the ongoing development process, and this offer will be taken up by the PressPass team.

The PressPass team will continue to explore philanthropic funding opportunities. However, the team will need to be careful about the complex requirements and specific outcomes that are often tied to funding. PressPass is a young company that needs the flexibility to grow and explore opportunities, and the team will need to seek funding that aligns with its goals.

\subsection{Government funding}

Alex has also explored the potential of government funding, looking into the options available through New Zealand Trade and Enterprise, as well as Callaghan Innovation funding allocated by Grow Wellington. At NZTE, Alex met with the business development manager for the San Francisco Bay Area. Alex enquired about a variety of NZTE funding initiatives, and the stage at which they would be most appropriate for PressPass. Alex was advised that the KLP8 programme would be the ideal starting point. This programme provides funding for flights and other expenses to spend 6-8 weeks testing market viability within the USA, while being based at the Kiwi Landing Pad. Further down the track, the Beachheads programme could also be useful to assist with more long-term establishment within the US market, supporting larger businesses with their expansion activities.

At Grow Wellington, Alex met with R\&D investment managers, as well as a business growth manager. The $R \& D$ managers explained that $R \& D$ project grants could be available to fund the development of new technology, particularly aspects of the PressPass platform that involve novel technical challenges. 'Getting Started' funding was recommended as a good first step, as it provides early support to fund project mapping that scopes out each core component of a project and helps outline core R\&D tasks that could be eligible for further funding. All grants from Grow Wellington involve matching funding, therefore PressPass will need to establish investment before 
funding can be approved. Once investment has been secured, further steps will be taken to apply for funding via Grow Wellington. 


\section{CHAPTER 10: FINANCIAL ANALYSIS}

\subsection{Pricing, commission structure and royalty distribution}

This section provides the proposed strategy for PressPass' pricing, commission, and royalty distribution, based on feedback obtained during meetings with potential news partners. Note that the following subsections contain variables that could change following further negotiations with news organisations.

\section{Pricing}

Each news organisation will be allowed to determine the pricing for a standalone subscription to their website. Pricing for the National PressPass and Global PressPass will be based on comprehensive market research to assess the ideal price point for each package. To determine a launch price, possible market research techniques include the Gabor-Granger method, as well as Van Westendorp's Price Sensitivity Meter. After launch, actual uptake rates will be compared to projections on an ongoing basis, with pricing adjusted as necessary to promote further uptake and maximise overall subscription revenue.

\section{PressPass commission}

We propose to take zero commission for sales of a standalone subscription to a single news website within the PressPass ecosystem. This will allow PressPass to be the cheapest available solution for standalone paywall infrastructure, minimising the costs of adoption and creating an incentive for publishers to switch to our platform if using a competitor's product. For sales of the national and global packages, we propose to take $20 \%$ commission. Furthermore, we plan to further reduce our commission as profit margins increase. Our low commission structure will be an important competitive advantage, allowing us to operate in a trustworthy manner that is transparent, fair and equitable to our news partners. 


\section{Conversion commission}

If a publisher converts a subscriber to the national or global package, they will be rewarded with a conversion commission. We propose that this commission will be $20 \%$ of the sale price for the first 24 months of payments. The conversion commission will serve as a further incentive for news partners to convert readers to the national or global package.

\section{Royalty distribution}

After the PressPass commission and conversion commission have been collected, all subscription revenue will be placed within a royalty pool to be distributed between our news partners. Our royalty distribution method will be aimed at equitably rewarding news organisations, relative to the level of reader engagement with their news content. Half of the royalty pool will be proportionally distributed based on page views, while the other half will be proportionally distributed according to time spent reading. Royalty payments for the national and global packages will be allocated from separate pools.

\section{Revenue flow: hypothetical breakdown}

The following scenario describes how revenue would be distributed, under the policies outlined above. This scenario describes the distribution of the first one million dollars in subscription fees collected from subscribers to the global package. A hypothetical news partner, Publisher XYZ, is used for illustrative purposes.

Step 1) PressPass receives a $20 \%$ commission for providing the platform infrastructure, receiving $\$ 200,000$ in commission fees.

Step 2) An additional 20\% from each sale is distributed as a conversion commission, paid directly to news partners whenever they convert a paying subscriber within their website. This amounts to a total of $\$ 200,000$ for all news partners. Publisher XYZ converted $40 \%$ of all subscribers during this period, receiving a total of $\$ 80,000$ commission.

Step 3) The remaining $60 \%$ of each sale is placed within a royalty pool, totalling $\$ 600,000$. This royalty pool is distributed between news partners every calendar month. 
i) Half of this royalty pool is distributed between publishers based on the proportion of page views they receive, totalling $\$ 300,000$. Publisher XYZ generated $45 \%$ of all page views from subscribers to the global package, receiving $\$ 135,000$.

ii) The other half of this royalty pool is distributed according to the proportion of time spent on each website, totalling $\$ 300,000$. Publisher XYZ accounted for $40 \%$ of the reading time accumulated by subscribers to the global package, receiving $\$ 120,000$.

Step 4) The same commission structure and royalty distribution method outlined above, is used to allocate revenue from the national package. The royalty pools, however, are kept separate and are allocated according to the readership metrics specific to each pool of subscribers.

\subsection{Financial model comparing a standalone strategy with global bundling}

High-level summary:

- News organisations can expect to make significantly more revenue if they adopt a strategy of global bundling.

- Under a standalone subscription strategy, the New Zealand Herald would generate an estimated $\$ 3.8$ million in annual revenue.

- By participating in a global bundle, the New Zealand Herald would generate an estimated \$7.6 million in annual revenue. This is a two-fold increase, and higher than the revenue generated by the entire industry under a standalone strategy.

- Under a standalone subscription strategy, the total estimated revenue generated by all news organisations is $\$ 7.4$ million.

- Under a global subscription strategy, the total estimated revenue generated by all news organisations is $\$ 28$ million, a 3.8 times increase.

The estimates within this section are based on actual readership metrics, provided within a custom report generated from October 2014's Nielsen Online Ratings (personal 
communication, H. Ottow, 19 November, 2014). For the purpose of simplicity, this section focuses on the estimated revenue of the New Zealand Herald website under a standalone strategy, compared with their estimated revenue from participating in a global bundle of news websites.

The global bundle is based on a hypothetical launch package, containing nzherald.co.nz, stuff.co.nz, 3news.co.nz, tvnz.co.nz/news, nytimes.com, nationalgeographic.com and economist.com. The total unduplicated audience of these websites is 2.1 million monthly unique visitors (Nielsen Online Ratings).

For the purposes of this financial model, it is assumed that two thirds of respondents who said 'definitely' would actually purchase a news subscription, along with one third of respondents who said 'probably'. For a standalone subscription, this results in an estimated conversion rate of $2.4 \%$, and a rate of $10.3 \%$ for a global news package.

A rough estimate of the ideal price point has been calculated using the mean preferred price of respondents ${ }^{5}$. For a standalone subscription, the mean preferred price point was $\$ 8.60$. For a global package, the mean preferred price point was $\$ 10.80$.

Under a standalone subscription strategy, all news organisations would earn an estimated \$7.4 million within the New Zealand market (Table 15). This is based on a cumulative news audience of 3.75 million, including duplicate users who visit multiple sites.

Table 15. Estimated revenue under standalone package, all news organisations

\begin{tabular}{|r|r|r|r|r|c|}
\hline $\begin{array}{c}\text { Culmulative online } \\
\text { news audience in NZ } \\
\text { (all news partners) }\end{array}$ & $\begin{array}{c}\text { Estimated } \\
\text { conversion rate }\end{array}$ & $\begin{array}{c}\text { Number of } \\
\text { subscribers }\end{array}$ & $\begin{array}{c}\text { Monthly } \\
\text { subscription fee }\end{array}$ & $\begin{array}{c}\text { Total annual } \\
\text { revenue }\end{array}$ & $\begin{array}{c}\text { Annual revenue after } \\
\text { PressPass commission } \\
(\mathbf{2 0 \%})\end{array}$ \\
\hline $3,745,000$ & $2.40 \%$ & 89,880 & $\$ 8.60$ & $\$ 9,275,616$ & $\$ 7,420,493$ \\
\hline
\end{tabular}

Under a standalone subscription strategy, the New Zealand Herald's estimated revenue is $\$ 3.28$ million (Table 16).

\footnotetext{
${ }^{5}$ The mean preferred price was calculated from respondents who said that they would 'definitely' or 'probably' pay for each option.
} 
Table 16. Estimated revenue under a standalone package, New Zealand Herald

\begin{tabular}{|c|r|r|r|c|}
\hline $\begin{array}{c}\text { Unique audience } \\
\text { (NZ Herald) }\end{array}$ & $\begin{array}{c}\text { Estimated } \\
\text { conversion rate }\end{array}$ & $\begin{array}{c}\text { Number of } \\
\text { subscribers }\end{array}$ & $\begin{array}{c}\text { Monthly } \\
\text { subscription fee }\end{array}$ & $\begin{array}{c}\text { Total annual } \\
\text { revenue }\end{array}$ \\
\hline $1,325,000$ & $2.40 \%$ & 31,800 & $\$ 8.60$ & $\$ 3,281,760$ \\
\hline
\end{tabular}

Under a global bundling strategy, the total estimated revenue generated within the entire ecosystem is \$28 million. After PressPass takes a 20\% commission on each sale, the total annual revenue distributed to news partners is \$22.4 million (Table 17).

Table 17. Total revenue under a global bundling strategy, all publishing partners

\begin{tabular}{|r|r|r|r|r|r|}
\hline $\begin{array}{c}\text { Unduplicated online } \\
\text { news audience in NZ } \\
\text { (all news partners) }\end{array}$ & $\begin{array}{c}\text { Estimated } \\
\text { conversion rate }\end{array}$ & $\begin{array}{c}\text { Number of } \\
\text { subscribers }\end{array}$ & $\begin{array}{c}\text { Monthly } \\
\text { subscription fee }\end{array}$ & $\begin{array}{c}\text { Total annual } \\
\text { revenue }\end{array}$ & $\begin{array}{c}\text { Annual revenue after } \\
\text { PressPass commission } \\
\text { (20\%) }\end{array}$ \\
\hline $2,100,000$ & $10.30 \%$ & 216,300 & $\$ 10.80$ & $\$ 28,032,480$ & $\$ 22,425,984$ \\
\hline
\end{tabular}

Within this ecosystem, the New Zealand Herald can expect to receive a total of $\$ 7.64$ million in payments (Table 18). This is 2.3 times greater than the revenue generated under a standalone strategy, and results in an additional $\$ 4.4$ million in annual revenue.

Table 18. Estimated revenue under a global bundling strategy, New Zealand Herald

\begin{tabular}{|l|c|c|c|l|}
\cline { 2 - 5 } \multicolumn{1}{c|}{$\begin{array}{l}\text { Conversion } \\
\text { commission }\end{array}$} & $\begin{array}{l}\text { Royalty payment: } \\
\text { page views }\end{array}$ & $\begin{array}{l}\text { Royalty payment: } \\
\text { time spent reading }\end{array}$ & $\begin{array}{l}\text { TOTAL } \\
\text { PAYMENTS }\end{array}$ \\
\hline NZ Herald & $\$ 1,836,673$ & $\$ 2,961,943$ & $\$ 2,840,600$ & $\$ 7,639,216$ \\
\hline
\end{tabular}

\subsection{PressPass revenue model}

High-level summary:

- Within the New Zealand market

- A high annual revenue estimate is $\$ 12.9$ million

○ A medium annual revenue estimate is $\$ 6.5$ million

○ A low annual revenue estimate is $\$ 3.2$ million

- Within the Australian market

○ A low annual revenue estimate is $\$ 16.6$ million 
- Within the US market

- A low annual revenue estimate is $\$ 255$ million

This section provides a simplified revenue model for the PressPass platform, based on different levels of success. It does not account for the cumulative acquisition of consumers over time, and instead provides a 12-month extrapolation of the revenue generated during one month of operation at the level of metrics stated.

Assumptions include

-A total New Zealand news audience of 2.1 million monthly unique users.

-A subscription fee of $\$ 11$ per month for the Global PressPass package. ${ }^{6}$

-A subscription fee of $\$ 9$ per month for the National PressPass package. ${ }^{7}$

-A ratio of 1:5 between the conversion rate of the national package and global package. ${ }^{8}$

-Participation by all major news organisations that are most popular within each launch market

-Note: revenue is not calculated for standalone subscriptions, since PressPass takes zero commission for this subscription option.

A high estimate of the subscriber conversion rate (20\% global package, $4 \%$ national package) results in a total annual PressPass commission of $\$ 12.9$ million within the New Zealand market (Table 19).

Table 19. Revenue model for New Zealand, high conversion rate estimate

\begin{tabular}{|l|r|r|r|r|r|r|}
\cline { 2 - 6 } \multicolumn{1}{c|}{} & $\begin{array}{c}\text { Unduplicated online } \\
\text { news audience in NZ } \\
\text { (all news partners) }\end{array}$ & Conversion rate & $\begin{array}{r}\text { Number of } \\
\text { subscribers }\end{array}$ & $\begin{array}{c}\text { Monthly } \\
\text { subscription fee }\end{array}$ & $\begin{array}{c}\text { Total annual } \\
\text { revenue }\end{array}$ & $\begin{array}{c}\text { PressPass commission } \\
\text { (20\%) }\end{array}$ \\
\hline Global PressPass & $2,100,000$ & $20.00 \%$ & 420,000 & $\$ 11.00$ & $\$ 55,440,000$ & $\$ 11,088,000$ \\
\hline National PressPass & $2,100,000$ & $4.00 \%$ & 84,000 & $\$ 9.00$ & $\$ 9,072,000$ & $\$ 1,814,400$ \\
\cline { 2 - 7 }
\end{tabular}

\footnotetext{
${ }^{6}$ Mean preferred price point, rounded to the nearest dollar

${ }^{7}$ Mean preferred price point, rounded to the nearest dollar

${ }^{8}$ Based on the ratio of subscribers willing to definitely pay for each of these packages.
} 
A medium estimate of the subscriber conversion rate (10\% global package, $2 \%$ national package) results in a total annual PressPass commission of $\$ 6.5$ million within the New Zealand market (Table 20).

Table 20. Revenue model for New Zealand, medium conversion rate estimate

\begin{tabular}{|c|c|c|c|c|c|c|}
\hline & \begin{tabular}{|c|} 
Unduplicated online \\
news audience in NZ \\
(all news partners)
\end{tabular} & Conversion rate & $\begin{array}{l}\text { Number of } \\
\text { subscribers }\end{array}$ & \begin{tabular}{|c|} 
Monthly \\
subscription fee
\end{tabular} & $\begin{array}{l}\text { Total annual } \\
\text { revenue }\end{array}$ & $\begin{array}{l}\text { PressPass commission } \\
(20 \%)\end{array}$ \\
\hline Global PressPass & $2,100,000$ & $10.00 \%$ & 210,000 & $\$ 11.00$ & $\$ 27,720,000$ & $\$ 5,544,000$ \\
\hline National PressPass & $2,100,000$ & $2.00 \%$ & 42,000 & $\$ 9.00$ & $\$ 4,536,000$ & $\$ 907,200$ \\
\hline & & & & \multicolumn{2}{|c|}{ TOTAL ANNUAL COMMISSION } & $\$ 6,451,200$ \\
\hline
\end{tabular}

A low estimate of the subscriber conversion rate (5\% global package, $1 \%$ national package) results in a total annual PressPass commission of $\$ 3.2$ million within the New Zealand market (Table 21).

Table 21. Revenue model for New Zealand, low conversion rate estimate

\begin{tabular}{|l|r|r|r|r|r|r|}
\cline { 2 - 7 } \multicolumn{1}{c|}{} & $\begin{array}{c}\text { Unduplicated online } \\
\text { news audience in NZ } \\
\text { (all news partners) }\end{array}$ & Conversion rate & $\begin{array}{c}\text { Number of } \\
\text { subscribers }\end{array}$ & $\begin{array}{c}\text { Monthly } \\
\text { subscription fee }\end{array}$ & $\begin{array}{r}\text { Total annual } \\
\text { revenue }\end{array}$ & $\begin{array}{c}\text { PressPass commission } \\
\text { (20\%) }\end{array}$ \\
\hline Global PressPass & $2,100,000$ & $5.00 \%$ & 105,000 & $\$ 11.00$ & $\$ 13,860,000$ & $\$ 2,772,000$ \\
\hline National PressPass & $2,100,000$ & $1.00 \%$ & 21,000 & $\$ 900$ & $\$ 2,268,000$ & $\$ 453,600$ \\
\cline { 2 - 7 }
\end{tabular}

If PressPass successfully expands into the Australian market, there is a total online news audience of 10.8 million unique adult visitors (The Newspaper Works, 2015). A low estimate of the conversion rate (5\% global package, $1 \%$ national package), results in a total annual commission of $\$ 16.6$ million (Table 22).

Table 22. Revenue model for Australian expansion, low conversion rate estimate

\begin{tabular}{|l|r|r|r|r|r|r|}
\cline { 2 - 7 } \multicolumn{1}{c|}{} & $\begin{array}{c}\text { Unduplicated online } \\
\text { news audience in } \\
\text { Australia }\end{array}$ & Conversion rate & $\begin{array}{c}\text { Number of } \\
\text { subscribers }\end{array}$ & $\begin{array}{c}\text { Monthly } \\
\text { subscription fee }\end{array}$ & $\begin{array}{c}\text { Total annual } \\
\text { revenue }\end{array}$ & $\begin{array}{c}\text { PressPass commission } \\
\mathbf{( 2 0 \% )}\end{array}$ \\
\hline Global PressPass & $10,800,000$ & $5.00 \%$ & 540,000 & $\$ 11.00$ & $\$ 71,280,000$ & $\$ 14,256,000$ \\
\hline National PressPass & $10,800,000$ & $1.00 \%$ & 108,000 & $\$ 9.00$ & $\$ 11,664,000$ & $\$ 2,332,800$ \\
\hline
\end{tabular}

If PressPass successfully expands into the US market, there is a total online news audience of 166 million unique adult visitors (Conaghan, 2014). A low estimate of the 
conversion rate (5\% global package, $1 \%$ national package), results in a total annual commission of \$255 million (Table 23).

Table 23. Revenue model for USA expansion, low conversion rate estimate

\begin{tabular}{|l|r|r|r|r|r|r|}
\cline { 2 - 6 } & \multicolumn{1}{c|}{$\begin{array}{c}\text { Unduplicated online } \\
\text { news audience in the } \\
\text { USA }\end{array}$} & Conversion rate & $\begin{array}{c}\text { Number of } \\
\text { subscribers }\end{array}$ & $\begin{array}{r}\text { Monthly } \\
\text { subscription fee }\end{array}$ & $\begin{array}{c}\text { Total annual } \\
\text { revenue }\end{array}$ & $\begin{array}{c}\text { PressPass commission } \\
\mathbf{( 2 0 \% )}\end{array}$ \\
\hline Global PressPass & $166,000,000$ & $5.00 \%$ & $8,300,000$ & $\$ 11.00$ & $\$ 1,095,600,000$ & $\$ 219,120,000$ \\
\hline National PressPass & $166,000,000$ & $1.00 \%$ & $1,660,000$ & $\$ 9.00$ & $\$ 179,280,000$ & $\$ 35,856,000$ \\
\cline { 2 - 7 }
\end{tabular}




\section{Bibliography}

APN News and Media. (2014). Supplemental Disclosure Information. Retrieved from http://investorcentre.apn.com.au/phoenix.zhtml?c=144006\&p=irol-news\&nyo=1

Conaghan, J. (2014). Newspaper Web Audience. Retrieved February 25, 2015, from http://www.naa.org/Trends-and-Numbers/Newspaper-Websites/NewspaperWeb-Audience.aspx

Doctor, K. (2012). The newsonomics of Pricing 201. from http://www.niemanlab.org/2012/09/the-newsonomics-of-pricing-201/

Ellis, J. (2014). If my newspaper puts up a metered paywall, how many people will pay? Here's some data. from http://www.niemanlab.org/2014/05/if-mynewspaper-puts-up-a-metered-paywall-how-many-people-will-pay-heres-somedata/

Fahy, B. (2014). Audience up, ad spend down: A depressing graph for Fairfax and APN? Or dodgy data? , from http://stoppress.co.nz/blog/2014/02/apn-fairfaxonline-ad-spend

Gray, J. (2015, February 13). Pay wall plan on track, says APN chief, New Zealand Herald. Retrieved from

http://www.nzherald.co.nz/business/news/article.cfm?c id=3\&objectid=114010 63

Grueskin, B., Seave, A., \& Graves, L. (2011). The story so far: What we know about the business of digital journalism. NY: Columbia Journalism School, Tow Center for Digital Journalism. Retrieved from http://cjrarchive.org/img/posts/report/The Story So Far.pdf

Myllylahti, M. (2013). JMAD New Zealand Media Ownership Report 2013. Retrieved from

http://www.academia.edu/5252012/JMAD_New_Zealand_Media_Ownership_R eport 2013

Pullar-Strecker, T. (2014). No paywall plans for news. Retrieved February 24, 2015, from http://www.stuff.co.nz/business/industries/63200873/fairfax-nz-has-nopaywall-plans-for-news

Siapera, E., \& Veglis, A. (Eds.). (2012). The Handbook of Global Online Journalism. West Sussex, UK: Wiley-Blackwell.

The New York Times. (2014). Innovation. NY: The New York Times. Retrieved from http://www.presscouncil.org.au/uploads/52321/ufiles/The New York Times In novation Report - March 2014.pdf

The Newspaper Works. (2015). Digital readership leaps by 9 per cent! Retrieved February 25, 2015, from http://www.thenewspaperworks.com.au/digitalreadership-gains-offset-print-result/

The Pew Research Center. (2013). The state of the news media 2013: Key findings. Retrieved from http://www.stateofthemedia.org/2013/overview-5/key-findings/ 